\title{
Non-occupational postexposure prophylaxis for HIV: a systematic review
}

J Bryant, ${ }^{*}$ L Baxter and S Hird

February 2009

DOI: $10.3310 /$ hta 13140

Health Technology Assessment

NIHR HTA Programme

www.hta.ac.uk

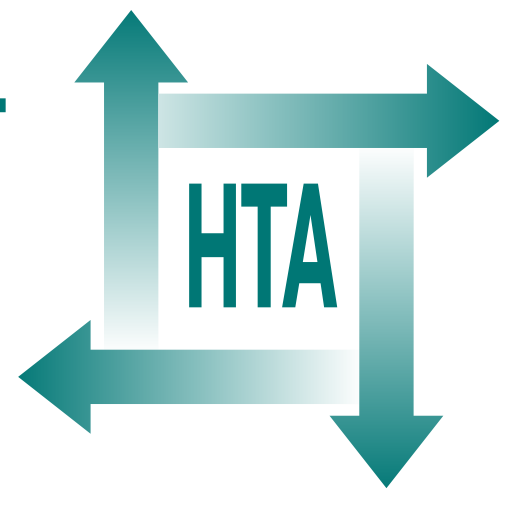




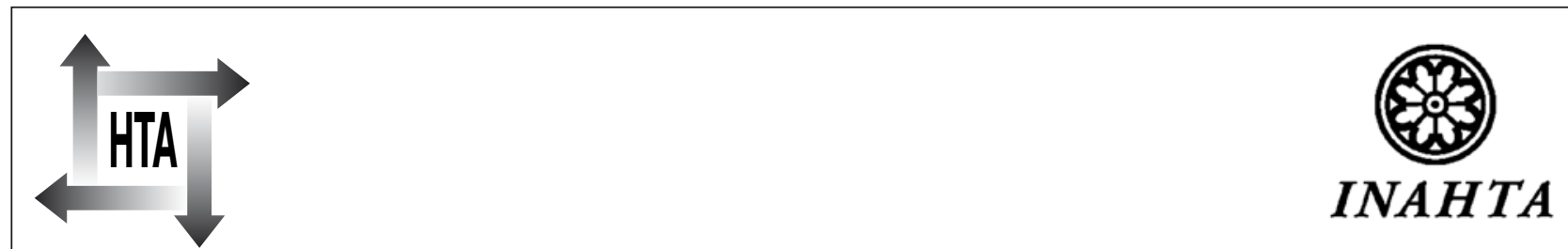

How to obtain copies of this and other HTA Programme reports.

An electronic version of this publication, in Adobe Acrobat format, is available for downloading free of charge for personal use from the HTA website (www.hta.ac.uk). A fully searchable CD-ROM is also available (see below).

Printed copies of HTA monographs cost $£ 20$ each (post and packing free in the UK) to both public and private sector purchasers from our Despatch Agents.

Non-UK purchasers will have to pay a small fee for post and packing. For European countries the cost is $\notin 2$ per monograph and for the rest of the world $£ 3$ per monograph.

You can order HTA monographs from our Despatch Agents:

- fax (with credit card or official purchase order)

- post (with credit card or official purchase order or cheque)

- phone during office hours (credit card only).

Additionally the HTA website allows you either to pay securely by credit card or to print out your order and then post or fax it.

\section{Contact details are as follows:}

HTA Despatch Email: orders@hta.ac.uk

c/o Direct Mail Works Ltd Tel: 02392492000

4 Oakwood Business Centre Fax: 02392478555

Downley, HAVANT PO9 2NP, UK $\quad$ Fax from outside the UK: +442392478 555

$\mathrm{NHS}$ libraries can subscribe free of charge. Public libraries can subscribe at a very reduced cost of $£ 100$ for each volume (normally comprising 30-40 titles). The commercial subscription rate is $£ 300$ per volume. Please see our website for details. Subscriptions can be purchased only for the current or forthcoming volume.

\section{Payment methods}

Paying by cheque

If you pay by cheque, the cheque must be in pounds sterling, made payable to Direct Mail Works Ltd and drawn on a bank with a UK address.

Paying by credit card

The following cards are accepted by phone, fax, post or via the website ordering pages: Delta, Eurocard, Mastercard, Solo, Switch and Visa. We advise against sending credit card details in a plain email.

Paying by official purchase order

You can post or fax these, but they must be from public bodies (i.e. NHS or universities) within the UK. We cannot at present accept purchase orders from commercial companies or from outside the UK.

\section{How do I get a copy of HTA on CD?}

Please use the form on the HTA website (www.hta.ac.uk/htacd.htm). Or contact Direct Mail Works (see contact details above) by email, post, fax or phone. HTA on CD is currently free of charge worldwide.

The website also provides information about the HTA Programme and lists the membership of the various committees. 


\section{Non-occupational postexposure prophylaxis for HIV: a systematic review}

\section{J Bryant," L Baxter and S Hird}

Southampton Health Technology Assessments Centre (SHTAC), Wessex Institute for Health Research and Development, University of Southampton, Southampton, UK

*Corresponding author

Declared competing interests of authors: none

Published February 2009

DOI: $10.3310 /$ hta 13140

This report should be referenced as follows:

Bryant J, Baxter L, Hird S. Non-occupational postexposure prophylaxis for HIV: a systematic review. Health Technol Assess 2009; I3(I4).

Health Technology Assessment is indexed and abstracted in Index Medicus/MEDLINE, Excerpta Medica/EMBASE, Science Citation Index Expanded $\left(\right.$ SciSearch $\left.{ }^{\circledR}\right)$ and Current Contents ${ }^{\circledR} /$ Clinical Medicine. 


\section{NIHR Health Technology Assessment Programme}

$\mathrm{T}$ he Health Technology Assessment (HTA) Programme, part of the National Institute for Health Research (NIHR), was set up in 1993. It produces high-quality research information on the effectiveness, costs and broader impact of health technologies for those who use, manage and provide care in the NHS. 'Health technologies' are broadly defined as all interventions used to promote health, prevent and treat disease, and improve rehabilitation and long-term care.

The research findings from the HTA Programme directly influence decision-making bodies such as the National Institute for Health and Clinical Excellence (NICE) and the National Screening Committee (NSC). HTA findings also help to improve the quality of clinical practice in the NHS indirectly in that they form a key component of the 'National Knowledge Service'.

The HTA Programme is needs led in that it fills gaps in the evidence needed by the NHS. There are three routes to the start of projects.

First is the commissioned route. Suggestions for research are actively sought from people working in the NHS, from the public and consumer groups and from professional bodies such as royal colleges and NHS trusts. These suggestions are carefully prioritised by panels of independent experts (including NHS service users). The HTA Programme then commissions the research by competitive tender.

Second, the HTA Programme provides grants for clinical trials for researchers who identify research questions. These are assessed for importance to patients and the NHS, and scientific rigour.

Third, through its Technology Assessment Report (TAR) call-off contract, the HTA Programme commissions bespoke reports, principally for NICE, but also for other policy-makers. TARs bring together evidence on the value of specific technologies.

Some HTA research projects, including TARs, may take only months, others need several years. They can cost from as little as $£ 40,000$ to over $£ 1$ million, and may involve synthesising existing evidence, undertaking a trial, or other research collecting new data to answer a research problem.

The final reports from HTA projects are peer reviewed by a number of independent expert referees before publication in the widely read journal series Health Technology Assessment.

\footnotetext{
Criteria for inclusion in the HTA journal series

Reports are published in the HTA journal series if (1) they have resulted from work for the HTA

Programme, and (2) they are of a sufficiently high scientific quality as assessed by the referees and editors.

Reviews in Health Technology Assessment are termed 'systematic' when the account of the search, appraisal and synthesis methods (to minimise biases and random errors) would, in theory, permit the replication of the review by others.
}

The research reported in this issue of the journal was commissioned by the HTA Programme as project number 07/40/01. The contractual start date was in December 2007. The draft report began editorial review in May 2008 and was accepted for publication in August 2008. As the funder, by devising a commissioning brief, the HTA Programme specified the research question and study design. The authors have been wholly responsible for all data collection, analysis and interpretation, and for writing up their work. The HTA editors and publisher have tried to ensure the accuracy of the authors' report and would like to thank the referees for their constructive comments on the draft document. However, they do not accept liability for damages or losses arising from material published in this report.

The views expressed in this publication are those of the authors and not necessarily those of the HTA Programme or the Department of Health.

Editor-in-Chief:

Professor Tom Walley

Series Editors:

Dr Aileen Clarke, Dr Peter Davidson, Dr Chris Hyde, Dr John Powell, Dr Rob

Riemsma and Professor Ken Stein

This monograph may be freely reproduced for the purposes of private research and study and may be included in professional journals provided that suitable acknowledgement is made and the reproduction is not associated with any form of advertising.

Applications for commercial reproduction should be addressed to: NCCHTA, Alpha House, Enterprise Road, University of Southampton Science Park, Southampton SO 16 7NS, UK.

Published by Prepress Projects Ltd, Perth, Scotland (www.prepress-projects.co.uk), on behalf of NCCHTA. 


\title{
Abstract
}

\section{Non-occupational postexposure prophylaxis for HIV: a systematic review}

\author{
J Bryant, ${ }^{*}$ L Baxter and S Hird \\ Southampton Health Technology Assessments Centre (SHTAC), Wessex Institute for Health Research \\ and Development, University of Southampton, Southampton, UK
}

*Corresponding author

Objective: To review the evidence on the clinical effectiveness and cost-effectiveness of non-occupational postexposure prophylaxis (PEP) for HIV.

Data sources: Eleven electronic databases were searched from inception to December 2007.

Review methods: Selected studies were assessed, subjected to data extraction using a standard template and quality assessment using published criteria. Studies were synthesised using a narrative approach with full tabulation of results from all included studies.

Results: One clinical effectiveness study meeting the inclusion criteria was identified, a cohort study of PEP in a high-risk HIV-negative homosexual male cohort in Brazil. The quality of the study was generally weak. Seroincidence in the cohort as a whole (2.9 per 100 person-years) was very similar to that expected in this population (3.I per 100 person-years, $p>0.97$ ), despite the seroconversion to HIV being $1 / 68$ in the PEP group and $10 / 132$ in the group not receiving PEP. High-risk sexual activities declined over time for both PEP and non-PEP users. Four economic evaluations met the inclusion criteria of the review. The methodological quality of the studies was mixed. The studies are constrained by a lack of published data on the clinical effectiveness of PEP after non-occupational exposure, with effectiveness data derived from one study of occupational PEP. Their generalisability to the UK is not clear. Results suggest that PEP following non-occupational exposure to HIV was cost saving for men who have unprotected receptive anal intercourse with men, whether the source partner is known to be HIV positive or not; heterosexuals after unprotected receptive anal intercourse; and intravenous drug users sharing needles with a known HIV-positive person. PEP following non-occupational exposure to HIV was costeffective for all male-male intercourse (unprotected receptive and insertive anal intercourse, unprotected receptive oral sex, and 'other') and was possibly costeffective for intravenous drug users and high-risk women. Four additional studies were identified giving further information about adverse events associated with PEP after non-occupational exposure to HIV. The majority of participants experienced adverse events with the most common being nausea and fatigue. Rates were generally higher in participants receiving triple therapy than in participants receiving dual therapy. Completion of PEP therapy was variable, ranging from $24 \%$ to $78 \%$ of participants depending on type of therapy. Toxicity was the main reason for discontinuation of treatment. Conclusions: It is not possible to draw conclusions on the clinical effectiveness of non-occupational PEP for HIV because of the limited evidence available. The review of cost-effectiveness suggests that nonoccupational PEP may be cost-effective, especially in certain population subgroups; however, the assumptions made and data sources used in the cost-effectiveness studies mean that their results should be used with caution. 



\section{Contents}

List of abbreviations

Executive summary

vii

ix

I Aim of the review

2 Background

Description of underlying health problem

Epidemiology

Current UK practice ...............................

Costs

Issues specific to non-occupational HIV exposure

Rationale for the study

3 Methods

Search strategy

Inclusion and data extraction process $\ldots . . . . \quad 9$

Quality assessment ................................... 9

Inclusion criteria .................................... 10

Data synthesis ...................................... 10

4 Clinical effectiveness

Quantity and quality of research available

Assessment of effectiveness

Summary of clinical effectiveness of PEP for non-occupational exposure to HIV

5 Cost-effectiveness 15

Quantity and quality of research available

Assessment of cost-effectiveness

Economic evaluation

Summary of cost-effectiveness of PEP for non-occupational exposure to HIV
6 Adverse events ................ 23

Completion of treatment $\ldots \ldots \ldots \ldots \ldots \ldots \ldots \ldots . . . . . . . . . . .23$

Assessment of toxicity ............................. 25

Summary of adverse events of PEP for nonoccupational exposure to HIV ............. 27

7 Discussion ............................................ 29

Statement of principal findings $\ldots \ldots \ldots \ldots \ldots . . . . .29$

Strengths and limitations of the assessment ......................................... 30

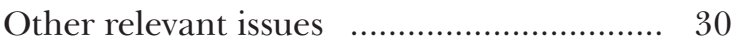

8 Conclusions ....................................... 33

Non-occupational PEP for HIV ............... 33

Research priorities ................................. 33

Acknowledgements ................................ 35

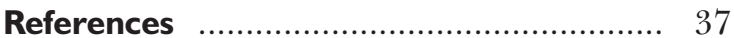

Appendix I Review methods from the research protocol

Appendix 2 Sources of information, including databases searched and search terms

Appendix 3 List of excluded studies

Appendix 4 Data extraction of clinical effectiveness study

Appendix 5 Data extraction of costeffectiveness studies

Health Technology Assessment reports published to date

Health Technology Assessment

Programme 



\section{List of abbreviations}

\begin{tabular}{|c|c|c|c|}
\hline 3TC & lamivudine & MSA & metropolitan statistical areas \\
\hline \multirow[t]{2}{*}{ AIDS } & $\begin{array}{l}\text { acquired immunodeficiency } \\
\text { syndrome }\end{array}$ & MSM & men who have sex with men \\
\hline & & $\mathrm{Nfv}$ & nelfinavir \\
\hline ART & Pritich $A$ concintion for Souml & PEP & postexposure prophylaxis \\
\hline BASHH & Health and HIV & PEPSE & $\begin{array}{l}\text { PEP following potential sexual } \\
\text { exposure to HIV }\end{array}$ \\
\hline CCT & controlled clinical trial & & \\
\hline \multirow[t]{2}{*}{$\mathrm{d} 4 \mathrm{~T}$} & stavudine & PI & protease inhibitor \\
\hline & didanosine & & randomised controlled trial \\
\hline ddI & human immunodeficiency virus & QALY & quality-adjusted life-year \\
\hline IDU & injecting/intravenous drug user & ZDV & zidovudine \\
\hline $\begin{array}{l}\text { All abbrer } \\
\text { known }(\mathrm{e} . \\
\text { figures/tal } \\
\text { notes at tl }\end{array}$ & $\begin{array}{l}\text { as that have been used in this rep } \\
\text { IS) or it has been used only once } \\
\text { ppendices, in which case the abbi } \\
\text { d of the table. }\end{array}$ & $\begin{array}{l}\text { are listec } \\
t \text { is a nol } \\
\text { tion is } d\end{array}$ & $\begin{array}{l}\text { unless the abbreviation is well } \\
\text { dard abbreviation used only in } \\
\text { in the figure legend or in the }\end{array}$ \\
\hline
\end{tabular}





\section{$\circ$ \\ Executive summary}

\section{Background}

Human immunodeficiency virus (HIV) is a sexually transmitted and bloodborne virus found primarily in the blood, semen or vaginal fluid of an infected person. It is transmitted in two main ways: by having unprotected sex (anal, vaginal or oral) with someone infected with HIV or by sharing needles and syringes with someone infected with HIV. Postexposure prophylaxis (PEP) for HIV is the prompt administration of antiretroviral therapy following known or potential exposure to HIV infection in an attempt to prevent the establishment of infection. The effectiveness of PEP in preventing seroconversion (i.e. converting from HIV negative to HIV positive, with the detection in the blood of antibodies to HIV) after nonoccupational exposure to HIV is unclear.

\section{Objectives}

The main aim of this study was to review the evidence on the clinical effectiveness and costeffectiveness of non-occupational PEP for HIV.

\section{Methods}

A systematic review of the evidence was undertaken using a priori methods.

\section{Data sources}

Eleven electronic databases were searched from inception to December 2007. Bibliographies of related papers were assessed for relevant studies and experts contacted to identify additional published references.

\section{Study selection}

Studies were included if they fulfilled the following criteria:

- Intervention: any antiretroviral drug regimen administered as non-occupational PEP for a short period (28 days) to HIV-negative people potentially exposed to HIV through unprotected sexual contact or use of a potentially contaminated needle or potentially contaminated biological fluid.

- Participants: humans with non-occupational exposure to HIV through unprotected sexual exposure (oral, vaginal, anal), either voluntary or rape, with an HIV-infected partner or partner of unknown HIV status; humans with exposure to a needle contaminated by a known or potentially infected substance in a nonoccupational setting.

- Comparator: no intervention; group not receiving PEP; a different PEP regimen.

- Outcomes: HIV seroconversion frequency; adverse effects and complications of PEP; adherence to PEP; health-related quality of life; costs or some measure of cost-effectiveness.

- Design: randomised controlled trial, controlled clinical trial, cohort study or case-control study; cost-effectiveness/utility studies; economic evaluations; prospective observational studies for adverse events.

Studies identified were assessed for inclusion in two stages with titles and abstracts and full papers of retrieved studies assessed independently by two reviewers, with differences in decisions resolved through discussion or through recourse to a third independent reviewer.

\section{Data extraction and quality assessment}

Data were extracted by two reviewers using a data extraction form developed a priori. Any disagreements were resolved through discussion or through recourse to independent assessment by a third reviewer. The methodological quality of the studies included in the systematic review was assessed by means of modified quality assessment tools using individual components of methodological quality rather than relying on summary scores. The quality criteria were applied by two reviewers, with any disagreements resolved through discussion or through recourse to a third independent reviewer. 


\section{Data synthesis}

Studies were synthesised using a narrative approach with full tabulation of results from all included studies.

\section{Results}

\section{Number and quality of studies}

One clinical effectiveness study meeting the inclusion criteria for the review was identified. This was a cohort study of PEP in a high-risk HIVnegative homosexual male cohort in Brazil. The methodological quality and the quality of reporting of the study were generally weak.

Four economic evaluations met the inclusion criteria of the review (three conducted in the US and one in France). The methodological quality of the studies is mixed. Each of the studies is constrained by a lack of published data on the clinical effectiveness of PEP after non-occupational exposure, with effectiveness data derived from one study of occupational PEP. Their generalisability to the UK is not clear.

\section{Summary of clinical effectiveness}

Seroincidence in the cohort as a whole (2.9 per 100 person-years) was very similar to that expected by the study authors in this population (3.1 per 100 person-years, $p>0.97$ ), despite the seroconversion to HIV being $1 / 68$ in the PEP group and 10/132 in the group not receiving PEP. The study reported that, on average, high-risk sexual activities declined over time for both PEP and non-PEP users. The study authors concluded that a public health PEP programme would not have a major impact on HIV transmission in the study population.

\section{Summary of cost-effectiveness}

Results from the included economic studies suggest that PEP following non-occupational exposure to HIV is cost saving for men who have unprotected receptive anal intercourse with men, whether the source partner is known to be HIV positive or not; heterosexuals after unprotected receptive anal intercourse; and intravenous drug users sharing needles with a known HIV-positive person.

PEP following non-occupational exposure to HIV was cost-effective for all male-male intercourse (unprotected receptive and insertive anal intercourse, unprotected receptive oral sex, and 'other'). PEP following non-occupational exposure to HIV was possibly cost-effective for intravenous drug users and high-risk women.

\section{Adverse events}

Four additional studies (two comparative studies and two observational studies) were identified that supplied further information about adverse events associated with PEP after non-occupational exposure to HIV. The majority of participants experienced adverse events with the most common being nausea and fatigue. Rates were generally higher in participants receiving triple therapy than in participants receiving dual therapy. Completion of PEP therapy was variable, ranging from $24 \%$ to $78 \%$ of participants depending on type of therapy. Toxicity was the main reason for discontinuation of treatment.

\section{Conclusions}

It is not possible to draw conclusions on the clinical effectiveness of non-occupational PEP for HIV because of the limited evidence in terms of quantity and quality of studies. Only one cohort study was identified that met the inclusion criteria for the systematic review. Cost-effectiveness has been assessed in four economic evaluations using evidence on effectiveness taken from the use of PEP in the occupational setting. Results are consistent across studies and suggest that non-occupational PEP may be cost-effective, especially in certain population subgroups. Although the studies have been conducted in an appropriate way and may have internal validity in terms of the structure of the model and plausible results, the assumptions and data sources mean that results should be used with caution. The generalisibility to the UK of studies conducted in the US is not clear as sexual behaviour and HIV incidence may not be similar.

\section{Suggested research priorities}

The most important research need is to establish the clinical effectiveness of non-occupational PEP within the UK. Ongoing research in the form of the NONOPEP project, an MRC-funded surveillance programme of PEP for non-occupational exposure to HIV, will address aspects of clinical effectiveness in terms of seroconversion rates in people who take PEP compared with those who do not and evaluate problems associated with taking antiretroviral medications. This project is due for submission shortly. Data generated from this study can then be assessed and used to inform future economic modelling of the cost-effectiveness of nonoccupational PEP in the UK. 


\section{Chapter I \\ Aim of the review}

$\mathrm{T}$ he aim of this project is to evaluate the effects of non-occupational postexposure prophylaxis (PEP) for human immunodeficiency virus (HIV) with a course of antiretroviral therapy.

The main objectives are as follows:

- to review the evidence on the clinical effectiveness of non-occupational PEP for HIV

- to summarise the best relevant evidence on the harms of non-occupational PEP for HIV
- $\quad$ to review the evidence on the costs and costeffectiveness of non-occupational PEP for HIV - to make recommendations for future research.

If appropriate, and if sufficient time and resources allow, an additional aim will be to develop an economic evaluation or adapt an existing one to model costs and cost-effectiveness in preventing seroconversion after non-occupational PEP for HIV. 



\section{Chapter 2 Background}

\section{Description of underlying health problem}

Human immunodeficiency virus is a sexually transmitted and bloodborne virus found primarily in the blood, semen or vaginal fluid of an infected person. HIV is transmitted in two main ways:

- by having unprotected sex (anal, vaginal or oral) with someone infected with HIV

- by sharing needles and syringes with someone infected with HIV.

Human immunodeficiency virus can also be transmitted through blood infected with HIV and being exposed as a fetus or infant to HIV before/during birth or through breastfeeding. Any person is at risk of infection with the virus if he or she is exposed to HIV through unprotected sex, contaminated blood products or HIV-infected bodily fluids. ${ }^{1}$

Seroconversion (converting from HIV negative to HIV positive) occurs when antibodies to HIV can be detected in the blood after infection with the virus. In individuals who become infected with HIV after exposure to the virus, about 30-70\% experience an acute seroconversion illness, typically between 2 and 6 weeks after exposure to the virus. The onset is acute and the illness lasts for 1-2 weeks. Its severity varies from a mild glandular fever-like illness with fever, sore throat, lymphadenopathy and a non-itchy maculopapular rash to a severe illness associated with mucocutaneous ulceration and neurological manifestations that requires treatment in hospital. ${ }^{2}$

Human immunodeficiency virus has a prolonged 'silent' period during which it often remains undiagnosed, particularly as the seroconversion illness (if present) may have been very mild. More persistent or severe symptoms may not appear for 10 years or more after HIV first enters the body in adults, or within 2 years in children born with HIV infection. This period of asymptomatic infection varies greatly in each person. Some people may begin to have symptoms within a few months whereas others may be symptom-free for more than 10 years. $^{3}$
Human immunodeficiency virus acts by attacking and destroying $\mathrm{CD} 4$ (cluster of differentiation) cells. These cells are a type of white blood cell called T lymphocytes (or helper/inducer cells), which are important in the body's immune system. Their depletion during HIV infection results in susceptibility to infection from opportunistic diseases such as tuberculosis, pneumonia and some cancers. ${ }^{4} \mathrm{~A} \mathrm{CD} 4$ cell count (a measure of the number of $\mathrm{CD} 4$ cells in a specified volume of blood) gives a measure of the degree to which an individual's immune system is 'compromised'. It helps to identify periods in which an individual is more vulnerable to opportunistic infections, consequently helping inform decisions to initiate antiretroviral treatment and therapies to prevent these infections. ${ }^{4}$ Acquired immunodeficiency syndrome (AIDS) is diagnosed in the UK when an HIV-infected individual presents with an AIDS-defining illness, such as Pneumocystis carinii pneumonia, pulmonary tuberculosis or extrapulmonary tuberculosis. ${ }^{5}$

The seroprevalence of HIV is the number of cases of HIV present in a specific population at a designated time, where a case is defined as someone who has HIV antibodies in their serum. ${ }^{6}$ Information on the seroprevalence of HIV in the UK relies on case and test result reporting. However, this can only give information on diagnosed infections. It is therefore supplemented by a programme of unlinked anonymous surveys (using the residue of specimens collected for routine testing for other purposes), which provide information about the total seroprevalence, including both diagnosed and undiagnosed infections, in population subgroups. ${ }^{6}$

The most effective methods for preventing HIV infection are preventive behaviours including sexual abstinence, having sexual relations only with a non-infected partner, correct condom use, abstinence from drug-injection use and consistent use of sterile equipment when using injection drugs. However, secondary prevention measures such as prophylactic antiretroviral drugs have been used to reduce the risk of HIV infection after occupational or non-occupational exposure. ${ }^{7}$ 


\section{Epidemiology}

Globally there are an estimated 39.5 million people living with HIV. There were 4.3 million new infections in 2006, with 2.8 million $(65 \%)$ of these occurring in sub-Saharan Africa and important increases in Eastern Europe and Central Asia, where there are some indications that infection rates have risen by more than 50\% since 2004 . In 2006, 2.9 million people died of AIDS-related illnesses. ${ }^{8}$

The most recent figures for the UK estimate that in 2006 there were 73,000 people living with HIV in the UK, around one-third of whom had not yet been diagnosed. There were an estimated 7800 reports of new diagnoses of HIV infection in 2006. A total of $59 \%$ of these were among heterosexuals, $36 \%$ in men who have sex with men (MSM) and $2.5 \%$ in intravenous drug users. In terms of ethnic group, $46 \%$ of persons newly diagnosed were black African and $42 \%$ were white. ${ }^{9}$

TABLE I HIV seroprevalence in different population subgroups in the UK

$\begin{array}{llc}\text { Community group } & \text { HIV seroprevalence (\%) } & \\ \text { Homosexual men } & & \\ \text { London } & 20.3 & \\ \text { Scotland } & 3.2 & \text { Female } \\ \text { Elsewhere } & 3.6 & 0.2 \\ \text { Heterosexuals (region of birth) } & \text { Male } & 0.2 \\ \text { UK } & 0.5 & 0.1 \\ \text { Rest of Europe } & 2.0 & 0.9 \\ \text { North America } & 2.9 & 1.0 \\ \text { Central and South America } & 2.4 & 0.4 \\ \text { Caribbean } & 1.2 & 11.3 \\ \text { North Africa and Middle East } & 0.5 & 0.6 \\ \text { Sub-Saharan Africa } & 6.9 & 0.7 \\ \text { South Asia } & 0.5 & 0.1 \\ \text { East and South-East Asia } & 0.5 & \\ \text { Australasia } & 0.8 & \\ \text { Injecting drug users } & & \\ \text { London } & 2.9 & \\ \text { Elsewhere in the UK } & 0.5 & \\ & & \end{array}$
higher risk of infection than others:

- homosexual men (MSM)

- injecting drug users (IDUs)

- men and women who have lived as adults in of HIV is common (notably South, East and Central Africa)

- children, from their infected mothers during pregnancy and birth. ${ }^{1}$

Table 1 shows the prevalence of HIV infection in different population subgroups in the UK. ${ }^{10}$

\section{Description of the intervention}

Postexposure prophylaxis for HIV is the prompt administration of antiretroviral therapy following known or potential exposure to HIV infection in an attempt to prevent the establishment of infection. ${ }^{11}$
There are certain groups in the UK who are at countries where heterosexual transmission 
Animal models show that, after initial exposure, HIV replicates within dendritic cells of the skin and mucosa before spreading through lymphatic vessels and developing into a systemic infection. This delay in systemic spread leaves a 'window of opportunity' for PEP using antiretroviral drugs designed to block replication of HIV. ${ }^{12}$ However, the evidence for the effectiveness of PEP in preventing seroconversion after non-occupational exposure to HIV is unclear.

Current UK guidance on PEP for non-occupational potential or actual exposure to HIV, based on the limited evidence available on the effectiveness of PEP after occupational exposure,,$^{10,12,13}$ recommends combination therapies. Although there is no direct evidence that they are more effective in preventing HIV post exposure than monotherapies, combination therapies are more efficacious in treating HIV-infected patients and in preventing perinatal transmission than monotherapies and so it is theorised that a combination of drugs would enhance the effectiveness of PEP. ${ }^{12}$ As yet, no antiretroviral drug has been licensed for use after non-occupational exposure to HIV in the UK. ${ }^{13}$ The current drug regimen recommended for HIV PEP starter packs after non-occupational exposure $^{14}$ is:

- one Combivir ${ }^{\circledast}$ (GlaxoSmithKline) tablet (300 mg zidovudine $+150 \mathrm{mg}$ lamivudine) twice daily, plus

- $\quad$ two Kaletra ${ }^{\circledR}$ (Abbott) film-coated tablets (200 mg lopinavir $+50 \mathrm{mg}$ ritonavir) twice daily.

Current UK guidance suggests that other drug combinations could be used when the physician considers them more appropriate for individual patients, such as including in the regimen ritonavir-boosted lopinavir, saquinavir or amprenavir. ${ }^{13}$ However, the current evidence on which drug regimen to use, the effectiveness of that regimen in preventing seroconversion following non-occupational exposure to HIV and adherence rates to different regimens is unclear. The guidance is based upon effectiveness of antiretroviral therapy in individuals chronically infected with HIV and on limited data of toxicity in PEP.

There are potential risks associated with PEP following non-occupational exposure or potential exposure to HIV. The drugs used have side effects such as gastrointestinal upset (nausea and diarrhoea), diabetic exacerbation, dangerous interactions with other drugs and nephrolithiasis. ${ }^{12}$ These side effects can increase non-adherence, which in turn can lead to seroconversion of the patient and the development of drug-resistant strains. ${ }^{12}$ There is also the potential for an increase in risk behaviours if PEP is perceived as preventing HIV infection. ${ }^{7}$

\section{Current UK practice}

Current UK practice for prescribing PEP after non-occupational exposure to HIV is based on guidance issued by the Department of Health ${ }^{13}$ and guidelines from the British Association for Sexual Health and HIV (BASHH). ${ }^{10}$

The Department of Health guidance (2004) states that the lack of evidence of effectiveness of PEP following non-occupational exposure to HIV prevents a recommendation either in favour of or against its use. ${ }^{13}$ It suggests that expert advice should be sought urgently from a physician experienced in the treatment of HIV (or a paediatrician in the case of a child) in the event of any non-occupational exposure to HIV that is considered to carry a high risk of HIV infection. ${ }^{13}$ For optimal efficacy PEP should ideally be started within an hour of exposure, but as this time frame is unlikely to be met in nonoccupational exposures to HIV the risk of PEP failure is increased. However, longer periods from exposure should not be considered an absolute contraindication to PEP. ${ }^{13}$ A risk assessment of the circumstances surrounding the exposure should be made by the physician considering prescribing PEP, to determine the risk of infection. ${ }^{13}$ The guidance states that all of the considerations that apply to the prescription of PEP after occupational exposure apply equally to non-occupational PEP from the point of a decision being reached that it is appropriate to prescribe it..$^{13}$ The current recommended drug regimen has been outlined in the previous section.

The BASHH guidelines make recommendations for the use of PEP following potential sexual exposure to HIV (PEPSE). ${ }^{10}$ The recommendation is that PEPSE is given within 72 hours following unprotected vaginal or anal intercourse with an HIV-positive source or receptive anal intercourse with a source of unknown HIV status but from a group of $>10 \%$ HIV prevalence. It is suggested that patients complete 4 weeks of antiretroviral therapy and reattend for HIV testing at 3 months and 6 months post exposure. ${ }^{10}$ The recommended drug regimen has been outlined in the previous section. 
A recent audit of practice against these guidelines suggests that PEPSE is being prescribed and dispensed as the BASHH guidelines recommend, but that completion rates for the full course of medication [53\%, 95\% confidence interval (CI) 40.84-64.21] and attendance for 3 and 6 months postexposure HIV testing (12\%, 95\% CI 5.5621.29) are low. ${ }^{15}$

A survey of UK genitourinary medicine clinics in 1999 found that there were 242 requests for prophylactic antiretroviral drugs made at 56 clinics following a potential non-occupational exposure to HIV. ${ }^{11}$ In total, $60 \%$ of these requests were made to nine clinics, six of which were located in the London area. The survey also found that there had been a fourfold increase in the number of requests for prophylactic antiretroviral drugs and a sevenfold increase in the number of prescriptions between 1997 and 1999. ${ }^{11}$ Most of the requests had come from HIV-serodiscordant couples who had either had unprotected sex (13 cases, 29\%) or had condom breakage during sex (10 cases, 22\%).

\section{Costs}

One cost estimate suggests that the drug cost of a full 28-day course of PEP is approximately $£ 600$ (not including staff time,) whereas the lifetime costs of treatment for an HIV-positive individual are estimated to be between $£ 135,000$ and $£ 181,000$. $^{10}$

\section{Issues specific to non- occupational HIV exposure}

There are a number of factors specific to nonoccupational HIV exposure that impact on establishing the effectiveness of PEP in this situation or that have particular implications which are different from those in occupational exposures. ${ }^{16}$

\section{Ethical issues}

The study types available to investigate the efficacy of PEP for non-occupational exposures are limited as it is not deemed ethical to randomly allocate subjects to an intervention or a control group after such an exposure. No controlled trials are likely to take place for this reason. ${ }^{7}$

\section{Time from exposure to PEP initiation}

As mentioned in the section on current UK practice, current UK guidance on the use of PEP for non-occupational exposure to HIV recommends that PEP should be considered when individuals present within 72 hours of exposure. ${ }^{10}$ This contrasts with guidance for initiation of treatment within 1 hour of occupational exposure. ${ }^{13}$ The average length of time between non-occupational exposure and presentation at health services is unknown. One study of requests for PEP from UK genitourinary medicine clinics found that the time interval between exposure and request was known for 141 out of 242 requests for PEP. ${ }^{11}$ Out of these 141 requests, 116 (82\%) were made within 48 hours.

\section{Potential multiple exposures to HIV pre- and post-PEP initiation}

Unlike occupational exposure to HIV in which the exposure incident will usually be a single exposure, non-occupational exposures to HIV can be multiple. ${ }^{16}$

There is a possibility that HIV infection could take place as a result of another exposure immediately before the exposure that led to PEP being sought. ${ }^{16}$ Individuals presenting for PEP after non-occupational exposure who subsequently seroconvert have reported additional potential exposures (with partners known to be HIV positive or with unknown HIV status) between initiating the PEP regimen and their subsequent seroconversion. ${ }^{16}$ This, combined with potential multiple exposures before PEP, makes it difficult to determine whether seroconversion resulted from failure of PEP or from other exposures. ${ }^{16}$

\section{Virus concentration}

A high plasma viral load in the source may increase the risk of transmission..$^{10}$ Although low or undetectable plasma viral loads probably reduce the risk, transmission may still be possible. ${ }^{10}$ Although viral loads in the genital tract normally correlate with plasma viral loads, it is possible to have a detectable genital viral load with an undetectable plasma viral load. ${ }^{10}$ This may be important in non-occupational exposures, where the exposures may be repeated. 


\section{Knowledge of HIV status of source}

In many circumstances the estimated risk of HIV transmission following non-occupational exposure is greater than that following occupational exposure in which PEP is routinely considered (Table 2). ${ }^{10}$ Homosexual men having unprotected receptive anal intercourse with a known HIV-positive source have an estimated risk of transmission of $3 \%$ (or a 1 in 33 chance of infection). ${ }^{10}$ This compares with an estimated risk of transmission of $0.3 \%$ ( 1 in 333 chance of infection) following a needlestick injury when the source is HIV positive. ${ }^{10}$

In occupational exposure the HIV status of the source may already be known or there may be an opportunity to establish the HIV status of the source. In non-occupational exposure the HIV status of the source may also be known, for example in known HIV-discordant partners. However, the HIV status of the source may not be known and it may be very difficult or impossible to find out. This could make calculating the estimated risk of transmission after non-occupational exposures less accurate. The proportion of requests for PEP after non-occupational exposure for which the HIV status of the source is unknown is not currently established.

Furthermore, knowledge of the HIV status of the source is important because it may lead to better prescribing of antiretrovirals, for example in cases in which the source is known to have a drugresistant strain of HIV. This can lead to higher adherence to medication and potentially greater effectiveness in preventing seroconversion.

\section{Concomitant exposures to other pathogens}

Risky sexual behaviour places individuals at risk of sexually transmitted infections other than HIV, such as gonorrhoea and syphilis. ${ }^{13}$ Exposure through sharing drug-injecting equipment can expose a person to the risk of other bloodborne infections such as hepatitis B and C. ${ }^{13}$ Epidemiological studies have shown that the presence of other sexually transmitted infections enhances HIV transmission. ${ }^{10}$

\section{The impact of local trauma on the risk of transmission}

Breaches in the mucosal barrier as a result of trauma (e.g. following sexual assault or first intercourse) may increase the risk of HIV acquisition. ${ }^{10}$ Menstruation or other bleeding may also facilitate transmission. ${ }^{10}$

\section{Non-compliance with therapy and follow-up testing}

As mentioned previously in the section on description of the intervention, the drugs used to prevent HIV seroconversion have side effects such as gastrointestinal upset (nausea and diarrhoea), diabetic exacerbation, dangerous interactions with other drugs and nephrolithiasis. ${ }^{12}$ Because of this the BASHH guidelines state that these potential side effects need to be considered in situations in which the presenting patient is in a state of acute anxiety but the assessment of risk of transmission is low. ${ }^{10}$

TABLE 2 Risk of HIV transmission following an exposure from a known HIV-positive individual ${ }^{10}$

\begin{tabular}{ll}
\hline Type of exposure & Estimated risk of HIV transmission per exposure (\%) \\
\hline Blood transfusion (one unit) & $90-100$ \\
Receptive anal intercourse & $0.1-3.0$ \\
Receptive vaginal intercourse & $0.1-0.2$ \\
Insertive vaginal intercourse & $0.03-0.09$ \\
Insertive anal intercourse & 0.06 \\
Receptive oral sex (fellatio) & $0-0.04$ \\
Needlestick injury & $0.3(95 \% \mathrm{Cl} 0.2-0.5)$ \\
Sharing injecting equipment & 0.67 \\
Mucous membrane exposure & $0.09(95 \% \mathrm{Cl} 0.006-0.5)$ \\
\hline Cl, confidence interval. &
\end{tabular}


Patients have cited side effects as a reason for discontinuing PEP after sexual exposure. ${ }^{15}$ The $\mathrm{BASHH}$ guidelines recommend that at least $75 \%$ of people receiving PEP following sexual exposure to HIV should complete the 4-week course of HIV therapy, and at least $75 \%$ should attend for a 3and 6-month follow-up HIV test. ${ }^{10}$ However, one study $^{15}$ found that only $53 \%$ (95\% CI 40.84-64.21) of patients completed therapy and only $12 \%$ (95\% CI 5.56-21.29) attended for both a 3- and 6-month follow-up HIV test. They speculate that this low completion rate may reflect recipients independently clarifying their source's HIV status, poor documentation of adherence and/or a high default rate from follow-up, with patient-perceived low risk, inadequate recall of non-attendees and a mobile population also contributing. ${ }^{15}$

Poor adherence to PEP regimens is important as it may theoretically result in the acquisition of a drugresistant virus should the individual become HIV infected. ${ }^{10}$

\section{Behavioural impact of PEP availability and programmes}

There are concerns that the availability of PEP for non-occupational exposure to HIV will reduce commitment to primary prevention strategies such as using a condom during sex or avoiding needle sharing when injecting drugs. This could lead to a rise in the frequency of high-risk behaviours, thereby adding to, rather than lessening, HIV transmission. ${ }^{10,17}$ The most desirable outcome is that promoting PEP will cut rates of HIV infection in exposed individuals and reinforce safer sexual

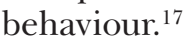

A number of possible scenarios have been envisaged including:

- no impact of availability of PEP on behaviour

- negative impact: availability of PEP results in an increase in risky behaviours

- positive impact: the 'close call' may act to motivate and sustain risk reduction in individuals who have engaged in risk behaviour. ${ }^{10}$
Currently there is conflicting evidence with different studies providing evidence for each of the three scenarios. ${ }^{10}$ At the moment there are no data suggesting that a significant number of individuals will repeatedly present for PEP following nonoccupational exposure. ${ }^{10}$

Another possible outcome of PEP for nonoccupational exposures is that the overall number of HIV infections remains unchanged because the numbers protected by PEP are counterbalanced by additional infections in individuals whose risk behaviour is increased by awareness of PEP but who then fail to use it. ${ }^{17}$ There is the potential for PEP to cause net harm by protecting only a few individuals at the expense of adverse effects on behaviour and increased HIV transmission in the wider community. ${ }^{17}$ There are also implications for the cost and cost-effectiveness of non-occupational PEP, particularly if the awareness of availability of PEP for non-occupational exposures leads to increased demand from those with a low-risk exposure. ${ }^{17}$ Although these are important concerns there does not appear to be much evidence to support or refute them.

\section{Rationale for the study}

There is growing clinical and patient enthusiasm for the use of non-occupational PEP to prevent HIV infection, although the reduction in the risk of seroconversion may be small, therapy can have unpleasant side effects and other issues as described may impact on effectiveness. No systematic review of the existing literature has been identified. Research is therefore needed to synthesise the available evidence on the effectiveness, harms and cost-effectiveness of nonoccupational PEP for HIV.

From the perspective of the patient the pressing clinical issue is to prevent HIV infection. The wider NHS perspective is the most appropriate and costeffective use of expensive antiretroviral drugs. 


\section{Chapter 3 Methods}

$\mathrm{T}$ he a priori methods used for the review are outlined in the research protocol (see Appendix 1). This was sent to members of the advisory group for the review for expert comments (see Acknowledgements). Helpful comments were received relating to the general content of the research protocol; no specific problems with the proposed methods of the review were identified.

Some changes, additions or points of clarification were made to the methods discussed in the original protocol.

- It was felt important that a comparator group of some sort was included in any study that was considered for inclusion as evidence of clinical effectiveness. This could be either a group not receiving PEP, either through study design or by individual choice not to receive medication, or a group receiving an alternative drug regimen. As such, several studies that initially appeared to meet the inclusion criteria were excluded on the basis of not reporting relevant outcomes for comparator groups.

- The main outcome of interest to assess the clinical effectiveness of non-occupational PEP for HIV was the HIV seroconversion rate. However, adverse events are also an important outcome measure and to supplement the limited adverse event data from the clinical effectiveness section of the report additional studies were sought. Studies that did not report the main outcome of interest (seroconversion rates) but which did present adverse event data for both an intervention group and a comparator group were included for adverse events, as were prospective observational studies that met the inclusion criteria in terms of population and intervention.

The research methods used for the systematic reviews are summarised below.

\section{Search strategy}

The following databases were searched for published studies and ongoing research, from inception to December 2007: the Cochrane
Library (Database of Systematic Reviews and the Cochrane Central Register of Controlled Trials), MEDLINE (Ovid), EMBASE (Ovid), PubMed, NHS Economic Evaluations Database (NHS EED), NHS Health Technology Assessment database (NHS HTA), Database of Abstracts of Reviews of Effectiveness (DARE), EconLit, National Research Register (NRR), Current Controlled Trials and ClinicalTrials.gov. Grey literature and conference proceedings were also searched. Searches were restricted to the English language and to human studies. Bibliographies of identified papers were assessed for other relevant studies. Investigators of studies were not contacted because of time constraints. Further details, including key search terms, can be found in Appendix 2.

\section{Inclusion and data extraction process}

Titles and abstracts of studies identified by the search strategy were screened independently for inclusion by two reviewers. The full text of potentially eligible studies was obtained and examined independently for inclusion by two reviewers. Data from each of the included studies were extracted by two reviewers on standard data extraction forms. Any disagreements were resolved by consensus or arbitration by a third reviewer if necessary.

The process for identifying and including studies is illustrated in Appendix 2, Figure 1. The primary reason for excluding studies was that they did not meet the inclusion criteria; for example they did not have a comparator group or results were not presented separately for the intervention and comparator groups. A list of studies excluded at various stages of the process can be found in Appendix 3.

\section{Quality assessment}

The methodological quality of included studies was assessed using modified formal tools specific to the design of the study and focusing on possible sources of bias. The clinical effectiveness study 
was assessed for quality using criteria developed by Spitzer et al. ${ }^{18}$ Quality assessment of economic evaluations was conducted using a checklist adapted from those developed by Drummond and Jefferson ${ }^{19}$ and Philips and colleagues. ${ }^{20}$

Quality criteria were applied to each included study independently by two reviewers. At each stage any differences in opinion were resolved through discussion or if necessary by arbitration by a third reviewer.

\section{Inclusion criteria}

The inclusion criteria used for studies of the clinical and cost-effectiveness of non-occupational PEP for HIV are shown below.

\section{Intervention}

- Any antiretroviral drug regimen administered as non-occupational PEP for a short period (28 days) to HIV-negative people potentially exposed to HIV through unprotected sexual contact or use of a potentially contaminated needle or potentially contaminated biological fluid.

\section{Population}

- Humans with non-occupational exposure to HIV. This may be by:

- unprotected sexual exposure (oral, vaginal, anal), either voluntary or rape, with an HIVinfected partner or partner of unknown HIV status
- exposure to a needle contaminated by a known or potentially infected substance in Comparator a non-occupational setting.

- No intervention.

- Group not receiving PEP.

- A different PEP regimen.

\section{Outcomes}

- HIV seroconversion frequency.

- Adverse effects and complications of PEP.

- Adherence to PEP.

- Health-related quality of life.

- Costs or some measure of cost-effectiveness.

\section{Study type}

- Randomised controlled trial (RCT), controlled clinical trial (CCT), cohort study or casecontrol study.

- Cost-effectiveness/utility studies.

- Economic evaluations.

- Prospective observational studies for adverse events.

\section{Data synthesis}

Synthesis of data was through narrative review with full tabulation of results of all included studies. Full data extraction forms are shown in Appendices 4 and 5 . Meta-analysis was not possible because of the limited data found. 


\section{Chapter 4}

\section{Clinical effectiveness}

\section{Quantity and quality of research available}

One published study met the inclusion criteria for the review, which was a cohort study conducted by Schechter and colleagues ${ }^{21}$ in Brazil (Table 3, Figure 1 in Appendix 2 and Appendix 4).

The methodological quality and the quality of reporting of the included study were generally weak (Table 4).
Significant selection bias may have occurred during the recruitment of study participants. Participants were recruited from an unreported number of eligible participants of a previous HIV seroincidence study of MSM. A total of 250 of those deemed eligible were contacted by telephone and the first 200 to agree to participate were included in this study. The authors do not report the total number of eligible participants in the previous study or how the 250 eligible participants that were telephoned were selected, nor do they

TABLE 3 Details of included study

\begin{tabular}{|lllll|}
\hline Study & Population & Intervention & Comparison & Outcome measures \\
\hline $\begin{array}{l}\text { Schechter et } \\
\text { al. 2004 }\end{array}$ & $\begin{array}{l}\text { Brazilian cohort of 200 } \\
\text { high-risk men who } \\
\text { have sex with men } \\
\text { (MSM) }\end{array}$ & $\begin{array}{l}\text { 28-day course of PEP after potential high- } \\
\text { risk exposure to HIV (zidovudine } 300 \mathrm{mg} \\
\text { and lamivudine I50 } \mathrm{mg} \text { orally, fixed-dose }\end{array}$ & $\begin{array}{l}\text { Non-PEP } \\
\text { combination tablet twice daily) }\end{array}$ & $\begin{array}{l}\text { Reported behaviour, } \\
\text { PEP utilisation, adverse } \\
\text { events, incident HIV } \\
\text { infection }\end{array}$ \\
\hline
\end{tabular}

TABLE 4 Quality assessment of included study

\begin{tabular}{|c|c|c|c|c|c|c|}
\hline & Yes & $\mathbf{U} / \mathbf{I} / \mathbf{S}^{\mathbf{a}}$ & No & DK/NR ${ }^{b}$ & N/A & Comments \\
\hline $\begin{array}{l}\text { Proper random } \\
\text { assignment }\end{array}$ & & & No & & & \\
\hline Proper sampling & & $U$ & & & & $\begin{array}{l}250 \text { potential participants invited to participate by telephone; } \\
\text { first eligible } 200 \text { who agreed were enrolled. Participants were } \\
\text { given PEP to begin after an eligible exposure }\end{array}$ \\
\hline $\begin{array}{l}\text { Adequate sample } \\
\text { size }\end{array}$ & & $\mathrm{U}$ & & & & $\begin{array}{l}\text { Authors comment that the } 109 \text { exposures for which PEP } \\
\text { was taken represent a small proportion of the total eligible } \\
\text { exposures that occurred during the study }\end{array}$ \\
\hline $\begin{array}{l}\text { Objective } \\
\text { outcomes }\end{array}$ & & I & & & & Self-reported high-risk sexual activity \\
\hline Blind assessment & & & No & & & \\
\hline $\begin{array}{l}\text { Objective eligibility } \\
\text { criteria }\end{array}$ & Yes & & & & & \\
\hline Reported attrition & Yes & & & & & \\
\hline $\begin{array}{l}\text { Comparability of } \\
\text { groups }\end{array}$ & Yes & & & & & \\
\hline Generalisability & & $U$ & & & & $\begin{array}{l}\text { Limited to men who have sex with men from a previously } \\
\text { known high-risk cohort, aged 18-35 years }\end{array}$ \\
\hline
\end{tabular}


report any attempt to minimise volunteer bias. No power calculation is provided to justify why 200 participants were needed.

Participants allocated themselves to the intervention or the control group depending on whether or not they initiated chemoprophylaxis after an eligible exposure by taking the 4-day supply of PEP that they had been given. If PEP was initiated, after 4 days the participant was assessed by study personnel to establish whether the exposure was considered a high enough risk to warrant a further 24 days of PEP. Further selection bias may have occurred at this point as the authors do not report what was considered to be a high-risk exposure or the procedure by which study personnel made such decisions. However, the authors do report the demographic and behavioural characteristics of all study participants, which suggests that there were no significant differences between those who did and those who did not use PEP over the course of the study.

The authors do not report blinding of study participants or personnel. Although it would not have been possible to have fully blinded both study personnel and participants, it may have been possible at the routine follow-up appointments to have blinded personnel to PEP use by participants. This could have reduced potential detection bias.

In the analysis the authors report that two participants had no follow-up data and were therefore excluded from analysis, meaning that an intention to treat analysis was not conducted. The authors report the seroincidence rate (incidence of seroconversions per 100 person-years) for all of the study participants together, compared with the expected number of incident HIV cases in the absence of PEP (modelled from the previous HIV incidence study). The authors state that they did this because of a lack of a control group (participants not taking PEP). However, the reported results seem to suggest that there is a control group with follow-up data (participants who did not initiate PEP after an eligible exposure). It is therefore not clear why the authors did not calculate the incidence of seroconversion for those who took PEP and for those who did not take PEP, to give an estimate of the effectiveness of PEP in preventing seroconversion for non-occupational exposures.

This study reports the use of PEP amongst a wellestablished cohort of high-risk sexually active MSM, aged 18-35 years, in Rio de Janeiro, Brazil. The study cohort may have some similarities with populations of MSM living in other big cities, although the limited age range of study participants prevents generalisation to populations of MSM as a whole. It is also not possible to generalise the findings of this study to the population as a whole, in which potential exposure to HIV may also occur through heterosexual sex or non-occupational needlestick injuries.

\section{Assessment of effectiveness}

Tables 5-9 present the results of the included cohort study $^{21}$ in terms of seroincidence of HIV within the cohort, PEP use, non-completion of PEP, adverse events and reports of risky behaviours.

\section{Seroconversion to HIV}

The HIV seroincidence is presented in Table 5. One incidence of seroconversion to HIV was reported in the group of participants that took PEP, compared with 10 from the 'no PEP' group. No $p$-value was reported. Over the course of the study the overall incidence of HIV was 2.9 per 100 person-years (95\% CI 1.4-5.1). The authors report that, based on the risk profile of the participants and experience from a previous study, the expected number of new HIV infections overall was $11.8(p>0.97$ compared with the observed 11 infections) and the expected seroincidence was 3.1 per 100 person-years $(p>0.97$ compared with the seroincidence of 2.9 found in this study).

TABLE 5 HIV seroincidence

\begin{tabular}{|llll} 
& PEP $(n=68)$ & No PEP $(n=132)$ & -value \\
\hline Seroconversion to HIV & I & 10 & Not reported
\end{tabular}


TABLE 6 PEP use (28-day course)

\begin{tabular}{lll} 
& PEP $(\boldsymbol{n}=\mathbf{6 8})$ & No PEP $(\boldsymbol{n}=132)$ \\
\hline Prescribed once, $n(\%)$ & $49(72.1)$ & - \\
Prescribed twice, $n(\%)$ & $14(20.6)$ & - \\
Prescribed three times, $n(\%)$ & $2(2.9)$ & - \\
Prescribed four times, $n(\%)$ & $2(2.9)$ & - \\
Prescribed nine times, $n(\%)$ & $\mathrm{I}(1.5)$ &
\end{tabular}

\section{PEP use}

The PEP use in the cohort is presented in Table 6 . In the majority of cases the full 28-day course was prescribed once per participant $(72.1 \%)$. In total, 100 out of 109 exposures for which PEP was initiated by participants were considered eligible and received the 4 -week course. The authors report that the most common reasons for not initiating PEP ( $\geq$ one possible response per participant) were sex with a steady partner $(n=150)$, the participant did not consider the exposure to be of sufficiently high risk to warrant PEP $(n=94)$ and concerns about side effects $(n=23)$.

\section{Adverse events and adherence}

The number of non-completed PEP courses is shown in Table 7. The authors report that the full 28-day regimen of PEP was completed for $89(89 \%)$ of the eligible exposures, including the participant who seroconverted, and that the 11 discontinuations correspond to nine participants.

Two of the participants did not come back to the study site to complete their visits at 28 days.

There were seven discontinuations of PEP because of adverse events. At least one side effect was reported in $82 \%$ of episodes of PEP use. Nausea was the most commonly reported side effect: six of the discontinuations for adverse events were due to this. Apart from one patient with a history of pancreatitis who had to stop taking PEP because of an asymptomatic increase in pancreatic enzymes, it is reported that there were no clinically significant laboratory abnormalities among those receiving PEP.

\section{Risk behaviours and PEP use}

The median numbers of male partners reported by participants are presented in Table 8 . These remained the same from the baseline visit to the last visit at 24 months for both groups, although the range was increased in both groups at the last visit.

Table 9 shows the types of risk behaviours that participants were asked to report and the changes from the 6 months previous to the baseline visit to the 6 months previous to the last follow-up visit at 24 months. Reported unprotected anal intercourse decreased in both groups; in the no PEP group this decrease was statistically significant. Reported unprotected oral intercourse decreased significantly in both the PEP and the no PEP groups. Unprotected vaginal intercourse increased; this was not statistically significant.

Self-reported results should be viewed with some caution where there is the possibility that highrisk behaviour has been under-reported or where reports may be inconsistent.

TABLE 7 Non-completed PEP courses

\begin{tabular}{llll} 
& PEP $(n=68)$ & No PEP $(n=132)$ \\
\hline Did not return to complete course & 2 & - \\
Discontinued because of adverse events & 7 & -
\end{tabular}


TABLE 8 Numbers of male partners and PEP use

\begin{tabular}{lll} 
& PEP $(\boldsymbol{n}=\mathbf{6 8})$ & No PEP $(\boldsymbol{n}=132)$ \\
\hline $\begin{array}{l}\text { Median number of male partners 6 months } \\
\text { before baseline (range) }\end{array}$ & $4(0-50)^{\mathrm{a}}$ & $2(0-40)^{\mathrm{b}}$ \\
$\begin{array}{l}\text { Median number of male partners 6 months } \\
\text { before last visit (range) }\end{array}$ & $4(0-180)^{\mathrm{a}}$ & $2(0-100)^{\mathrm{b}}$ \\
\hline $\begin{array}{l}\text { a } p=0.43 . \\
\text { b } p=0.46 .\end{array}$ & \\
\hline
\end{tabular}

TABLE 9 Risk behaviours and PEP use

\begin{tabular}{|lllllll}
\hline & PEP $(n=68)$ & & \multicolumn{2}{l}{ No PEP $(\boldsymbol{n}=132)$} \\
\hline & $\begin{array}{l}\text { 6 months } \\
\text { before } \\
\text { baseline }\end{array}$ & $\begin{array}{l}\text { 6 months } \\
\text { before last } \\
\text { visit }\end{array}$ & $p$-value & $\begin{array}{l}\text { 6 months } \\
\text { before } \\
\text { baseline }\end{array}$ & $\begin{array}{l}\text { 6 months } \\
\text { before last } \\
\text { visit }\end{array}$ & $p$-value \\
\hline $\begin{array}{l}\text { Unprotected anal } \\
\text { intercourse, } n(\%)\end{array}$ & $32(47.1)$ & $27(39.7)$ & $p=0.35$ & $48(36.4)$ & $32(24.2)$ & $p=0.008$ \\
$\begin{array}{l}\text { Unprotected oral } \\
\text { intercourse, } n(\%)\end{array}$ & $16(23.5)$ & $8(11.8)$ & $p=0.06$ & $32(24.4)$ & $16(12.2)$ & $p=0.002$ \\
$\begin{array}{l}\text { Unprotected vaginal } \\
\text { intercourse }\end{array}$ & $1.6 \%$ & $4.7 \%$ & $p=0.16$ & $6.1 \%$ & $8.3 \%$ & $p=0.26$
\end{tabular}

\section{Summary of clinical effectiveness of PEP for non-occupational exposure to HIV}

- One cohort study of PEP in a high-risk HIVnegative homosexual male cohort in Brazil met the inclusion criteria of the review. The methodological quality and the quality of the reporting of the study were generally weak.

- The seroconversion to HIV rate in this study was one in the PEP group and 10 in the nonPEP group.

- The results suggest that PEP made no difference to the expected seroconversion to HIV for this cohort.

- Over the course of the study the overall seroincidence (combining the PEP and nonPEP groups) was 2.9 per 100 person-years (95\% CI 1.4-5.1). This was compared with the authors expected seroincidence of 3.1 per 100 person-years $(\mathrm{p}>0.97$ compared with the observed seroincidence of 2.9).
- PEP was rarely prescribed on more than two occasions per participant, with the majority (72.1\%) receiving just one course.

- The number of non-completed courses appears to be low, with only 2 out of 68 not returning to complete the course and 7 out of 68 discontinuing because of adverse events.

- The authors report that, on average, highrisk sexual activities declined over time for both PEP and non-PEP users. This does not appear to be related to the decision to initiate PEP; both groups had access to interventions designed to prevent/reduce risk behaviour, including at each visit pre- and post-test counselling, provision of condoms and safer sex workshops.

- The authors conclude that the results from their study 'argue against establishing a public health PEP programme in our population with the aim of having a major impact on HIV transmission' because of the observed overall seroincidence of $2.9 \%$ being so similar to that expected for this population. 


\section{Chapter 5 Cost-effectiveness}

$\mathrm{T}$ he aim of this chapter is to evaluate the costeffectiveness of non-occupational PEP for HIV. A systematic review of the literature was conducted to identify economic evaluations of the use of PEP in people with non-occupational exposure to HIV. The feasibility of developing an economic model was also considered.

The methods used for the systematic review are described in Chapter 3. The details of the inclusion and exclusion criteria are shown in Appendix 1 and the search strategies are shown in Appendix 2.

Titles and abstracts of studies identified by the search strategy were assessed for potential eligibility by two reviewers. The full text of relevant papers was obtained and inclusion criteria were applied to each study independently by two reviewers. Differences in opinion were resolved through discussion or by arbitration by a third reviewer if necessary.

Economic evaluations were eligible for inclusion if they reported on the cost or cost-effectiveness of any antiviral drug regimen administered as PEP in people with non-occupational exposure to HIV (unprotected sexual exposure or needle contamination) compared with another PEP regimen or a group of people not receiving PEP (Appendix 1).

\section{Quantity and quality of research available}

Four economic evaluations ${ }^{22-25}$ met the inclusion criteria for the review and are shown in Table 10 (details in Figure 2 in Appendix 2 and Appendix 5).

A summary of the methodological quality of reporting in the four included studies is shown in Table 11. Each of the cost-effectiveness studies outlined a well-defined question: to assess the cost-effectiveness of PEP for HIV following a nonoccupational exposure..$^{22-25}$ The patient group was clearly stated in three of the four studies. ${ }^{23-25}$ In the study by Pinkerton and colleagues ${ }^{22}$ the patient group is less clear as the authors have referred to a hypothetical cohort of 10,000 'patients' (a cohort that includes women) but have used this term interchangeably with 10,000 'men who have sex with men'.

All of the studies clearly stated that their perspective was societal, with the analysis including all identifiable costs, regardless of who bore them. However, Pinkerton and colleagues ${ }^{22}$ stated only the monetary costs of PEP drugs and of treating a patient with HIV/AIDS. Herida and colleagues ${ }^{25}$ referred only to health sector costs in their study, despite employing a societal perspective.

Two of the studies ${ }^{23,25}$ gave a clear description of the interventions considered. One study ${ }^{24}$ does not describe the PEP programme employed, whereas in the other ${ }^{22}$ the intervention applied to a hypothetical cohort was assumed to be zidovudine, lamivudine and indivadir, or zidovudine and lamivudine only, but no further details are given. Three of the four studies ${ }^{22,24,25}$ employed the comparator of 'no PEP' whereas in the fourth study $^{23}$ the comparator used is unclear.

The study types used were appropriate for economic analysis in each case; three of the four studies included both cost-effectiveness and cost-utility analyses ${ }^{22,23,25}$ and one employed a costutility analysis alone. ${ }^{24}$

Each of the four studies is limited as the effectiveness of the intervention, PEP in nonoccupational exposure to HIV, has not been established. The effectiveness parameter in each of the papers is based on the results of a case-control study undertaken in health-care workers who were prescribed zidovudine monotherapy. The dual or triple drug regimens considered in these costeffectiveness studies are assumed to be as effective as zidovudine alone in this study of occupational exposure. Pinkerton and colleagues ${ }^{22}$ have taken their effectiveness parameter, the probability that PEP is effective, from the original study, ${ }^{26}$ set at $79 \%$. The remaining three studies ${ }^{23-25}$ have taken their effectiveness parameter from the update of that study, ${ }^{27}$ in which effectiveness is set at $81 \%$, although one of these studies ${ }^{25}$ reports that an effectiveness of $80 \%$ is used. 
TABLE 10 Study characteristics of economic evaluations

\begin{tabular}{|c|c|c|c|c|}
\hline & $\begin{array}{l}\text { Pinkerton et al. } \\
1998^{22}\end{array}$ & $\begin{array}{l}\text { Pinkerton et al. } \\
2004^{23}\end{array}$ & $\begin{array}{l}\text { Pinkerton et al. } \\
2004^{24}\end{array}$ & Herida et al. $2006^{25}$ \\
\hline Country of origin & US & US & US & France \\
\hline Base year prices & 1996 US\$ & 2000 US\$ & 2000 US\$ & 2002 Euros \\
\hline Intervention & $\begin{array}{l}\text { PEP following potential } \\
\text { HIV exposure through } \\
\text { sexual contact with a } \\
\text { partner who may or } \\
\text { may not be infected vs a } \\
\text { 'no programme option'. } \\
\text { PEP was assumed to } \\
\text { consist of a 4-week } \\
\text { regimen of triple } \\
\text { combination therapy } \\
\text { with ZDV, 3TC and } \\
\text { the protease inhibitor } \\
\text { indivadir }\end{array}$ & $\begin{array}{l}\text { Initial 7-day PEP with } \\
\text { additional } 2 \text { I days } \\
\text { supplied at follow-up } \\
\text { visit. Also medical } \\
\text { evaluation, HIV risk } \\
\text { assessment, risk- } \\
\text { reduction counselling. } \\
\text { Response to medication } \\
\text { of HIV-infected sources } \\
\text { was obtained if possible } \\
\text { to tailor PEP to that } \\
\text { most appropriate }\end{array}$ & $\begin{array}{l}\text { Hypothetical PEP } \\
\text { programme in } 96 \text { US } \\
\text { metropolitan statistical } \\
\text { areas (MSA), based } \\
\text { on San Francisco PEP } \\
\text { programme }\end{array}$ & $\begin{array}{l}\text { PEP programme vs } \\
\text { 'no PEP' alternative. } \\
\text { Clinicians prescribe } \\
\text { drugs of their choice } \\
\text { (usually tri-therapy } \\
\text { containing protease } \\
\text { inhibitor). Antiretroviral } \\
\text { drugs and counselling } \\
\text { provided at each visit }\end{array}$ \\
\hline Study type & $\begin{array}{l}\text { Cost-utility analysis; } \\
\text { decision-analytical } \\
\text { model to evaluate cost- } \\
\text { effectiveness }\end{array}$ & $\begin{array}{l}\text { Cost-effectiveness and } \\
\text { cost-utility study }\end{array}$ & Cost-utility analysis & $\begin{array}{l}\text { Cost-effectiveness } \\
\text { analysis based on } \\
\text { decision trees and } \\
\text { cost-utility study }\end{array}$ \\
\hline Study group & $\begin{array}{l}\text { A hypothetical cohort } \\
\text { of } 10,000 \text { patients } \\
\text { who reported sexual } \\
\text { intercourse with a } \\
\text { partner of unknown } \\
\text { HIV status }\end{array}$ & $\begin{array}{l}40 \text { I participants } \\
\text { with possible non- } \\
\text { occupational exposure } \\
\text { to HIV (sexual, } \\
\text { needle sharing, } \\
\text { non-occupational } \\
\text { needlestick injury, other } \\
\text { (bite or assault) }\end{array}$ & $\begin{array}{l}\text { Information on PEP } \\
\text { clients taken from the } \\
\text { San Francisco PEP } \\
\text { programme, which was } \\
\text { used to estimate the } \\
\text { number of potential } \\
\text { PEP clients in each } \\
\text { group in each MSA }\end{array}$ & $\begin{array}{l}\text { I2,55I individuals } \\
\text { who sought PEP } \\
\text { between July I } 999 \text { and } \\
\text { December 2003; } 8958 \\
\text { (7I\%) were prescribed } \\
\text { PEP and included in a } \\
\text { national hospital-based } \\
\text { voluntary surveillance } \\
\text { of PEP programme } \\
\text { for both occupational } \\
\text { and non-occupational } \\
\text { exposure }\end{array}$ \\
\hline Perspective & Societal & Societal & Societal & Societal \\
\hline Industry role & None stated & $\begin{array}{l}\text { None stated (one } \\
\text { of the authors has } \\
\text { received honorariums } \\
\text { from GlaxoSmithKline, } \\
\text { Bristol-Myers } \\
\text { Squibb and Agouron } \\
\text { Pharmaceuticals) }\end{array}$ & Not stated & Not stated \\
\hline
\end{tabular}

3TC, lamivudine; ZDV, zidovudine.

The effectiveness of PEP and its effects on the costutility ratios presented in the studies, along with other parameters, are clearly explored in sensitivity analyses in each of the studies. ${ }^{22-25}$ Authors of two of the studies reported multivariate and threshold analyses in addition to the univariate sensitivity analysis. ${ }^{22,23}$

Costs and consequences were judged to have been valued credibly in three of the four included studies. ${ }^{22,23,25}$ Pinkerton and colleagues ${ }^{24}$ have calculated the costs of providing PEP from a previously published cost analysis.

Three of the four studies have used a lifetime horizon for analysis. ${ }^{22,24,25}$ A shorter time horizon of 10 years has been employed for estimating long-term infection, but no justification has been given. ${ }^{23}$ Discount rates are clearly reported in three studies. In two studies ${ }^{23,25}$ an annual rate of $3 \%$ was used to discount both costs and benefits, such as future savings in averted HIV-related 
TABLE II Summary of the methodological quality of reporting of the cost-effectiveness studies

\begin{tabular}{|c|c|c|c|c|}
\hline Quality criteria & $\begin{array}{l}\text { Pinkerton et al. } \\
1998^{22}\end{array}$ & $\begin{array}{l}\text { Pinkerton et al. } \\
2004^{23}\end{array}$ & $\begin{array}{l}\text { Pinkerton et al. } \\
2004^{24}\end{array}$ & $\begin{array}{l}\text { Herida et al. } \\
2006^{25}\end{array}$ \\
\hline Is there a well-defined question? & Yes & Yes & Yes & Yes \\
\hline $\begin{array}{l}\text { Is there a clear description of } \\
\text { alternatives (i.e. who did what to } \\
\text { whom, where and how often)? }\end{array}$ & Unclear & Yes & No & Yes \\
\hline $\begin{array}{l}\text { Has the correct patient group/ } \\
\text { population of interest been clearly } \\
\text { stated? }\end{array}$ & No & Yes & Yes & Yes \\
\hline Is the correct comparator used? & Yes & Unclear & Yes & Yes \\
\hline Is the study type reasonable? & Yes & Yes & Yes & Yes \\
\hline $\begin{array}{l}\text { Is the perspective of the analysis clearly } \\
\text { stated? }\end{array}$ & Yes & Yes & Yes & Yes \\
\hline $\begin{array}{l}\text { Is the perspective employed } \\
\text { appropriate? }\end{array}$ & Unclear & Yes & Yes & Unclear \\
\hline $\begin{array}{l}\text { Is the effectiveness of the intervention } \\
\text { established? }\end{array}$ & No & No & No & No \\
\hline $\begin{array}{l}\text { Has a lifetime horizon been used for } \\
\text { analysis? If not, has a shorter time } \\
\text { horizon been justified? }\end{array}$ & Yes & No & Yes & Yes \\
\hline $\begin{array}{l}\text { Are the costs and consequences valued } \\
\text { credibly? }\end{array}$ & Yes & Yes & Unclear & Yes \\
\hline Is differential timing considered? & Yes & Yes & Unclear & Yes \\
\hline Is incremental analysis performed? & Yes & No & No & No \\
\hline $\begin{array}{l}\text { Is sensitivity analysis undertaken and } \\
\text { presented clearly? }\end{array}$ & Yes & Yes & Yes & Yes \\
\hline
\end{tabular}

medical costs. Pinkerton and colleagues ${ }^{22}$ used a $3 \%$ annual rate (applied to both costs and benefits) and altered this to $0 \%$ (undiscounted) and $5 \%$ in the sensitivity analysis. It is unclear if discounting has been applied in one of the 2004 Pinkerton and colleagues studies. ${ }^{24}$

Incremental analysis was reported by only one of the studies. ${ }^{22}$ The remaining three papers report cost-utility ratios but no incremental ratios.

Pinkerton and colleagues ${ }^{23}$ compare their results with previously published papers.

Table 12 presents a summary of the external validity of the included cost-effectiveness studies. Three of the four studies are set in the $\mathrm{US}^{22-24}$ and the fourth in France, ${ }^{25}$ where the institutional healthcare arrangements and resource costs, and access to them, are not comparable to those in England and Wales. It is unclear whether the patient groups are similar to those of interest in England and Wales as these studies are set in differing health-care systems but are conducted among the relevant population: those taking PEP after a non-occupational exposure.
Either the intervention in each of the four studies was not sufficiently clear for a judgement to be made of treatment comparability ${ }^{24,25}$ or the research protocol included such elements as counselling and adherence counselling that may not be a feature of clinical management. ${ }^{23}$ Pinkerton and colleagues ${ }^{22}$ have assumed that the PEP in their study consists of triple combination therapy, which is comparable to that recommended in the $\mathrm{UK}$, but no further details are given.

\section{Assessment of cost- effectiveness}

Summaries of the results of the four published economic evaluations in terms of cost-utility ratios for different population subgroups are shown in Tables 13-15.

Herida and colleagues ${ }^{25}$ found that the French PEP programme did not appear to be costeffective overall, with a cost-effectiveness ratio of $€ 996,104$ per infection averted and $€ 88,692$ per quality-adjusted life-year (QALY) saved. 
TABLE I 2 Summary of the external validity of the cost-effectiveness studies

\begin{tabular}{|c|c|c|c|c|}
\hline Quality criteria & $\begin{array}{l}\text { Pinkerton et al. } \\
1998^{22}\end{array}$ & $\begin{array}{l}\text { Pinkerton et al. } \\
2004^{23}\end{array}$ & $\begin{array}{l}\text { Pinkerton et al. } \\
2004^{24}\end{array}$ & $\begin{array}{l}\text { Herida et al. } \\
2006^{25}\end{array}$ \\
\hline $\begin{array}{l}\text { Patient group - are the patients } \\
\text { in the study similar to those of } \\
\text { interest in England and Wales? }\end{array}$ & Unclear & Unclear & Unclear & Unclear \\
\hline $\begin{array}{l}\text { Health-care system/setting } \\
\text { - comparability to England } \\
\text { and Wales; comparability of } \\
\text { available alternatives; similar } \\
\text { levels of resources; institutional } \\
\text { arrangements comparable? }\end{array}$ & No & No & No & No \\
\hline $\begin{array}{l}\text { Treatment - comparability with } \\
\text { clinical management? }\end{array}$ & Unclear & Unclear & Unclear & Unclear \\
\hline $\begin{array}{l}\text { Resource costs - comparability } \\
\text { between study and setting/ } \\
\text { population of interest? }\end{array}$ & No & No & No & No \\
\hline
\end{tabular}

TABLE I3 Base-case cost-utility ratios for men who have sex with men

\begin{tabular}{|c|c|c|c|c|c|c|}
\hline $\begin{array}{l}\text { Type of } \\
\text { exposure }\end{array}$ & $\begin{array}{l}\text { Probability } \\
\text { PEP effective }\end{array}$ & $\begin{array}{l}\text { HIV } \\
\text { transmission } \\
\text { probability }\end{array}$ & $\begin{array}{l}\text { Probability } \\
\text { source is HIV } \\
\text { positive }\end{array}$ & $\begin{array}{l}\text { Estimated or } \\
\text { actual PEP } \\
\text { compliance }\end{array}$ & Cost per QALY & Study \\
\hline \multirow{5}{*}{$\begin{array}{l}\text { Unprotected } \\
\text { receptive } \\
\text { anal } \\
\text { intercourse }\end{array}$} & 0.80 & 0.02 & 1.00 & 0.83 & $-€ 22,|4|$ & $\begin{array}{l}\text { Herida et } \\
\text { al. } 2006^{25}\end{array}$ \\
\hline & 0.80 & 0.02 & 0.14 & 0.74 & $€ 31,862$ & $\begin{array}{l}\text { Herida et } \\
\text { al. } 2006^{25}\end{array}$ \\
\hline & 0.81 & 0.02 & 0.293 & $1.00^{\mathrm{a}}$ & $\begin{array}{l}\text { Cost saving (actual } \\
\text { cost per QALY not } \\
\text { reported) }\end{array}$ & $\begin{array}{l}\text { Pinkerton et } \\
\text { al. } 2004^{23}\end{array}$ \\
\hline & 0.81 & 0.02 & Not reported & 0.778 & $\begin{array}{l}\text { US\$ }<0 \text { (actual } \\
\text { figure not } \\
\text { reported) }\end{array}$ & $\begin{array}{l}\text { Pinkerton et } \\
\text { al. } 2004^{24}\end{array}$ \\
\hline & 0.79 & 0.02 & 0.18 & 0.69 & US\$6354 & $\begin{array}{l}\text { Pinkerton et } \\
\text { al. } 1998^{22}\end{array}$ \\
\hline \multirow{5}{*}{$\begin{array}{l}\text { Unprotected } \\
\text { insertive anal } \\
\text { intercourse }\end{array}$} & 0.80 & 0.0006 & 1.00 & 0.83 & $€ 241,716$ & $\begin{array}{l}\text { Herida et } \\
\text { al. } 2006^{25}\end{array}$ \\
\hline & 0.80 & 0.0006 & 0.14 & 0.80 & $€ 1,952,497$ & $\begin{array}{l}\text { Herida et } \\
\text { al. } 2006^{25}\end{array}$ \\
\hline & 0.81 & 0.0006 & 0.293 & $1.00^{\mathrm{a}}$ & US\$686,525 & $\begin{array}{l}\text { Pinkerton et } \\
\text { al. } 2004^{23}\end{array}$ \\
\hline & 0.81 & 0.0006 & Not reported & 0.778 & US\$554,8I4 & $\begin{array}{l}\text { Pinkerton et } \\
\text { al. } 2004^{24}\end{array}$ \\
\hline & 0.79 & 0.0006 & 0.18 & 0.69 & US\$773,785 & $\begin{array}{l}\text { Pinkerton et } \\
\text { al. } 1998^{22}\end{array}$ \\
\hline \multirow{2}{*}{$\begin{array}{l}\text { All } \\
\text { exposures } \\
\text { combined }^{\mathrm{b}}\end{array}$} & & & & & US\$8607 & $\begin{array}{l}\text { Pinkerton et } \\
\text { al. } 2004^{23}\end{array}$ \\
\hline & & & & & US\$4907 & $\begin{array}{l}\text { Pinkerton et } \\
\text { al. } 2004^{24}\end{array}$ \\
\hline \multicolumn{7}{|c|}{$\begin{array}{l}\text { QALY, quality-adjusted life-year. } \\
\text { a PEP was assumed to be effective only if the patient was known to have completed the regimen; otherwise effectiveness } \\
\text { was set to } 0 \text {. } \\
\text { b Receptive or insertive anal intercourse, receptive oral sex and 'other' } \\
\text { References for sources of data can be found in the individual papers. }{ }^{22-25}\end{array}$} \\
\hline
\end{tabular}


TABLE I4 Base-case cost-utility ratios for heterosexuals

\begin{tabular}{|c|c|c|c|c|c|c|}
\hline $\begin{array}{l}\text { Type of } \\
\text { exposure }\end{array}$ & $\begin{array}{l}\text { Probability PEP } \\
\text { effective }\end{array}$ & $\begin{array}{l}\text { HIV } \\
\text { transmission } \\
\text { probability }\end{array}$ & $\begin{array}{l}\text { Probability } \\
\text { source is } \\
\text { HIV positive }\end{array}$ & $\begin{array}{l}\text { Estimated or } \\
\text { actual PEP } \\
\text { compliance }\end{array}$ & Cost per QALY & Study \\
\hline \multirow{5}{*}{$\begin{array}{l}\text { Unprotected } \\
\text { receptive } \\
\text { anal } \\
\text { intercourse }\end{array}$} & 0.80 & 0.02 & 1.00 & 0.81 & $-€ 22,031$ & $\begin{array}{l}\text { Herida et al. } \\
2006^{25}\end{array}$ \\
\hline & 0.80 & 0.02 & 0.005 & 0.60 & $€ 1,943,685$ & $\begin{array}{l}\text { Herida et al. } \\
2006^{25}\end{array}$ \\
\hline & 0.81 & 0.02 & 0.041 & $1.00^{\mathrm{a}}$ & US\$165,289 & $\begin{array}{l}\text { Pinkerton et } \\
\text { al. } 2004^{23}\end{array}$ \\
\hline & 0.81 & 0.02 & Not reported & 0.778 & $\begin{array}{l}\text { US } \$<0 \text { (actual } \\
\text { figure not } \\
\text { reported) }\end{array}$ & $\begin{array}{l}\text { Pinkerton et } \\
\text { al. } 2004^{24}\end{array}$ \\
\hline & 0.79 & 0.02 & 0.18 & 0.69 & US\$6354 & $\begin{array}{l}\text { Pinkerton et } \\
\text { al. } 1998^{22}\end{array}$ \\
\hline \multirow{5}{*}{$\begin{array}{l}\text { Unprotected } \\
\text { receptive } \\
\text { vaginal } \\
\text { intercourse }\end{array}$} & 0.80 & 0.001 & 1.00 & 0.81 & $€|35| I \mid$, & $\begin{array}{l}\text { Herida et al. } \\
2006^{25}\end{array}$ \\
\hline & 0.80 & 0.001 & 0.005 & 0.62 & $€ 38,653,452$ & $\begin{array}{l}\text { Herida et al. } \\
2006^{25}\end{array}$ \\
\hline & 0.81 & 0.001 & 0.041 & $1.00^{\mathrm{a}}$ & US\$262,562 & $\begin{array}{l}\text { Pinkerton et } \\
\text { al. } 2004^{23}\end{array}$ \\
\hline & 0.81 & 0.001 & Not reported & 0.778 & US\$380,89I & $\begin{array}{l}\text { Pinkerton et } \\
\text { al. } 2004^{24}\end{array}$ \\
\hline & 0.79 & 0.001 & 0.02 & 0.69 & US $\$ 4,254,916$ & $\begin{array}{l}\text { Pinkerton et } \\
\text { al. } 1998^{22}\end{array}$ \\
\hline \multicolumn{2}{|l|}{$\begin{array}{l}\text { All } \\
\text { exposures } \\
\text { combined: } \\
\text { heterosexual } \\
\text { females }^{\text {b }}\end{array}$} & & & & US\$161,114 & $\begin{array}{l}\text { Pinkerton et } \\
\text { al. } 2004^{24}\end{array}$ \\
\hline \multicolumn{2}{|l|}{$\begin{array}{l}\text { All } \\
\text { exposures } \\
\text { combined: } \\
\text { heterosexual }{ }^{c} \\
\text { males }^{c}\end{array}$} & & & & US\$685,560 & $\begin{array}{l}\text { Pinkerton et } \\
\text { al. } 2004^{24}\end{array}$ \\
\hline \multicolumn{7}{|c|}{$\begin{array}{l}\text { QALY, quality-adjusted life-year. } \\
\text { a PEP was assumed to be effective only if the patient was known to have completed the regimen; otherwise effectiveness } \\
\text { was set to } 0 \text {. } \\
\text { b Male-female receptive anal intercourse, male-female receptive vaginal intercourse. } \\
\text { c Male-female insertive anal intercourse, male-female insertive vaginal intercourse, male-female other sexual exposure. }\end{array}$} \\
\hline
\end{tabular}

TABLE I5 Base-case cost-utility ratios for intravenous drug users (IDUs)

\begin{tabular}{|c|c|c|c|c|c|c|}
\hline $\begin{array}{l}\text { Type of } \\
\text { exposure }\end{array}$ & $\begin{array}{l}\text { Probability PEP } \\
\text { effective }\end{array}$ & $\begin{array}{l}\text { HIV } \\
\text { transmission } \\
\text { probability }\end{array}$ & $\begin{array}{l}\text { Probability } \\
\text { source is HIV } \\
\text { positive }\end{array}$ & $\begin{array}{l}\text { Estimated or } \\
\text { actual PEP } \\
\text { compliance }\end{array}$ & $\begin{array}{l}\text { Cost per } \\
\text { QALY }\end{array}$ & Study \\
\hline \multirow[t]{3}{*}{ IDU } & 0.80 & 0.0067 & 1.00 & 0.61 & $-€|| 4 \mid$ & $\begin{array}{l}\text { Herida et } \\
\text { al. } 2006^{25}\end{array}$ \\
\hline & 0.81 & 0.003 & 0.214 & 1.00 & US $\$ 86,462$ & $\begin{array}{l}\text { Pinkerton et } \\
\text { al. } 2004^{23}\end{array}$ \\
\hline & 0.81 & 0.003 & Not reported & 0.778 & US\$97,867 & $\begin{array}{l}\text { Pinkerton et } \\
\text { al. } 2004^{24}\end{array}$ \\
\hline
\end{tabular}


However, the authors report major differences in the cost-effectiveness ratio according to the type of exposure. PEP after receptive anal intercourse with an HIV-infected individual (men -€22,141, women -€22,031 per QALY saved) and PEP to an intravenous drug user (IDU) after sharing a needle with an HIV-infected person (-€1141 per QALY saved) were cost saving. PEP was cost-effective for MSM having receptive anal intercourse with a partner of unknown status (€31,862 per QALY saved). PEP was not considered cost-effective (cost per QALY $€ 50,000$ ) for all other exposures considered in the analysis.

One-way sensitivity analyses were performed on the compliance and life expectancy of HIV-infected individuals in this study. ${ }^{25} \mathrm{PEP}$ after receptive anal intercourse with an HIV-infected individual remained cost saving (-€17,778 and $-€ 18,860$ per QALY saved for MSM and heterosexual women respectively). PEP to an IDU after needle sharing with an HIV-infected person remained costeffective but was no longer cost saving (€18,445 per QALY saved). Further sensitivity analyses incorporating higher lifetime HIV costs resulting from longer survival resulted in the three exposure risks with negative ratios in the base case remaining cost saving but with higher cost ratios.

Herida and colleagues ${ }^{25}$ also performed threshold analyses for exposures with cost-effectiveness ratios under $€ 200,000$ per QALY saved, using minimum values of prevalence, per-contact HIV transmission or compliance required to achieve the cost-saving threshold (€0 per QALY saved) or the cost-effective threshold (€50,000 per QALY saved). The authors reported that PEP for MSM after receptive anal intercourse with a partner of unknown HIV status was cost saving for a percontact transmission risk of at least equal to 0.0411 or an HIV prevalence of at least 0.208 . For needle sharing with an individual of unknown serostatus the authors reported that cost-effectiveness occurred with a compliance of $\geq 0.92$ with both the highest values of prevalence $(0.21)$ and of the per-contact transmission risk (0.0092). The costeffectiveness ratio was reached for a per-contact transmission risk equal to 0.0208 for receptive vaginal intercourse with an HIV-infected partner.

Pinkerton and colleagues ${ }^{23}$ cost-utility analysis of a PEP programme for 401 participants with possible non-occupational exposure to HIV found that the use of PEP prevented an estimated 1.59 HIV infections (1.26 infections after adjusting for continuing risk behaviours over the subsequent
10 years), with an overall cost-utility ratio of US $\$ 14,449$ per QALY saved. In total, 96\% of averted infections were among men who reported exposure through receptive anal intercourse with other men.

The authors report that the PEP programme was cost saving amongst men who have receptive anal intercourse with other men, and when the partner was known to be HIV positive. ${ }^{23}$ The overall cost-utility ratio for men reporting exposure through male-male sex (receptive or insertive anal intercourse, receptive oral intercourse or 'other') was US\$8607 per QALY saved, whereas the cost-utility ratio for all other exposures combined was US\$258,667 per QALY saved. The cost per QALY saved for exposure by injecting drugs and male-female receptive anal sex was US $\$ 86,462$ and US\$165,289 respectively.

The results of the sensitivity analyses reported by the authors suggest that the PEP programme remained cost-effective when the effectiveness of PEP was set as low as $48 \%$ (base case $81 \%$ ) and as long as PEP completion rates were greater than $29 \%{ }^{23}$ The programme also remained cost-effective regardless of the percentage of partners known to be infected with HIV or the prevalence of infection among partners whose HIV status was unknown.

The cost-utility ratio was most sensitive to the receptive anal intercourse transmission probability. ${ }^{23}$ The authors report that the PEP programme would be cost saving overall if this probability exceeded 0.033 and would be costeffective (defined by the authors as a cost-utility ratio of US $\$ 60,000$ per QALY saved) for probabilities as small as 0.009 (the base case was set at 0.02 ).

The Pinkerton and colleagues study ${ }^{24}$ of PEP in 96 metropolitan statistical areas in the US estimated the respective mean and median cost-utility ratios to be US $\$ 15,728$ and US $\$ 15,367$ per QALY saved, with $63.9 \mathrm{HIV}$ infections averted. PEP was cost saving for male-male and male-female receptive anal intercourse exposures (see Tables 13-15). Costutility ratios for needle sharing and needlestick exposures were US $\$ 97,867$ and $\$ 159,686$ per QALY saved respectively. The cost-utility ratio exceeded $\$ 380,000$ per QALY saved for all other types of exposure.

The authors report ${ }^{24}$ that the sensitivity analysis suggests that the results are moderately sensitive to PEP effectiveness and somewhat sensitive to the 
proportion of people completing the PEP regimen, the proportion of PEP clients with known infected source partners and the lifetime costs of medical care and lost QALYs associated with a case of HIV infection.

The authors ${ }^{24}$ conclude that PEP is only costeffective in limited circumstances such as following receptive anal intercourse with a partner at high risk of infection and possibly following other highrisk exposures with a partner known to be infected. The authors state that PEP was highly cost-effective for MSM, less cost-effective for IDUs and high-risk women, and probably not cost-effective for general population exposures or heterosexual men. ${ }^{24}$

The study by Pinkerton and colleagues ${ }^{22}$ evaluating the cost-effectiveness of PEP for a hypothetical cohort of 10,000 patients reporting sexual intercourse with a partner of unknown HIV status estimated that 19.62 HIV infections would be averted following receptive anal intercourse, 0.59 following insertive anal intercourse, 0.11 following receptive vaginal intercourse and 0.07 following insertive vaginal intercourse.

In this study ${ }^{22}$ the base-case analysis suggested that PEP is only cost-effective for receptive anal intercourse (all other cost-utility ratios exceeded US $\$ 750,000$ per QALY saved). The cost-utility ratio following receptive anal intercourse among MSM was US\$6354 per QALY saved. This became cost saving if the probability that the source partner was HIV positive was greater than 0.25 (see Tables $13-15)$.

The sensitivity analysis reported by Pinkerton and colleagues $^{22}$ showed that PEP following receptive anal intercourse was always cost-effective across a range of values. PEP following receptive vaginal intercourse became cost-effective when the probability that the source partner was HIV positive was at least 0.73 . The authors report that triple therapy was unlikely to be cost-effective relative to double therapy as the additional drug costs were not offset by treatment savings. The results did not appear to be sensitive to repeated exposure to HIV and PEP. ${ }^{22}$

\section{Economic evaluation}

One of the aims of the current report was to draw together the best available evidence to estimate the cost-effectiveness of non-occupational PEP for HIV in a UK setting. The current authors explored the feasibility of developing a de novo economic model, either by adapting an existing cost-effectiveness model or by constructing a new one. However, the available data to inform any cost-effectiveness analysis are very sparse, making it inappropriate to model the cost-effectiveness of non-occupational PEP for HIV at the present time. The limitation in the extent of the evidence for the clinical effectiveness of non-occupational PEP for HIV is the main reason for arriving at this conclusion, that is, the effectiveness of nonoccupational PEP is unknown. Only one study met the systematic review criteria for assessing the clinical effectiveness of non-occupational PEP, and the authors state that the study design and relatively small number of seroconversions do not allow conclusions about the effectiveness of PEP in preventing infection. In addition, there were limited data for other model parameters, such as per-exposure transmission probabilities, prevalence of HIV among different population groups and treatment compliance. Any modelling using such data inputs will be of limited value.

However, should better quality and more relevant data become available, the modelling frameworks presented by Pinkerton and colleagues ${ }^{23}$ and Herida and colleagues ${ }^{25}$ may be useful starting points for cost-effectiveness analysis. Although these studies should be viewed with caution, because the clinical effectiveness was informed from one study of the use of PEP in an occupational setting and was based on assumptions that the same conditions exist in a non-occupational setting, they have been conducted in an appropriate way and appear to have internal validity in terms of model structure. Any model should incorporate PEP adverse events and completion rates as these have important economic consequences.

\section{Summary of cost- effectiveness of PEP for non-occupational exposure to HIV}

- Four economic evaluations met the inclusion criteria of the review.

- The methodological quality of the four studies is mixed. Each had a well-defined question, stated a reasonable study type and perspective and undertook a clear sensitivity analysis. However, each of the studies is constrained by a lack of published data on the clinical effectiveness of PEP after non-occupational 
exposure, the per-exposure transmission risk, the compliance with medication and the prevalence of HIV infection amongst different population subgroups.

- In addition, external validity appears to be poor. None of the studies was clearly generalisable to the UK. Lack of detailed information on the PEP regimes used in all of the studies prevented comparison with UK clinical management, as did the lack of information on study participants.

- Results from the included studies suggest that PEP following non-occupational exposure to HIV is cost saving for:

- men who have unprotected receptive anal intercourse with men, whether the source partner is known to be HIV positive or not

- heterosexuals after unprotected receptive anal intercourse

- intravenous drug users sharing a needle with a known HIV-positive person.

- PEP following non-occupational exposure to HIV was cost-effective for all male-male intercourse (unprotected receptive and insertive anal intercourse, unprotected receptive oral sex and 'other').

- PEP following non-occupational exposure to HIV was possibly cost-effective for intravenous drug users and high-risk women.

- In general, sensitivity analyses did not greatly alter the base-case findings. Some sensitivity to the following parameters was noted:
- $\quad$ transmission probability following receptive anal intercourse

- effectiveness of PEP

- proportion of clients completing PEP

- proportion of clients with known HIVpositive partners

- lifetime costs of treatment and number of lost QALYs

- receptive vaginal intercourse (which became cost-effective) when the probability of the source partner being HIV positive was $\geq 0.73$.

- In summary, although the results of the studies are consistent and suggest that nonoccupational PEP may be cost-effective, the results should be treated with caution. It may not be appropriate to make assumptions that the same conditions exist in a non-occupational setting as in an occupational setting. The generalisibility to the UK of studies conducted in the US and France is not clear. Although transmission risks for specific sexual practices are likely to be the same, sexual behaviour and HIV incidence may not be similar and local costs may be different.

- Because of limited data, especially on the effectiveness of non-occupational PEP for HIV, no de novo economic evaluation was conducted in the present study. 


\section{Chapter 6}

\section{Adverse events}

$F^{\prime}$ our additional studies were identified that report data on adverse events and they are presented here to provide further information on this issue. Two comparative studies ${ }^{28,29}$ consider different non-occupational PEP interventions and two prospective observational studies ${ }^{30,31}$ in relevant populations report data on toxicity and completion of medication. Details of the four studies are shown below (Table 16). Study results are presented in Tables 17 and 18.

In one prospective comparative study ${ }^{28}$ of sexual assault victims who sought treatment within 72 hours of sexual exposure, participants were assigned to either medium or high severity groups according to factors that could influence HIV transmission. Those in the medium severity group ( $n=141)$ were given zidovudine plus lamivudine and those in the high severity group $(n=137)$ were given zidovudine plus lamivudine plus protease inhibitor. Follow-up was at 6 months and toxicity and compliance are reported. In the other comparative study ${ }^{29}$ PEP was provided within 72 hours to individuals with exposures from partners known to have been or to be at risk for HIV infection through sexual exposure or injecting drug use. In total, $97 \%$ of participants were treated exclusively with dual reverse transcriptase inhibitors. Rates of completion of PEP and toxicities after 4 weeks are reported. ${ }^{29}$

In one 18-month prospective observational study ${ }^{30}$ sexual assault survivors attending one of 24 Sexual Assault Treatment Centres (SATCs) within 72 hours of the assault were offered PEP if considered to be at high or unknown risk of HIV infection. The primary outcomes in this study were acceptance and completion rate, and adverse events were also reported. All participants were prescribed Combivir (zidovudine + lamivudine) and Kaletra (lopinavir + ritonavir) and received counselling regarding dosing, adherence and adverse events. Follow-up visits were scheduled for days $2-4$ and weeks 1, 2, 3 and 4 . The second prospective observational study ${ }^{31}$ enrolled patients presenting after sexual exposure to HIV from source partners known to be, or suspected of being, infected with HIV. The participants were prescribed zidovudine plus lamivudine if reporting the exposure within 72 hours and also received risk reduction counselling.
Follow-up visits were scheduled for weeks 1, 2, 4, 6, 12 and 26. The primary outcomes for this study were enrolment into concurrent behavioural risk reduction interventions, demand for nonoccupational PEP and characteristics of those treated. Completion and adverse events were also reported.

All of the studies have methodological limitations in that, although there were objective criteria for the eligibility of subjects, subjects were selfreferring and there was non-blinded assessment of self-reported outcomes. Not all outcomes are reported separately for all treatment groups in the comparative studies and it is not clear whether the different groups within each study are comparable; participants were also allowed to switch between treatment groups. The observational studies are limited by the lack of control groups. Although all of the sexual assault survivors attending SATCs were offered PEP, ${ }^{30} 25.9 \%$ of health-care providers prescribing PEP reported strongly encouraging or encouraging participants to accept and 3.1\% reported strongly discouraging or discouraging acceptance, which could affect both acceptance and possibly completion. Selected outcomes were reported separately for the high-risk and unknownrisk groups. ${ }^{30}$ The recruitment by Shoptaw and colleagues $^{31}$ focused on an underserved area and participants then self-referred to the study, meaning that the generalisability of the study findings is unclear.

\section{Completion of treatment}

Completion of treatment rates in the four studies are shown in Table 17. Garcia and colleagues ${ }^{28}$ found that participants who received dual therapy were more likely to complete PEP $(68 \%)$ than those who received three drugs $(53 \%)(p=0.01)$. In the high severity group $21 \%$ interrupted the use of protease inhibitor and completed PEP with two drugs, with the main reason for interruption being toxicity. Compliance at 6 months of followup was similar in both the medium and the high severity groups [odds ratio (OR) 1.0, 95\% CI 0.8-1.3]. ${ }^{28}$ In the San Francisco PEP study, ${ }^{29}$ over all groups, $78 \%$ of participants completed 4 weeks of treatment. Significantly more patients treated 
TABLE I6 Studies reporting adverse event/compliance data

\begin{tabular}{|c|c|c|}
\hline Study & Population & Interventions \\
\hline Garcia et al. $2005^{28}$ & Sexual assault victims & \\
\hline \multicolumn{3}{|l|}{ Brazil } \\
\hline \multicolumn{3}{|l|}{ Prospective cohort study } \\
\hline & $\begin{array}{l}\text { Medium-risk group }(n=|4|) \text { (vaginal/oral intercourse } \\
\text { with ejaculation but without trauma) }\end{array}$ & $Z D V+3 T C$ \\
\hline & $\begin{array}{l}\text { High-risk group ( } n=137) \text { [anal penetration; vaginal } \\
\text { exposure with genital trauma; exposure to many } \\
\text { aggressors; presence of factors that increase risk } \\
\text { (inflammation, ulcers, bleeding, trauma, laceration, } \\
\text { menstruation); aggressor known to be HIV positive] }\end{array}$ & $Z D V+3 T C+P I$ \\
\hline & $\begin{array}{l}\text { All patients offered psychological and supportive } \\
\text { counselling }\end{array}$ & \\
\hline Kahn et al. $2001^{29}$ & Sexual or injecting drug use exposure & \\
\hline San Francisco & Source HIV status/ART history unknown $(n=35 \mathrm{I})$ & ZDV + 3TC (combined pill twice daily) \\
\hline \multirow[t]{5}{*}{ PEP study } & $\begin{array}{l}\text { As above with source plasma HIV RNA levels on } \\
\text { treatment above the limits of detection }(n=8)\end{array}$ & $\begin{array}{l}\mathrm{ZDV}+3 T C+N f v(\text { combined pill twice } \\
\text { daily }+N f v \text { three times daily) }\end{array}$ \\
\hline & Source receiving or participant refused ZDV $(n=3 \mathrm{I})$ & ddl + d4T (two pills twice daily) \\
\hline & $\begin{array}{l}\text { As above with source plasma HIV RNA levels on } \\
\text { treatment above the limits of detection }(n=5)\end{array}$ & $\begin{array}{l}\mathrm{ddl}+\mathrm{d} 4 \mathrm{~T}+\mathrm{Nfv} \text { (two pills twice } \\
\text { daily }+\mathrm{Nfv} \text { three times daily) }\end{array}$ \\
\hline & $\begin{array}{l}\text { If source was receiving Nfv and had detectable plasma } \\
\text { HIV RNA levels, alternative to Nfv given }(n=2)\end{array}$ & Other ART \\
\hline & $\begin{array}{l}\text { All groups received risk reduction counselling and } \\
\text { medication adherence counselling }\end{array}$ & \\
\hline \multirow{2}{*}{$\begin{array}{l}\text { Loutfy et al. } 2008^{30} \\
\text { Canada } \\
\text { Prospective observational } \\
\text { study }\end{array}$} & $\begin{array}{l}\text { Sexual assault survivors }(n=798): 69 \text { high risk; } 729 \\
\text { unknown risk }\end{array}$ & $\begin{array}{l}\text { Combivir (ZDV + 3TC) (one pill twice } \\
\text { daily) and Kaletra (lopinavir/ritonavir) } \\
\text { (three capsules orally twice a day) for } \\
28 \text { days }\end{array}$ \\
\hline & $\begin{array}{l}\text { Counselling regarding dosing, the importance of } \\
\text { adherence and adverse events was provided }\end{array}$ & \\
\hline \multirow{3}{*}{$\begin{array}{l}\text { Shoptaw et al. } 2008^{31} \\
\text { US } \\
\text { Prospective observational } \\
\text { study }\end{array}$} & $\begin{array}{l}\text { Patients presenting post sexual exposure to persons } \\
\text { known or suspected to be infected with HIV }(n=100)\end{array}$ & ZDV + 3TC (twice daily) \\
\hline & & \\
\hline & Risk reduction counselling provided & \\
\hline
\end{tabular}

with didanosine plus stavudine completed 4 weeks of therapy than did those receiving zidovudine plus lamivudine (94\% versus $76 \%, p=0.01$ ). However, the higher rates of completion seen in participants using didanosine plus stavudine may have been due to the study protocol. This discouraged participants from changing to zidovudine plus lamivudine if they developed tolerable adverse events, in an attempt to provide treatment against a possibly resistant strain. In contrast, those taking zidovudine plus lamivudine who experienced adverse events were encouraged to switch to didanosine plus stavudine to complete their treatment course. Among participants who completed 4 weeks of therapy, the percentage of participants reporting complete adherence during 
TABLE I7 Assessment of completion of treatment

\begin{tabular}{|c|c|c|c|c|c|}
\hline Study & Compliance & \multicolumn{4}{|c|}{ Intervention } \\
\hline \multirow[t]{6}{*}{$\begin{array}{l}\text { Garcia et al. } \\
2005^{28}\end{array}$} & & \multicolumn{2}{|c|}{$\begin{array}{l}\text { Medium severity group (dual } \\
\text { therapy, } n=|4| \text { ) }\end{array}$} & \multicolumn{2}{|c|}{$\begin{array}{l}\text { High severity group (triple } \\
\text { therapy, } n=137 \text { ) }\end{array}$} \\
\hline & $\begin{array}{l}\text { Completed } 6 \text { months of follow-up } \\
\text { and } 28 \text { days of PEP, } n(\%)\end{array}$ & \multicolumn{2}{|l|}{$69(48.9)$} & \multicolumn{2}{|l|}{$53(38.7)$} \\
\hline & $\begin{array}{l}\text { Completed } 6 \text { months of follow-up, } \\
\text { interruption of PEP, } n(\%)\end{array}$ & \multicolumn{2}{|l|}{ II (7.8) } & \multicolumn{2}{|l|}{$23(16.8)$} \\
\hline & $\begin{array}{l}\text { Abandoned follow-up but } \\
\text { completed } 28 \text { days of PEP, } n(\%)\end{array}$ & \multicolumn{2}{|l|}{$27(19.2)$} & \multicolumn{2}{|l|}{$20(14.6)$} \\
\hline & $\begin{array}{l}\text { Abandoned follow-up and } 28 \text { days } \\
\text { of PEP, } n(\%)\end{array}$ & \multicolumn{2}{|l|}{$34(24.1)$} & \multicolumn{2}{|l|}{$41(30)$} \\
\hline & Total, $n(\%)$ & \multicolumn{2}{|l|}{$14 \mid(100)$} & \multicolumn{2}{|l|}{$137(100)$} \\
\hline \multirow[t]{8}{*}{$\begin{array}{l}\text { Kahn et al. } \\
2001^{29}\end{array}$} & & $\begin{array}{l}\text { ZDV }+3 T C \\
(n=35 I)\end{array}$ & $\begin{array}{l}\mathrm{ZDV}+3 \mathrm{TC}+\mathrm{Nfv} \\
(n=8)\end{array}$ & $\begin{array}{l}d d l+d 4 T \\
(n=3 I)\end{array}$ & $\begin{array}{l}\mathrm{ddl}+\mathrm{d} 4 \mathrm{~T}+\mathrm{Nfv} \\
(n=5)\end{array}$ \\
\hline & $\begin{array}{l}\text { Completed } 4 \text { weeks of assigned } \\
\text { PEP, } n(\%)\end{array}$ & $267(76)$ & $6(75)$ & $29(94)$ & $5(100)$ \\
\hline & $\begin{array}{l}\text { Completed } 4 \text { weeks but changed } \\
\text { initial PEP, } n(\%)\end{array}$ & $3(1)$ & 0 & 0 & 0 \\
\hline & Discontinued PEP, $n(\%)$ & $47(13)$ & 0 & $\mathrm{I}(<\mathrm{I})$ & 0 \\
\hline & Toxicity, n (\%) & $27(8)$ & - & 0 & - \\
\hline & Source not infected, $n(\%)$ & $10(3)$ & - & 0 & - \\
\hline & Participant preference, $n(\%)$ & $6(2)$ & - & $\mathrm{I}(<\mathrm{I})$ & - \\
\hline & Participant HIV infected, n (\%) & $4(1)$ & - & 0 & - \\
\hline $\begin{array}{l}\text { Loutfy et al. } \\
2008^{30}\end{array}$ & Non-adherent (\%) & \multicolumn{4}{|c|}{$\begin{array}{l}76.0 \text { high-risk group } \\
66.7 \text { unknown-risk group }\end{array}$} \\
\hline$n=798$ & 28 -day course completed $(\%)$ & \multicolumn{4}{|c|}{$\begin{array}{l}23.9 \text { high-risk group } \\
33.2 \text { unknown-risk group }\end{array}$} \\
\hline Shoptaw et & Non-adherent (\%) & \multicolumn{4}{|l|}{36} \\
\hline$n=100$ & 28 -day course completed (\%) & \multicolumn{4}{|l|}{64} \\
\hline
\end{tabular}

the 4 days before the clinic visit ranged from $78 \%$ to $84 \% .{ }^{29}$

The percentage of participants receiving Combivir and Kaletra who completed the course of PEP was $23.9 \%$ in the high-risk group and $33.2 \%$ in the unknown-risk group in the study of sexual assault survivors by Loutfy and colleagues. ${ }^{30}$ This study found that health-care provider-perceived moderate or high participant anxiety at the initial visit, assault by a stranger or an assailant known to the participant less than 24 hours previously or absence of concomitant physical assault were predictors of completion. Reasons for discontinuation included adverse events (81.2\%), interference with usual routine $(42 \%)$, inability to take time away from work, school or other commitments $(21.7 \%)$ and reassessment of HIV risk $(18.8 \%)$. In the study by Shoptaw and colleagues ${ }^{31}$ $86 \%$ of participants were dispensed the full 28-day supply of PEP and $64 \%$ of participants receiving zidovudine plus lamivudine completed treatment.

\section{Assessment of toxicity}

Toxicity results are shown in Table 18 . In one study $^{28} 93 \%$ of the participants receiving three drugs reported at least one side effect, compared with $66 \%$ of the participants receiving two drugs $(p<0.01)$. Digestive discomfort was the most common side effect and was statistically more 
TABLE 18 Assessment of toxicity

\begin{tabular}{|c|c|c|c|c|}
\hline Study & Side effect & & & \\
\hline \multirow[t]{16}{*}{$\begin{array}{l}\text { Garcia et al. } \\
2005^{28}\end{array}$} & & $\begin{array}{l}\text { Medium severity group } \\
\text { (dual therapy, } n=|4| \text { ) }\end{array}$ & $\begin{array}{l}\text { High severity group (triple } \\
\text { therapy, } n=137 \text { ) }\end{array}$ & $p$-value \\
\hline & Any referred intolerance, $n(\%)$ & $76(66)$ & $106(93)$ & $p<0.01$ \\
\hline & Digestive intolerance, $n(\%)$ & $70(60)$ & I0I (89) & $p<0.01$ \\
\hline & Nausea, $n(\%)$ & $62(53)$ & $93(82)$ & $p<0.01$ \\
\hline & Vomiting, $n(\%)$ & $23(20)$ & $55(48)$ & $p<0.01$ \\
\hline & Dyspepsia, n (\%) & $20(17)$ & $40(35)$ & $p<0.01$ \\
\hline & Malaise, $n(\%)$ & $26(12)$ & $60(53)$ & $p<0.01$ \\
\hline & Headache, $n(\%)$ & $14(12)$ & $19(17)$ & $p=0.35$ \\
\hline & Fever, $n(\%)$ & - & $6(5)$ & $p=0.01$ \\
\hline & Asthenia, $n(\%)$ & $4(3)$ & $13(11)$ & $p=0.02$ \\
\hline & Dizziness, $n(\%)$ & $7(6)$ & $20(18)$ & $p<0.01$ \\
\hline & Myalgia, $n(\%)$ & $2(2)$ & $5(4)$ & $p=0.28$ \\
\hline & Cutaneous rash, $n(\%)$ & $3(3)$ & $16(14)$ & $p<0.01$ \\
\hline & Nephrolithiasis, $n(\%)$ & - & $9(8)$ & $p<0.01$ \\
\hline & Laboratorial abnormalities, $n$ (\%) & $18(16)$ & $39(33)$ & $p<0.01$ \\
\hline & $\begin{array}{l}\text { Premature interruption of PEP (all } \\
\text { drugs), } n(\%)\end{array}$ & $12(10)$ & $35(29)$ & $p<0.01$ \\
\hline \multirow{2}{*}{$\begin{array}{l}\text { Kahn et al. } \\
200 I^{29}\end{array}$} & Adverse events experienced: & \multicolumn{3}{|l|}{ Combined treatment groups } \\
\hline & Nausea & \multicolumn{3}{|l|}{$52 \%$} \\
\hline \multirow[t]{4}{*}{$n=396$} & Fatigue & \multicolumn{3}{|l|}{$44 \%$} \\
\hline & Headache & \multicolumn{3}{|l|}{$24 \%$} \\
\hline & Diarrhoea & \multicolumn{3}{|l|}{$15 \%$} \\
\hline & Anorexia & \multicolumn{3}{|l|}{$12 \%$} \\
\hline $\begin{array}{l}\text { Loutfy et al. } \\
2008^{30}\end{array}$ & $\begin{array}{l}\text { Adverse events resulting in drug } \\
\text { discontinuation, } n\end{array}$ & \multicolumn{3}{|l|}{3} \\
\hline$n=798$ & $\begin{array}{l}\text { Participants reporting at least one } \\
\text { adverse event, any grade, } n(\%)\end{array}$ & \multicolumn{3}{|l|}{$265(96.4)$} \\
\hline & $\begin{array}{l}\text { Participants reporting at least one } \\
\text { adverse event grade } 2-4 \text { (median } 3 \text {, } \\
\text { range I-8), } n(\%)\end{array}$ & \multicolumn{3}{|l|}{$212(77.1)$} \\
\hline & Adverse events experienced: & & & \\
\hline & Fatigue & \multicolumn{3}{|l|}{$58.5 \%$} \\
\hline & Nausea & \multicolumn{3}{|l|}{$49.5 \%$} \\
\hline & Diarrhoea & \multicolumn{3}{|l|}{$22.5 \%$} \\
\hline & Headache & \multicolumn{3}{|l|}{$20.7 \%$} \\
\hline & Mood changes & \multicolumn{3}{|l|}{$20.7 \%$} \\
\hline & Vomiting & \multicolumn{3}{|l|}{$20.4 \%$} \\
\hline & Stomach problems & \multicolumn{3}{|l|}{$16.4 \%$} \\
\hline
\end{tabular}

common in participants who received three drugs $(p<0.01) .{ }^{28}$ Severe side effects were seen in patients receiving three drugs and hospitalisation occurred in six cases, as a result of StevensJohnson syndrome $(n=1)$, nephrolithiasis $(n=2)$ the San Francisco study ${ }^{29}$ subjective toxicity for all study groups included nausea (52\%), fatigue (44\%), headache (24\%), diarrhoea (15\%) and anorexia $(12 \%)$. Toxicity was the main reason for discontinuing treatment $(n=27,8 \%) .{ }^{29}$ 
TABLE 18 Assessment of toxicity (continued)

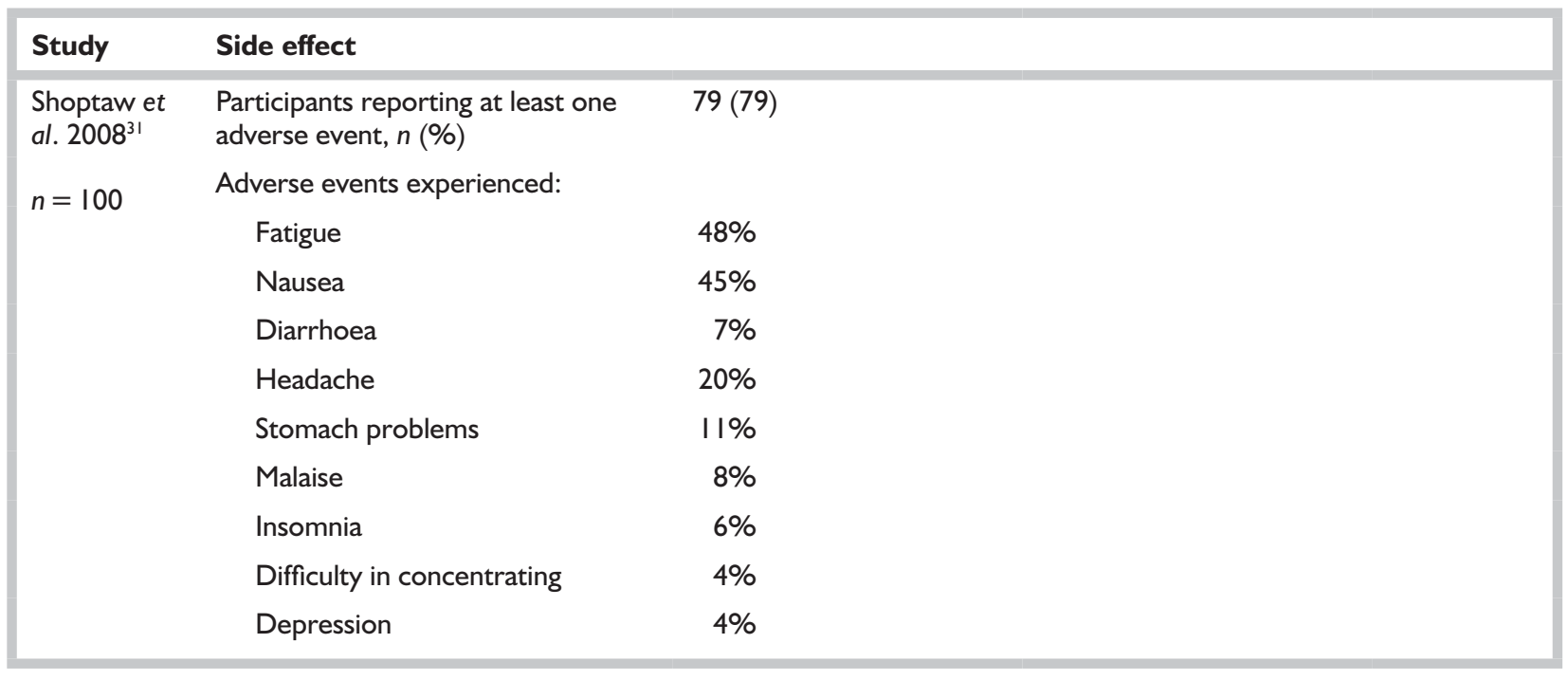

The most common adverse events experienced in both observational studies were also fatigue $\left(58.5 \%^{30}\right.$ and $\left.48 \%^{31}\right)$ and nausea $\left(49.5 \%^{30}\right.$ and $\left.45 \%^{31}\right)$. Loutfy and colleagues ${ }^{30}$ report that the majority of sexual assault survivors $(77.1 \%)$ reported at least one adverse event (median 3, range $1-8$ ) of grade $2-4$ severity [adverse events were graded 1-4 using the US National Institute of Allergy and Infectious Diseases standardised toxicity grading system (grade 4 most severe)]. Three participants discontinued PEP because of adverse events, but no further details were given. The authors reported that participants who experienced vomiting were less likely to complete PEP than those who did not (OR 0.27, 95\% CI $0.12-0.6, p=0.0007) .{ }^{30}$ Shoptaw and colleagues ${ }^{31}$ describe one participant requiring hospitalisation for suicide ideation, but this was not thought to be as a result of the study medication.

\section{Summary of adverse events of PEP for non-occupational exposure to HIV}

- $\quad$ There is limited evidence in terms of quantity and quality, with two comparative studies and two prospective observational studies reporting adverse events and/or treatment completion rates for non-occupational PEP for HIV.

- One comparative study reported a significantly higher degree of toxicity and therapy discontinuation among sexual assault victims taking a three-drug regimen compared with those taking a two-drug therapy. Digestive discomfort was the most common side effect and was significantly higher in participants who received three drugs. PEP therapy was completed by $68 \%$ of participants receiving dual therapy and $53 \%$ of those receiving triple therapy.

- A second comparative study reported statistically higher completion rates among participants taking didanosine plus stavudine compared with those taking zidovudine plus lamivudine, although this may have been due to the study protocol. Complete adherence at 4 weeks was $78 \%$ overall, ranging from $40 \%$ to $79 \%$ for different drug combinations. Toxicity was the main reason for discontinuation of treatment, with nausea and fatigue being the most common side effects.

- One prospective observational study reported low completion of treatment rates, with $23.9 \%$ in the high-risk group and $33.2 \%$ in the unknown-risk group completing the course of PEP. The most common adverse events experienced by the participants were fatigue and nausea.

- A second prospective observational study also found that fatigue and nausea were the most commonly experienced adverse events and that the majority of participants experienced adverse events. PEP therapy was completed by $64 \%$ of participants. 



\section{Chapter 7 Discussion}

\section{Statement of principal findings \\ Clinical effectiveness}

One cohort study ${ }^{21}$ met the inclusion criteria for the review of clinical effectiveness.

This study had methodological limitations and limitations in the quality of the reporting: it was unclear how the sample was selected, whether the sample size was adequate and whether the study is generalisable beyond the specific cohort among which it was conducted. Dropouts are reported but are not included in the analysis and there is no blind assessment of outcomes. The authors do report objective eligibility criteria and the groups are comparable at baseline.

The study reported seroconversion to HIV, drug use and risk behaviours in a group receiving nonoccupational PEP for HIV. The participants in the study were a Brazilian cohort of 200 high-risk MSM.

Seroincidence in the cohort as a whole (2.9 per 100 person-years) was very similar to that expected by the study authors in this population (3.1 per 100 person-years, $p>0.97)$, despite the seroconversion to HIV being 1 out of 68 in the PEP group and 10 out of 132 in the group not receiving PEP. The study reported that, on average, high-risk sexual activities declined over time for both PEP and non-PEP users. The study authors concluded that a public health PEP programme would not have a major impact on HIV transmission in this population.

\section{Cost-effectiveness}

Four studies ${ }^{22-25}$ met the inclusion criteria for the review of cost-effectiveness.

The methodological quality of the cost-effectiveness studies was mixed, with each employing welldefined questions, the appropriate perspective, appropriate methods of analysis and clear sensitivity analyses. Each study is, however, limited by the unknown effectiveness of the intervention, both the dual/triple drug regimen and the use of PEP in a non-occupational exposure patient group.

All four studies evaluated 28 days of PEP post non-occupational exposure to HIV, but full details are not given. Two of the studies considered hypothetical cohorts. ${ }^{22,24}$

Results from the studies suggest that PEP following non-occupational exposure to HIV is cost saving for men who have unprotected receptive anal intercourse with men, whether the source partner is known to be HIV positive or not; heterosexuals after unprotected receptive anal intercourse; and intravenous drug users sharing needles with a known HIV-positive person.

PEP following non-occupational exposure to HIV was cost-effective for all male-male intercourse (unprotected receptive and insertive anal intercourse, unprotected receptive oral sex and 'other'). PEP following non-occupational exposure to HIV was possibly cost-effective for intravenous drug users and high-risk women.

In general, sensitivity analyses did not greatly alter the base-case findings.

In summary, although the results of the studies are consistent and suggest that non-occupational PEP may be cost-effective, the results should be treated with caution. It may not be appropriate to make assumptions that the same conditions exist in a non-occupational setting as in an occupational setting and the generalisibility to the UK of studies conducted in the US and France is questionable as sexual behaviour and HIV incidence may not be similar.

\section{Adverse events}

Additional studies were sought to supply further information on adverse events. The evidence was limited in terms of quantity and quality, with two comparative studies and two observational studies reporting adverse events and/or treatment completion rates for non-occupational PEP. 
One comparative study ${ }^{28}$ reported a significantly higher degree of toxicity and therapy discontinuation among rape victims taking a three-drug regimen compared with those taking a two-drug regimen. Completion of PEP therapy was low in both dual and triple therapy. A second comparative study ${ }^{29}$ reported statistically higher completion rates among participants taking didanosine plus stavudine compared with those taking zidovudine plus lamivudine, although this may have been due to the study protocol.

One prospective observational study reported low rates of completion of treatment, with $23.9 \%$ in the high-risk group and $33.2 \%$ in the unknownrisk group completing the course of PEP. The most common adverse events experienced by the participants were fatigue and nausea. ${ }^{30} \mathrm{~A}$ second prospective observational study ${ }^{31}$ also found that fatigue and nausea were the most commonly experienced adverse events and that the majority of participants experienced adverse events. PEP therapy was completed by $64 \%$ of participants.

\section{Strengths and limitations of the assessment}

The review has certain strengths:

- It is independent of any vested interest.

- The review brings together the evidence for the clinical effectiveness and the costeffectiveness of non-occupational PEP for HIV and adverse event data by applying consistent methods of critical appraisal, presentation and transparency.

- The review was guided by the principles of undertaking a systematic review. Before undertaking the review the methods were set out in a research protocol (Appendix 1) and this was commented on by an advisory group. The protocol defined the research question, inclusion criteria, quality criteria, data extraction process and methods employed to undertake the different stages of the review.

- An advisory group has informed the review from its initiation, through the development of the research protocol and completion of the report.

In contrast, there were certain limitations placed upon the review:

- The number and type of studies available for inclusion in the review was limited. No RCTs were identified and the economic evaluations were not conducted in the UK.

- Synthesis of the included studies was through narrative review. Because of the limitations of the literature, meta-analysis was not possible.

- Time and resource constraints for this short report together with the lack of effectiveness data for the use of non-occupational PEP for HIV prevented the development of an economic evaluation and so the assessment of cost-effectiveness was limited to a systematic review of existing cost-effectiveness studies.

\section{Other relevant issues}

- Only one cohort study met the systematic review inclusion criteria for the assessment of the clinical effectiveness of non-occupational PEP for HIV. The study design and relatively small number of seroconversions do not allow conclusions to be made about the effectiveness of PEP in preventing infection. However, results suggest that PEP made no difference to the expected HIV seroconversion rate for a high-risk HIV-seronegative homosexual male cohort in Rio de Janeiro, Brazil.

- One of the issues of concern is that PEP may be relied upon as a primary form of HIV prevention and will fail to reduce or may actually increase high-risk exposures because it is perceived to fully prevent virus transmission. In the included study PEP was not associated with an increase in reported high-risk behaviour. Reported high-risk behaviour declined slightly for the cohort as a whole but these results should be viewed with caution because of the potential for under-reporting of self-reported high-risk activities.

- Various assumptions were made in the studies considering the cost-effectiveness of nonoccupational PEP for HIV. Of most concern is the use of the estimate of effectiveness from the occupational PEP setting, which is based on the assumption that the same conditions exist in the non-occupational setting as in the occupational setting.

- Other assumptions are acknowledged in the studies. For example, in the study conducted in France ${ }^{25}$ compliance could only be estimated from the database for $47 \%$ of PEP prescriptions and so overall compliance was estimated at 0.75 . However, overestimation of compliance would improve the cost-effectiveness ratio. There were no available data for lifetime HIV/AIDS costs in France and so these were 
estimated by the authors. The model did not take into account the possibility that some patients seeking PEP may continue at-risk behaviour. The study also did not consider PEP adverse events. The authors state that taking these into account would further reduce the cost-effectiveness ratio of the overall PEP programme. The number of HIV infections predicted by the model was higher than that actually seen; however, HIV serology 6 months after PEP initiation was only available for $18 \%$ of patients and so the authors suggest that the true number of PEP failures may be higher.

- $\quad$ Pinkerton and colleagues ${ }^{24}$ acknowledge that there are a number of issues of uncertainty in their study of non-occupational PEP in US metropolitan statistical areas. The results were most sensitive to the effectiveness of PEP and the per-exposure transmission probability for receptive anal intercourse. The lack of evidence of effectiveness of PEP for non-occupational exposures to HIV means that the results should be interpreted with caution. With regard to per-exposure transmission probabilities, the probabilities used in this study did not take into account variations in infectiousness over the course of HIV disease, interpersonal variability or potential reductions from the use of highly active antiretroviral therapy.

- Pinkerton and colleagues conclude from their hypothetical cohort study ${ }^{22}$ that, from an economic effectiveness perspective, PEP should be restricted to partners of infected persons (e.g. serodiscordant couples), patients reporting unprotected receptive anal intercourse (including condom breakage) and possibly cases in which there is a substantial likelihood that the partner is infected.

- Various uncertainties, such as HIV prevalence rates, per-exposure transmission rates, completion of treatment and the impact of the number of pills prescribed daily, HIV status of partner and incomplete suppression of virus, some of which may vary in different locales, must be considered when modelling cost-effectiveness. Also, the potential for PEP programmes to incorporate risk counselling and the opportunity for intensive prevention counselling at the time of medication with PEP to influence future exposures must also be considered. 



\section{Chapter 8 Conclusions}

\section{Non-occupational PEP for HIV}

It is not possible to draw conclusions on the clinical effectiveness of non-occupational PEP for HIV because of the limited evidence in terms of the quantity and quality of studies. Only one small cohort study was identified that met the inclusion criteria for the systematic review. Cost-effectiveness has been assessed in four economic evaluations using evidence on effectiveness taken from the use of PEP in the occupational setting. Results are consistent across studies and suggest that nonoccupational PEP may be cost-effective, especially in certain population subgroups. Although the studies have been conducted in an appropriate way and have internal validity in terms of the structure of the model and plausible results, the assumptions and data sources mean that the results should be treated with caution. The generalisibility to the UK of studies conducted in the US and France is not clear. Although transmission risks for specific sexual practices are likely to be the same, sexual behaviour and HIV incidence may not be similar and local costs may be different.

\section{Research priorities}

The most important research need is a comparative study to establish the effectiveness of using nonoccupational PEP compared with not using PEP, preferably within the UK using the currently recommended intervention. Data are also needed on HIV prevalence, seroconversion rates, perexposure transmission, adverse events, treatment compliance rates, viral resistance rates, high-risk behaviours and effects of intensive counselling in different population groups. Some of these issues will be addressed by the NONOPEP project, which is an MRC-funded surveillance programme of PEP for non-occupational exposure to HIV. The study aims to describe current PEP prescribing practices and the demographic and exposure characteristics of individuals presenting for PEP; to evaluate the problems associated with taking antiretroviral therapy such as adverse events; to assess whether seroconversion has occurred and within which groups; and to contribute to a wider European study on the efficacy of PEP in the nonoccupational setting. Data have been collected on individuals by means of a paper questionnaire, submitted to the Communicable Disease Surveillance Centre at baseline (presentation at clinic) and at three follow-up intervals (4 weeks, 3 months and 6 months). This study is due for submission shortly. Although there are challenges in conducting this research because of factors such as self-referral and follow-up of participants and self-reported outcomes, data generated from this study will be useful for informing any future economic modelling of the cost-effectiveness of non-occupational PEP in the UK. 



\section{. \\ Acknowledgements}

$\mathrm{V}$ arious people contributed to the project, including members of the advisory group who commented on the protocol and/ or draft of the report, and we are grateful for their help: Paul Benn, Consultant in HIV/ Genitourinary Medicine, Camden Primary Care Trust; Andrew Clegg, Professor and Director of SHTAC, WIHRD, University of Southampton; Martin Fisher, Consultant Physician in HIV/ Genitourinary Medicine, Brighton and Sussex University Hospitals NHS Trust; Elizabeth Hodson, Information Assistant, WIHRD, University of Southampton; Alison Price, Information Scientist, WIHRD, University of Southampton; Jonathan Shepherd, Principal Research Fellow, SHTAC, WIHRD, University of Southampton; Kim Wherry, Finance Officer, WIHRD, University of Southampton.

\section{Contribution of authors}

Jackie Bryant was responsible for protocol development, the screening of the clinical effectiveness studies for inclusion, analysis and interpretation of the clinical effectiveness studies, the screening of the cost-effectiveness studies for inclusion, analysis and interpretation of the cost-effectiveness studies, writing the report and project management and report editing. Susan Hird was responsible for protocol development, the screening of the clinical effectiveness studies for inclusion, data extraction and critical appraisal of the clinical effectiveness studies, analysis and interpretation of the clinical effectiveness studies, screening of the cost-effectiveness studies for inclusion, data extraction and critical appraisal of the cost-effectiveness studies, analysis and interpretation of the cost-effectiveness studies and report writing. Louise Baxter was responsible for the screening of the clinical effectiveness studies for inclusion, data extraction and critical appraisal of the clinical effectiveness studies, analysis and interpretation of the clinical effectiveness studies, the screening of the cost-effectiveness studies for inclusion, data extraction and critical appraisal of the cost-effectiveness studies, analysis and interpretation of the cost-effectiveness studies and report writing. 



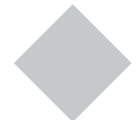 \\ References}

1. Health Protection Agency. General information: HIV and AIDS. URL: www.hpa.org.uk/infections/ topics_az/hiv_and_sti/hiv/general.htm. Accessed 26 November 2007.

2. McCarthy GA, Mercey D. The changing clinical features of HIV-1 infection in the UK. Commun Dis Rep Rev 1994;4:R53-8.

3. National Institute of Allergy and Infectious Diseases. HIV infection and AIDS: an overview. URL: www.niaid.nih.gov/factsheets/hivinf.htm. Accessed 26 November 2007.

4. Health Protection Agency. The national CD4 surveillance scheme. URL: www.hpa.org.uk/infections/ topics_az/hiv_and_sti/hiv/epidemiology/cd4.htm. Accessed 26 November 2007.

5. The UK Collaborative Group for HIV and STI Surveillance. A complex picture. HIV and other sexually transmitted infections in the United Kingdom: 2006. URL: www.hpa.org.uk/publications/2006/ hiv_sti_2006/pdf/a_complex_Picture_2006_last.pdf. Accessed 26 November $200 \overline{7}$.

6. Evans B, McHenry A, Mortimer J. HIV and AIDS in the UK. An epidemiological review: 2000. London: Communicable Disease Surveillance Centre; 2001.

7. Martin NV, Almeda J, Casabona J. Effectiveness and safety of HIV post-exposure prophylaxis after sexual, injecting-drug-use or other nonoccupational exposure (Protocol). Cochrane Database Syst Rev 2005;2:CD005273.

8. WHO and UNAIDS. AIDS epidemic update: December 2006. Geneva: UNAIDS; 2006.

9. The UK Collaborative Group for HIV and STI Surveillance. Testing times. HIV and other sexually transmitted infections in the United Kingdom. London: Health Protection Agency, Centre for Infections; 2007.

10. Fisher M, Benn P, Evans B, Pozniak A, Jones M, Maclean S, et al. UK guideline for the use of postexposure prophylaxis for HIV following sexual exposure. Int J STD AIDS 2006;17:81-92.

11. Giele CM, Maw R, Carne CA, Evans BG, British Co-operative Clinical Group of the Medical Society for the Study of Venereal Diseases. Post-exposure prophylaxis for non-occupational exposure to HIV: current clinical practice and opinions in the UK. Sex Transm Infect 2002;78:130-2.

12. Young TN, Arens FJ, Kennedy GE, Laurie JW, Rutherford GW. Antiretroviral post-exposure prophylaxis (PEP) for occupational HIV exposure. Cochrane Database Syst Rev 2007;1:CD002835.

13. Department of Health (Expert Advisory Group on AIDS). HIV post-exposure prophylaxis: guidance from the UK Chief Medical Officers' Expert Advisory Group on AIDS. London: Department of Health; 2004.

14. Chief Medical Office. Update to HIV post-exposure prophylaxis (PEP) guidance from the Expert Advisory Group on AIDS (EAGA) following the recent recall of Viracept (gateway reference 8562). London: Department of Health; 2007.

15. Day S, Mears A, Bond K, Kulasegaram R. Postexposure HIV prophylaxis following sexual exposure: a retrospective audit against recent draft BASHH guidance. Sex Transm Infect 2006;82:236-7.

16. Roland ME, Neilands TB, Krone MR, Katz MH, Franses K, Grant RM, et al. Seroconversion following nonoccupational postexposure prophylaxis against HIV. Clin Infect Dis 2005;41:1507-13.

17. Richens J, Edwards SG, Sadiq ST. Can the promotion of post-exposure prophylaxis following sexual exposure to HIV (PEPSE) cause harm? Sex Transm Infect 2005;81:190-1.

18. Spitzer WO, Lawrence V, Dales R, Hill G, Archer MC, Clarck P. Links between passive smoking and disease: a best evidence synthesis. Clin Invest Med 1990;13:17-42.

19. Drummond MF, Jefferson TO. Guidelines for authors and peer reviewers of economic submissions to the BMJ. Br Med J 1996;313:275-83.

20. Philips Z, Ginnelly L, Sculpher M, Claxton K, Golder S, Riemsma R, et al. Review of guidelines for good practice in decision-analytic modelling in health technology assessment. Health Technol Assess $2004 ; 8(36)$.

21. Schechter M, do Lago RF, Mendelsohn AB, Moreira RI, Moulton LH, Harrison LH, et al. Behavioral impact, acceptability, and HIV incidence among homosexual men with access to postexposure chemoprophylaxis for HIV.J Acquir Immune Defic Syndr 2004;35:519-25. 
22. Pinkerton SD, Holtgrave DR, Bloom FR. Costeffectiveness of post-exposure prophylaxis following sexual exposure to HIV. AIDS 1998;12:1067-78.

23. Pinkerton SD, Martin JN, Roland ME, Katz MH, Coates TJ, Kahn JO. Cost-effectiveness of postexposure prophylaxis after sexual or injectiondrug exposure to human immunodeficiency virus. Arch Intern Med 2004;164:46-54.

24. Pinkerton SD, Martin JN, Roland ME, Katz MH, Coates TJ, Kahn JO. Cost-effectiveness of HIV postexposure prophylaxis following sexual or injection drug exposure in 96 metropolitan areas in the United States. AIDS 2004;18:2065-73.

25. Herida M, Larsen C, Lot F, Laporte A, Desenclos JC, Hamers FF. Cost-effectiveness of HIV post-exposure prophylaxis in France. AIDS 2006;20:1753-61.

26. Centers for Disease Control and Prevention (CDC). Case-control study of HIV seroconversion in health care workers after percutaneous exposure to HIVinfected blood - France, United Kingdom, and United States, January 1988-August 1994. MMWR Morb Mortal Wkly Rep 1995;44:929-33.
27. Cardo DM, Culver DH, Ciesielski CA, Srivastava PU, Marcus R, Abiteboul D, et al. A case-control study of HIV seroconversion in health care workers after percutaneous exposure. Centers for Disease Control and Prevention Needlestick Surveillance Group. N Engl J Med 1997;337:1485-90.

28. Garcia MT, Figueiredo RM, Moretti ML, Resende MR, Bedoni AJ, Papaiordanou PM. Postexposure prophylaxis after sexual assaults: a prospective cohort study. Sex Transm Dis 2005;32:214-19.

29. Kahn JO, Martin JN, Roland ME, Bamberger JD, Chesney M, Chambers D, et al. Feasibility of postexposure prophylaxis (PEP) against human immunodeficiency virus infection after sexual or injection drug use exposure: the San Francisco PEP Study. J Infect Dis 2001;183:707-14.

30. Loutfy MR, Macdonald S, Myhr T, Husson H, Du Mont J, Balla S, et al. Prospective cohort study of HIV post-exposure prophylaxis for sexual assault victims. Antivir Ther 2008;13:87-95.

31. Shoptaw S, Rotheram-Fuller E, Landovitz RJ, Wang J, Moe A, Kanouse DE, et al. Non-occupational post exposure prophylaxis as a biobehavioral HIVprevention intervention. AIDS Care 2008;20:376-81. 


\section{Appendix I}

\section{Review methods from the research protocol}

$\mathrm{T}$ he a priori methods used for the review are outlined below. The sources of information used are outlined in Appendix 2.

\section{Study inclusion}

Specific inclusion criteria will be defined. The full literature search results will be screened by one reviewer and checked by a second reviewer to identify all citations that may meet the inclusion criteria. Full manuscripts of all selected citations will be retrieved and assessed by two reviewers against the inclusion criteria. Disagreements over study inclusion will be resolved by consensus or if necessary by arbitration by a third reviewer.

The planned inclusion/exclusion criteria for the systematic review are as follows.

\section{Population}

Humans with non-occupational exposure to HIV. This may be by:

- unprotected sexual exposure (oral, vaginal, anal), either voluntary or rape, with an HIVinfected partner or partner of unknown HIV status

- $\quad$ exposure to a needle contaminated by a known or potentially infected substance in a nonoccupational setting.

\section{Intervention}

Any antiretroviral drug regimen administered as PEP for a short period (28 days) to HIV-negative people potentially exposed to HIV through unprotected sexual contact or use of a potentially contaminated needle or potentially contaminated biological fluid.

\section{Comparator}

- No intervention.

- Group not receiving PEP.

- A different PEP regimen.

\section{Outcomes}

- HIV seroconversion frequency.

- Adverse effects and complications of PEP.
- Adherence to PEP.

- Health-related quality of life.

- Costs or some measure of cost-effectiveness.

\section{Design}

- $\quad$ RCT, CCT, cohort study or case-control study.

- Cost-effectiveness/utility studies.

- Descriptive studies with no control group will be excluded.

\section{Data extraction}

The extraction of study findings will be conducted by two reviewers using a predesigned and piloted data extraction form to avoid any errors. Any disagreements between reviewers will be resolved by consensus or if necessary by arbitration by a third reviewer.

\section{Quality assessment}

The methodological quality of included studies will be assessed using formal tools specific to the design of the study and focusing on possible sources of bias. Quality assessment of RCTs will be conducted using criteria developed by the NHS Centre for Reviews and Dissemination; observational studies will be assessed using criteria developed by Spitzer et al. ${ }^{18}$ Quality assessment of economic evaluations will be conducted using a checklist adapted from those developed by Drummond and Jefferson ${ }^{19}$ and Philips et al. ${ }^{20}$ Study quality will be assessed by two reviewers. Any disagreements between reviewers will be resolved by consensus or if necessary by arbitration involving a third reviewer.

\section{Data synthesis}

The methods of data synthesis will be determined by the nature of the studies identified through searches and included in the review. Quantitative synthesis of results, for example meta-analysis, will be considered if there are several highquality studies of the same design and sources of heterogeneity will be investigated by subgroup analyses if applicable. The results of any included studies suitable for quantitative synthesis will also 
be summarised in a narrative form along with a narrative synthesis of the results from studies for which quantitative synthesis is not possible. All results will also be tabulated.

\section{Economic evaluation}

When appropriate, and if time and resources allow, an economic model will be devised by adapting an existing cost-effectiveness model or constructing a new one using the best available evidence to determine cost-effectiveness in a UK setting. Data on resource use and costs will be taken from the published literature and from NHS sources when appropriate and available. The perspective of the economic analysis will be that of the NHS and Personal Social Services. Effectiveness data will be taken from published studies and used in conjunction with other relevant data (e.g. resource use, unit costs) to populate the model to obtain measures of cost-effectiveness. If available, quality of life information will be obtained from the literature or other sources to calculate costutility estimates in terms of cost per QALY. The robustness of the results to the assumptions made in the model will be examined through sensitivity analysis and/or probabilistic sensitivity analysis. 


\section{Appendix 2}

\section{Sources of information, including databases searched and search terms}

$\mathrm{T}$

The following search strategy was used in Ovid MEDLINE(R) from 1950 to November Week 22007 and adapted for other databases. Results were obtained for English language and nonEnglish language papers. Bibliographies of related papers were assessed for relevant studies. Tables 19 and 20 outline the databases and issues/dates searched. Figures 1 and 2 provide flowcharts of the clinical effectiveness and cost-effectiveness studies respectively.

The search strategy used for non-occupational PEP was as follows:

$1 \operatorname{exp~HIV/~(59429)~}$

2 exp hiv-1/ (46463)

3 exp hiv-2/ (3192)

4 exp HIV Infections/ (169604)

5 exp hiv antibodies/ (7992)

6 (hiv or human immunodeficincy virus $\$$ ).ti,ab. (140649)

7 exp Acquired Immunodeficiency Syndrome/ (68119)

8 or/1-7 (214277) Population set 1

9 (post?exposure prophylax\$or PEP or nPEP or PEPSE).ti,ab. (4037)

10 post-exposure prophylax $\$ . t i, a b .(475)$

11 post exposure prophylax $\$ . t i, a b .(475)$

12 postexposure prophylax\$.ti,ab. (483)

13 or/9-12 (4402) Population set 2

14 (highly active antiretroviral therapy or haart). ti,ab. (7126)
15 exp antiviral agents/ (210658)

16 exp anti-retroviral agents/ (40013)

17 exp anti-hiv agents/ (34216)

18 exp hiv fusion inhibitors/ (438)

19 exp hiv integrase inhibitors/ (470)

20 exp hiv protease inhibitors/ (7818)

21 (combivir or zidovudine or lamivudine or kaletra or lopinavir or ritonavir).ti,ab. (9741)

22 or/14-21 (215377) Intervention 1 set 1

23 non?occupational.ti,ab. (506)

24 nonoccupational.ti,ab. (506)

25 non occupational.ti,ab. (671)

26 or/23-25 (1169) Population set 3

27 Occupational Exposure/ (28336) Population set 4

288 and 13 (514) Combined population set 5

2928 and 22 (345) PEP population with intervention

3029 not 27 (212) Non-occupational set

31 limit 30 to (humans and english language) (182) Non-occupational set English language download A

3230 not 31 (30) Non-occupational set nonEnglish download B

3329 not 30 (133) Occupational set all languages download $\mathrm{C}$

34 from 31 keep 1-182 (182)

35 from 32 keep 1-30 (30)

36 from 33 keep 1-133 (133)

The search strategies were translated to run in the databases listed above. Full search strategies are available upon request. 
TABLE 19 Clinical effectiveness and cost-effectiveness searches

\begin{tabular}{|c|c|c|}
\hline Databases searched & $\begin{array}{l}\text { Clinical effectiveness: issues or } \\
\text { dates searched }\end{array}$ & $\begin{array}{l}\text { Cost-effectiveness: issues or dates } \\
\text { searched }\end{array}$ \\
\hline Cochrane Library - CDSR & $\begin{array}{l}\text { Issue } 4 \text { 2007; searched I } 3 \text { September } \\
2007\end{array}$ & \\
\hline Cochrane Library - CENTRAL & Issue 42007 & \\
\hline Ovid MEDLINE(R) & I950-November Week 22007 & I950-November Week 22007 \\
\hline EMBASE & 1980-2007 Week 49 & I 980-2007 Week 49 \\
\hline $\begin{array}{l}\text { Ovid MEDLINE(R) In-Process \& Other } \\
\text { Non-Indexed Citations }\end{array}$ & I2 December 2007 & I2 December 2007 \\
\hline $\begin{array}{l}\text { DARE (Database of Abstracts of } \\
\text { Reviews of Effectiveness) }\end{array}$ & I2 December 2007 & \\
\hline HTA database (on CRD databases) & I2 December 2007 & \\
\hline NRR (National Research Register) & I2 December 2007 & \\
\hline $\begin{array}{l}\text { ClinicalTrials.gov (http://clinicaltrials. } \\
\text { gov/) }\end{array}$ & I2 December 2007 & \\
\hline $\begin{array}{l}\text { NHS Economic Evaluations Database } \\
\text { 2005-2007 }\end{array}$ & & I2 December 2007 \\
\hline
\end{tabular}

TABLE 20 Adverse events searches

\begin{tabular}{ll}
\hline Databases & Years/dates searched \\
\hline $\begin{array}{l}\text { Ovid MEDLINE(R) } \\
\text { Ovid MEDLINE(R) In-Process \& Other Non-Indexed }\end{array}$ & 1996-September Week 3 2007; searched 2 October 2007 \\
$\begin{array}{l}\text { Citations } \\
\text { EMBASE }\end{array}$ & 1996-2007 Week 38
\end{tabular}




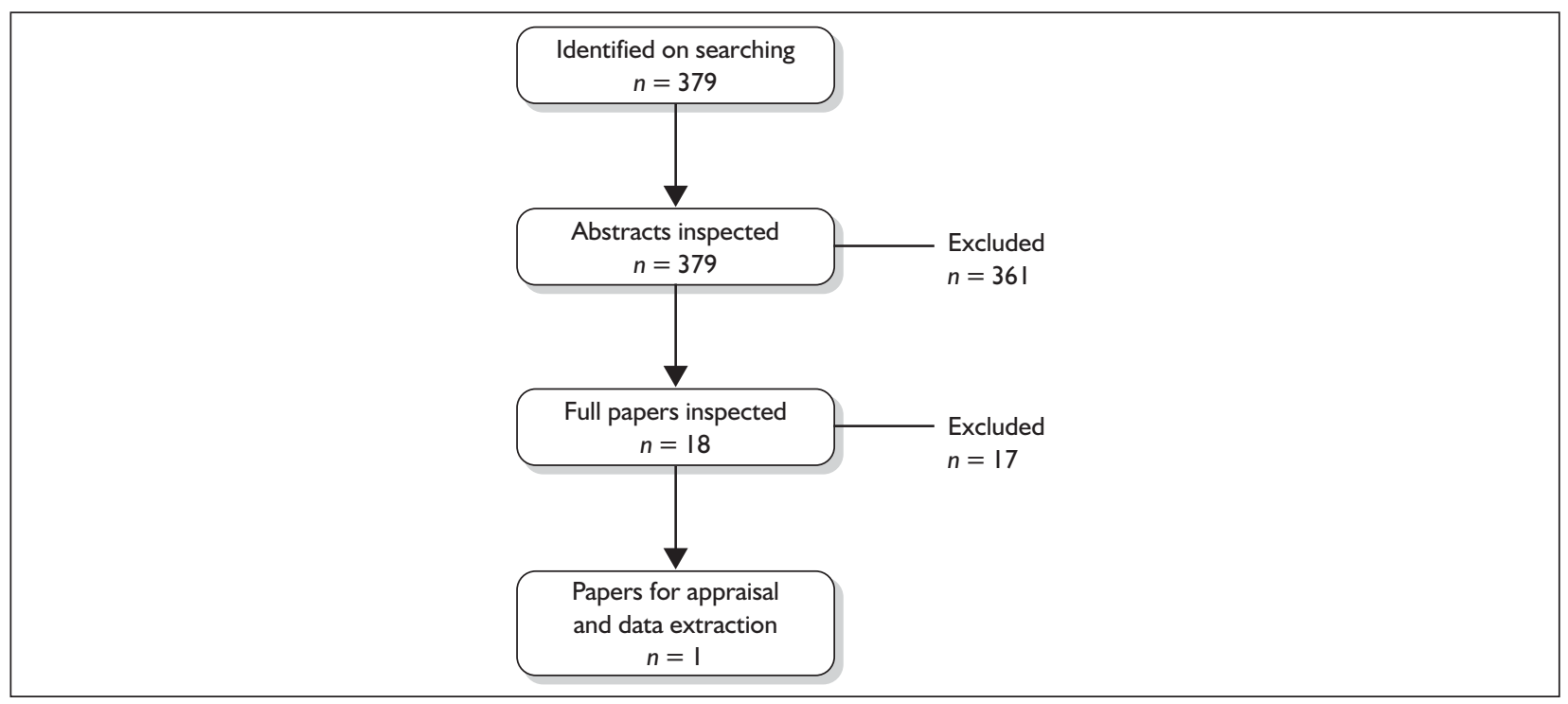

FIGURE I Flowchart of clinical effectiveness studies.

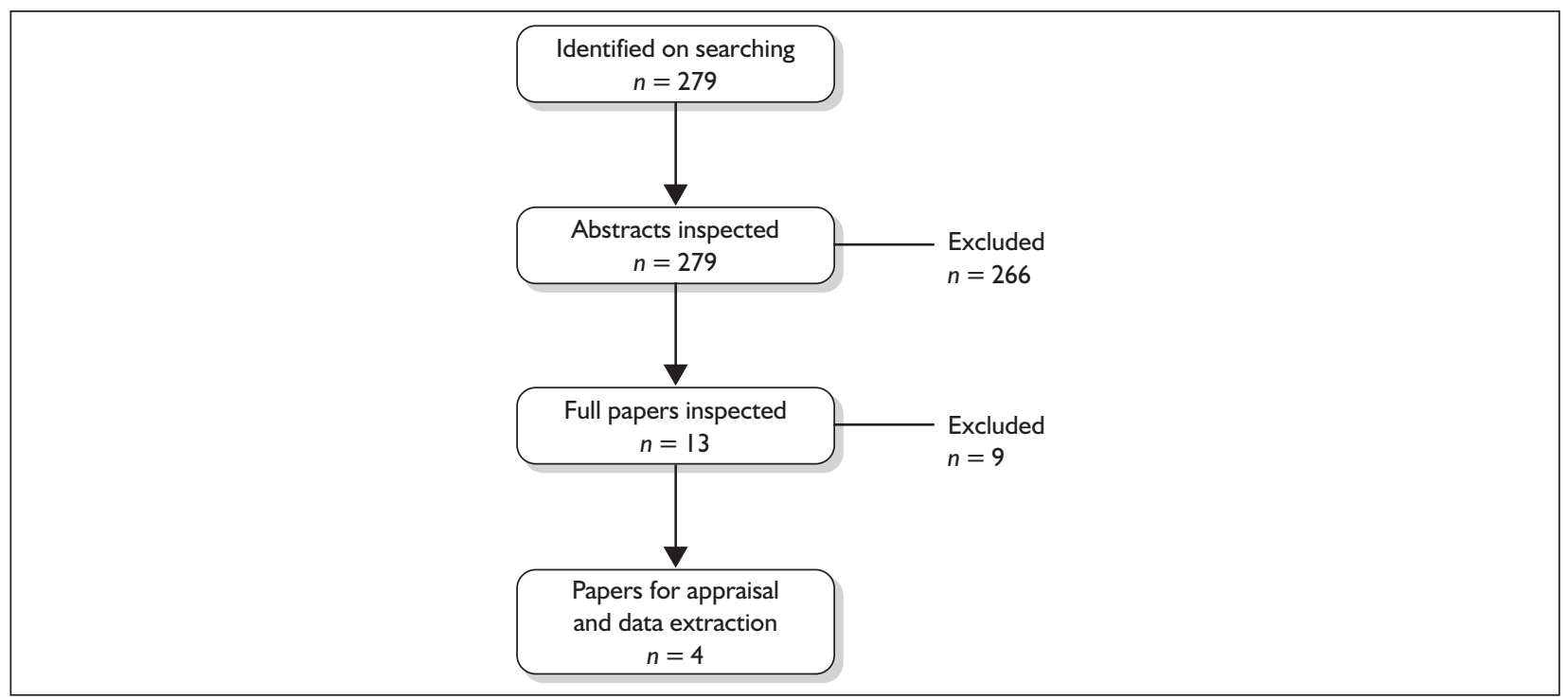

FIGURE 2 Flowchart of cost-effectiveness studies. 



\section{Appendix 3 \\ List of excluded studies}

\section{Clinical effectiveness studies}

Bernasconi E, Jost J, Ledergerber B, Hirschel B, Francioli P, Sudre P. Antiretroviral prophylaxis for community exposure to the human immunodeficiency virus in Switzerland, 1997-2000. Swiss Med Wkly 2001;131:433-7. (Questionnaire.)

Braitstein P, Chan K, Beardsell A, McLeod A, Montaner JS, O'Shaughnessy MV, et al. Prescribing practices in a population-based HIV postexposure prophylaxis program. AIDS 2002;16:1067-70. (No comparison group and prescribing practice as outcome.)

Luque A, Hulse S, Wang D, Shahzad U, Tanzman E, Antenozzi S, et al. Assessment of adverse events associated with antiretroviral regimens for postexposure prophylaxis for occupational and nonoccupational exposures to prevent transmission of human immunodeficiency virus. Infect Control Hosp Epidemiol 2007;28:695-701. (Chart review.)

Martin JN, Roland ME, Neilands TB, Krone MR, Bamberger JD, Kohn RP, et al. Use of postexposure prophylaxis against HIV infection following sexual exposure does not lead to increases in high-risk behavior. AIDS 2004;18:787-92. (No comparison group.)

Meel BL. HIV/AIDS post-exposure prophylaxis (PEP) for victims of sexual assault in South Africa. Med Sci Law 2005;45:219-24. (No comparison group.)

O'Sullivan BG, Levy MH, Dolan KA, Post JJ, Barton SG, Dwyer DE, et al. Hepatitis C transmission and HIV postexposure prophylaxis after needle- and syringe-sharing in Australian prisons. Med J Aust 2003;178:546-9. (Study design.)

Poynten IM, Smith DE, Cooper DA, Kaldor JM, Grulich AE. The public health impact of widespread availability of nonoccupational postexposure prophylaxis against HIV. HIV Med 2007;8:374-81. (No comparison group.)

Puro V, Soldani F, De Carli G, Lazarevic Z, Mattioli F, Ippolito G, et al. Drug-induced aminotransferase alterations during antiretroviral HIV post-exposure prophylaxis. AIDS 2003;17:1988-90. (Occupational exposure.)

Puro V, De Carli G, Orchi N, Palvarini L, Chiodera A, Fantoni M, et al. Short-term adverse effects from and discontinuation of antiretroviral post-exposure prophylaxis. J Biol Regul Homeost Agents 2001;15:238-42. (Includes health-care workers.)
Rabaud C, Bevilacqua S, Beguinot I, Dorvaux V, Schuhmacher H, May T, et al. Tolerability of postexposure prophylaxis with zidovudine, lamivudine, and nelfinavir for human immunodeficiency virus infection. Clin Infect Dis 2001;32:1494-5. (Included occupational exposure.)

Rabaud C, Burty C, Grandidier M, Christian B, Penalba C, Beguinot I, et al. Tolerability of postexposure prophylaxis with the combination of zidovudinelamivudine and lopinavir-ritonavir for HIV infection. Clin Infect Dis 2005;40:303-5. (No comparator.)

Rey D, Partisani M, Hess-Kempf G, Krantz V, Priester $\mathrm{M}$, Cheneau C, et al. Tolerance of a short course of nevirapine, associated with two nucleoside analogues, in postexposure prophylaxis of HIV.J Acquir Immune Defic Syndr 2004;37:1454-6. (Chart review.)

Roland ME, Neilands TB, Krone MR, Katz MH, Franses K, Grant RM, et al. Seroconversion following nonoccupational postexposure prophylaxis against HIV. Clin Infect Dis 2005;41:1507-13. (No comparison group.)

Schechter M. HIV vaccine evaluation center in Rio de Janeiro, Brazil. Vaccine 2002;20:1909-11. (Note.)

Sonder G, Regez R, Brinkman K, Prins J, Mulder J, Coutinho R, et al. Postexpositiebehandeling tegen HIV buiten het ziekenhuis in Amsterdam, januari-december 2000. Ned Tijdshr Geneeskd 2002;146:629-33. (NonEnglish.)

Timset F, Maillard A, Spindler E, Taquin Y, Deniaud, Ferchal F, et al. Traitment antirétroviral prophylactique après exposition sexuelle au VIH: 93 cas. Ann Dermatol Venereol 2002;129:866-9. (Non-English.)

Winston A, McAllister J, Amin J, Cooper DA, Carr A. The use of a triple nucleoside-nucleotide regimen for nonoccupational HIV post-exposure prophylaxis. HIV Med 2005;6:191-7. (Case note review.)

\section{Cost-effectiveness studies}

Allen UD, Read S, Gafni A. Zidovudine for chemoprophylaxis after occupational exposure to HIVinfected blood: an economic evaluation. Clin Infect Dis 1992;14:822-30. (Occupational exposure.)

Barham L, Lewis D, Latimer N. One to one interventions to reduce sexually transmitted infections and under the age of 18 conceptions: a systematic review of the 
economic evaluations. Sex Transm Infect 2007;83:441-6. (Not PEP.)

Creese A, Floyd K, Alban A, Guinness L. Costeffectiveness of HIV/AIDS interventions in Africa: a systematic review of the evidence [erratum appears in Lancet 2002;360:880]. Lancet 2002;359:1635-43. (Not PEP.)

Forst LS, Fletcher B. HIV prophylaxis for health care workers. J Occup Environ Med 1997;39:1212-19. (Occupational exposure.)

Greub G, Gallant S, Zurn P, Vannotti M, Burgisser P, Francioli P, et al. Spare non-occupational HIV postexposure prophylaxis by active contacting and testing of the source person. AIDS 2002;16:1171-6. (Not an economic evaluation.)
Hornberger J. A systematic review of cost-utility analyses in HIV/AIDS: implications for public policy. Med Decis Making 2007;27:789-821. (Not an economic evaluation of PEP.)

Marin MG, Van LJ, Yee A, Bonner E, Glied S. Costeffectiveness of a post-exposure HIV chemoprophylaxis program for blood exposures in health care workers. J Occup Environ Med 1999;41:754-60. (Occupational exposure.)

Pinkerton SD, Holtgrave DR, Pinkerton HJ. Costeffectiveness of chemoprophylaxis after occupational exposure to HIV. Arch Intern Med 1997;157:1972-80. (Occupational exposure.)

Scheid DC, Hamm RM, Stevens KW. Cost-effectiveness of human immunodeficiency virus postexposure prophylaxis for healthcare workers. Pharmacoeconomics 2000;18:355-68. (Occupational exposure.) 


\section{Appendix 4}

\section{Data extraction of clinical effectiveness study}

\begin{tabular}{|c|c|c|c|}
\hline $\begin{array}{l}\text { Reference and } \\
\text { design }\end{array}$ & Intervention & Participants & Outcome measures \\
\hline $\begin{array}{l}\text { Author: } \\
\text { Schechter et al. }{ }^{21} \\
\text { Year: } 2004 \\
\text { Country: Brazil } \\
\text { Study design: } \\
\text { cohort study } \\
\text { Number of } \\
\text { centres: one } \\
\text { Funding: } \\
\text { GlaxoSmithKline, } \\
\text { Conselho } \\
\text { Nacional de } \\
\text { Desenvolvimento } \\
\text { Científico e } \\
\text { Tecnológico, } \\
\text { National Institute } \\
\text { of Allergy and } \\
\text { Infectious } \\
\text { Diseases } \\
\text { (research career } \\
\text { award), Fogarty } \\
\text { International } \\
\text { Center (grant) }\end{array}$ & $\begin{array}{l}\text { Intervention: } \\
\text { postexposure } \\
\text { prophylaxis (PEP): } \\
\text { zidovudine } 300 \mathrm{mg} \\
\text { and lamivudine } \\
\text { I } 50 \mathrm{mg} \text { orally, fixed } \\
\text { dose combination } \\
\text { tablet, twice daily } \\
\text { for } 28 \text { days } \\
\text { Initial 4-day supply } \\
\text { of zidovudine } \\
\text { and lamivudine } \\
\text { to be taken post } \\
\text { eligible exposure; } \\
\text { additional } 24-d a y \\
\text { supply provided for } \\
\text { exposures deemed } \\
\text { eligible by study } \\
\text { personnel } \\
\text { Subjects were } \\
\text { instructed to } \\
\text { begin taking the } \\
\text { study regimen } \\
\text { immediately } \\
\text { after eligible } \\
\text { exposures and in } \\
\text { no circumstances } \\
>48 \text { hours after } \\
\text { the exposure } \\
\text { Control: no PEP }\end{array}$ & $\begin{array}{l}\text { Number of participants: } 200 \text { enrolled in the } \\
\text { study } \\
\text { Intervention: } 68 \text { took PEP at least once; } \\
\text { control: I } 32 \\
\text { Sample attrition/dropout: } 94 \% \text { ( } n=187 \text { ) } \\
\text { followed up for } 24 \text { months or until } \\
\text { seroconversion; two excluded immediately } \\
\text { because they had no follow-up data; seven } \\
\text { (53.9\%) had last interview at } 6 \text { months; two } \\
\text { (I5.4\%) had last interview at I } 2 \text { months; } \\
\text { four (30.8\%) had last interview at I } 8 \text { months } \\
\text { Inclusion criteria for study entry: male } \\
\text { gender, confirmed HIV seronegativity, } \\
\text { reported homosexual or bisexual behaviour, } \\
\text { sexually active, defined as anticipated sexual } \\
\text { activity in the next } 6 \text { months, willingness to } \\
\text { use PEP after high-risk exposures, age I8-35 } \\
\text { years } \\
\text { Exclusion criteria for study entry: high-risk } \\
\text { exposures for HIV in the previous } 48 \text { hours, } \\
\text { anaemia, leukopenia or hepatic enzyme } \\
\text { abnormalities at baseline, history of allergy or } \\
\text { intolerance to any of the study medications } \\
\text { Characteristics of participants: the cohort } \\
\text { was recruited from former participants of an } \\
\text { HIV seroincidence study conducted among } \\
\text { high-risk men who have sex with men } \\
\text { Intervention: see baseline characteristics } \\
\text { table below } \\
\text { Control: I } 32 \text { did not take PEP - } 86 \text { did } \\
\text { not take PEP despite reporting at least one } \\
\text { instance of high-risk behaviour, } 46 \text { denied any } \\
\text { high-risk behaviours during the study period }\end{array}$ & $\begin{array}{l}\text { Outcomes: reported behaviour, } \\
\text { PEP utilisation, adverse events, } \\
\text { incident HIV infection } \\
\text { Observed and expected incidences } \\
\text { were compared } \\
\text { Method of assessing outcomes: } \\
\text { detailed history taken at each } \\
\text { visit, physical examination with } \\
\text { focus on the presence of sexually } \\
\text { transmitted diseases. Laboratory } \\
\text { evaluation to assess for potential } \\
\text { medication toxicity at baseline, I2- } \\
\text { and } 24-m o n t h \text { visits. Participants to } \\
\text { report symptoms consistent with } \\
\text { severe toxicity. For participants } \\
\text { who seroconverted during the } \\
\text { study and who previously used } \\
\text { PEP, polymerase chain reaction } \\
\text { was performed on blood samples } \\
\text { at the beginning and end of the } \\
\text { PEP course to ensure that the } \\
\text { seroconversion was unrelated } \\
\text { to that exposure. Additional } \\
\text { laboratory evaluations were } \\
\text { undertaken for persons who took } \\
\text { PEP based on symptoms that could } \\
\text { have been caused by the study } \\
\text { medications or if there were other } \\
\text { medical reasons to suspect an } \\
\text { increased likelihood of PEP-related } \\
\text { side effects } \\
\text { HIV seroconversion was } \\
\text { defined as HIV enzyme-linked } \\
\text { immunoabsorbent assay (ELISA) } \\
\text { seronegativity at the baseline visit } \\
\text { with a subsequent positive ELISA } \\
\text { and western blot during a follow- } \\
\text { up visit } \\
\text { Drug-resistant HIV was assessed } \\
\text { for the one participant in whom } \\
\text { PEP failed } \\
\text { Recruitment dates: July I } 995 \text {-June } \\
\text { I998 } \\
\text { Follow up: median } 24.2 \text { months }\end{array}$ \\
\hline
\end{tabular}




\begin{tabular}{|c|c|c|c|c|}
\hline Baseline characteristics & PEP $(\mathrm{n}=68)$ & No PEP $(\mathrm{n}=132)$ & Total $(n=200)$ & p-value \\
\hline Age (years), median & 28 & 28 & 28 & $p=0.83$ \\
\hline \multicolumn{5}{|l|}{ Race, $n$ (\%): } \\
\hline White & $34(50)$ & $60(45)$ & $94(47)$ & $p=0.69$ \\
\hline Black & $15(22)$ & $26(20)$ & $4 I(2 I)$ & \\
\hline Mixed & $3(4)$ & $\mathrm{II}(8)$ & $14(7)$ & \\
\hline Other & $16(24)$ & $35(27)$ & $51(26)$ & \\
\hline Completed high school, $n$ (\%) & $55(8 \mathrm{I})$ & $93(70)$ & I 48 (74) & $p=0.11$ \\
\hline $\begin{array}{l}\text { Income per month (Brazilian } \\
\text { reais), median }\end{array}$ & 445 & 480 & 465 & $p=0.57$ \\
\hline $\begin{array}{l}\text { Receptive anal sex last } 6 \\
\text { months, } n(\%)\end{array}$ & $48(7 I)$ & $84(64)$ & $132(66)$ & $p=0.33$ \\
\hline $\begin{array}{l}\text { Unprotected receptive anal } \\
\text { sex last } 6 \text { months, } n(\%)\end{array}$ & $23(34)$ & $34(26)$ & $57(29)$ & $p=0.23$ \\
\hline $\begin{array}{l}\text { Insertive anal sex last } 6 \\
\text { months, } n(\%)\end{array}$ & $46(68)$ & $93(70)$ & $139(70)$ & $p=0.68$ \\
\hline $\begin{array}{l}\text { Unprotected insertive anal } \\
\text { sex last } 6 \text { months, } n(\%)\end{array}$ & $20(29)$ & $39(30)$ & $59(30)$ & $p=0.98$ \\
\hline $\begin{array}{l}\text { History of gonorrhoea last } 6 \\
\text { months, } n(\%)\end{array}$ & $7(10)$ & $32(24)$ & $39(20)$ & $p=0.02$ \\
\hline Illicit drug use, $n(\%)$ & $8(12)$ & $17(13)$ & $25(13)$ & $p=0.82$ \\
\hline $\begin{array}{l}\text { Hepatitis B core antibody } \\
\text { positive, } n(\%)\end{array}$ & $23(34)$ & $34(26)$ & $57(29)$ & $p=0.22$ \\
\hline \multicolumn{5}{|c|}{$\begin{array}{l}\text { Comments: The two groups were comparable on age, race, education, income, risk behaviours at enrolment, illicit drug use } \\
\text { and hepatitis B seroprevalence }\end{array}$} \\
\hline Outcomes: HIV incidence & $\operatorname{PEP}(\mathrm{n}=68)$ & No PEP & $=(32)$ & p-value \\
\hline Seroconversion to HIV & I & 10 & & Not reported \\
\hline \multicolumn{5}{|c|}{$\begin{array}{l}\text { Comments: II subjects had new HIV infections during the course of the study, for an overall seroincidence of } 2.9 \text { per } 100 \\
\text { person-years }(95 \% \mathrm{CI} \text { I.4-5.I). Based on the risk profile of the study participants and the experience of the authors' previous } \\
\text { cohort study the expected number of new HIV infections was II I.8 ( } p>0.97 \text { compared with the observed II infections), for } \\
\text { an expected seroincidence of } 3.1 \text { per } 100 \text { person-years }(p>0.97 \text { compared with the observed seroincidence of } 2.9)\end{array}$} \\
\hline $\begin{array}{l}\text { Outcomes: PEP use (28-day } \\
\text { course) }\end{array}$ & $\operatorname{PEP}(\mathrm{n}=68)$ & No PEP & $=(32)$ & p-value \\
\hline Prescribed once, $n(\%)$ & $49(72.1)$ & - & & - \\
\hline Prescribed twice, $n$ (\%) & $14(20.6)$ & - & & - \\
\hline Prescribed three times, $n(\%)$ & $2(2.9)$ & - & & - \\
\hline Prescribed four times, $n(\%)$ & $2(2.9)$ & - & & - \\
\hline Prescribed nine times, $n(\%)$ & $\mathrm{I}(\mathrm{I} .5)$ & - & & - \\
\hline \multicolumn{5}{|c|}{$\begin{array}{l}\text { PEP utilisation: PEP was initiated a total of } 109 \text { times by } 68 \text { participants. A total of } 100 \text { were considered eligible exposures, } \\
\text { for which a } 4 \text {-week course was prescribed (see above). The most common reasons for not initiating PEP ( } \geq \text { one possible } \\
\text { response per participant) were sex with a steady partner }(n=150) \text {, participant did not consider the exposure to be of } \\
\text { sufficiently high risk to warrant PEP }(n=94) \text { and concerns about side effects }(n=23)\end{array}$} \\
\hline
\end{tabular}




\begin{tabular}{|c|c|c|c|}
\hline Outcomes: non-completed PEP courses & $\operatorname{PEP}(\mathrm{n}=68)$ & No PEP $(\mathrm{n}=132)$ & p-value \\
\hline Did not return to complete course, $n$ & 2 & - & - \\
\hline Discontinued because of adverse events, $n$ & 7 & - & - \\
\hline \multicolumn{4}{|c|}{$\begin{array}{l}\text { Adverse events: At least one side effect was reported in } 82 \% \text { of episodes of PEP use; nausea was the most commonly } \\
\text { reported side effect and six discontinuations (of those for adverse events) were due to this. One patient with a history of } \\
\text { pancreatitis was instructed to stop taking PEP because of an asymptomatic increase in pancreatic enzymes. Apart from this } \\
\text { there were no clinically significant laboratory abnormalities among participants who took PEP. } \\
\text { Adherence: The full 28-day regimen of PEP was completed for } 89(89 \%) \text { of the eligible exposures, including the participant } \\
\text { who seroconverted. }\end{array}$} \\
\hline Outcomes: risk behaviours & $\operatorname{PEP}(\mathrm{n}=68)$ & No PEP $(\mathrm{n}=132)$ & p-value \\
\hline $\begin{array}{l}\text { Median number of male partners } 6 \text { months } \\
\text { before baseline (range) }\end{array}$ & $4(0-50)$ & $2(0-40)$ & $\begin{array}{l}\text { PEP: } p=0.43 \\
\text { no PEP: } \\
p=0.46\end{array}$ \\
\hline $\begin{array}{l}\text { Median number of male partners } 6 \text { months } \\
\text { before last visit (range) }\end{array}$ & $4(0-180)$ & $2(0-100)$ & $\begin{array}{l}\text { PEP: } p=0.43 \\
\text { no PEP: } \\
p=0.46\end{array}$ \\
\hline
\end{tabular}

Authors state that, on average, reported high-risk sexual activities declined over time for both PEP and non-PEP users

\section{Risk behaviours}

6 months before
baseline

Unprotected anal intercourse, $n(\%)$

Unprotected oral intercourse, $n(\%)$

Unprotected vaginal intercourse (\%)

\section{Additional comments}

- The study regimen was chosen because, at the time of the study, a two-drug regimen was recommended for most HIV exposures that warrant PEP

- PEP failure was defined as a documented HIV seroconversion that occurred within 2 months after the exposure for which PEP was taken. Seroconversions that occurred $\geq 2$ months after the exposure for which PEP was taken were not considered as PEP failures

\section{Methodological comments}

- Allocation to treatment groups: Participants decided whether to initiate PEP after a high-risk exposure. For seroconversion to HIV PEP users were compared with non-users

- Blinding: No blinding of assessors at follow-up visits

- Comparability of treatment groups: The groups that were compared within this study for seroconversions, PEP vs no PEP, were comparable at baseline 
- Method of data analysis: Data analysis was performed using SAS version 6.12. Comparisons between groups were analysed using chi-squared tests for categorical variables and Wilcoxon rank sum tests for continuous variables. Comparisons of numbers of male partners at 6 months before baseline and at last interview were analysed using the signed rank test. Behaviour practices over time were examined using the McNemar test. Authors used the final interview that individuals participated in for those participants who did not have a 24-month interview. Incidence rates are expressed as the incidence of seroconversions per 100 person-years of follow-up and exact $95 \%$ confidence limits were calculated.

- The 'control' was modelled by fitting a binomial regression model to the first cohort data with a complementary log (-log) link function that accounts for previously identified risk factors for incidence of HIV in that cohort. The coefficients from that model were applied to the covariate and follow-up patterns of current participants to calculate the expected number of HIV seroconversions and expected HIV seroincidence

- Sample size/power calculation: No power calculation was performed

- Attrition/dropout: A cohort of 200 was enrolled; of these 68 took the study drug 109 times

\section{General comments}

- Generalisability: The cohort was recruited from former participants of an HIV seroincidence study conducted among highrisk men who have sex with men aged $18-35$ years

- Outcome measures: The outcome measures were relevant to the study area

- Intercentre variability: N/A

- Conflicts of interest: Study was funded by GlaxoSmithKline, Conselho Nacional de Desenvolvimento Científico e Tecnológico, National Institute of Allergy and Infectious Diseases (research career award), Fogarty International Center (grant) 


\title{
Appendix 5
}

\section{Data extraction of cost-effectiveness studies}

\author{
Study characteristics \\ Study \\ Pinkerton et al. $1998^{22}$ \\ Country of origin \\ US \\ Base year prices \\ 1996 US\$ \\ Intervention \\ Postexposure prophylaxis (PEP) following potential HIV exposure through sexual contact \\ with a partner who may or may not be infected, compared with a 'no programme \\ option'. PEP was assumed to consist of a 4-week regimen of triple combination therapy \\ with zidovudine (ZDV), lamivudine (3TC) and the protease inhibitor indivadir and was \\ assumed to be as effective as ZDV monotherapy in the occupational setting \\ Study type \\ Cost-utility analysis; decision-analytical model to evaluate cost-effectiveness \\ Study group \\ A hypothetical cohort of 10,000 patients who reported sexual intercourse with a partner \\ of unknown HIV status

\section{Perspective} \\ Societal \\ Industry role \\ None stated \\ Effectiveness parameter \\ Probability PEP effective 0.79 from occupational study ${ }^{26}$ \\ Costs assessment \\ Primary cost of PEP is drug therapy: cost of PEP triple therapy per patient: US\$619. \\ Obtained from published literature (references given) \\ Utilities assessment \\ Quality-adjusted life-years (QALYs) saved per infection prevented: II.23. Obtained from \\ published literature (references given) \\ Ranges for sensitivity analyses \\ Effectiveness: $0.43-0.94$ \\ Costs: US\$400-955 \\ QALYs saved: 13.18-9.34 \\ Study base case 'headline' \\ predictions/findings \\ PEP should be restricted to partners of infected persons, to patients reporting \\ unprotected receptive anal intercourse and possibly to cases where there is substantial \\ likelihood that the partner is infected
}

Results

Base case

Authors use predetermined threshold of US\$50,000 per QALY saved

The base-case analysis for a cohort of 10,000 patients receiving PEP reported: 19.62 HIV infections averted following receptive anal intercourse; $0.59 \mathrm{HIV}$ infections averted following insertive anal intercourse; 0. I I HIV infections averted following receptive vaginal intercourse; and $0.07 \mathrm{HIV}$ infections averted following insertive vaginal intercourse

Authors report that prophylaxis is not cost-effective for sex act/role combinations other than receptive anal intercourse (all cost-utility ratios exceed US\$750,000 per QALY saved)

They also report that PEP following receptive vaginal intercourse appears to be costeffective if certain that the partner is infected [HIV prevalence (probability of HIV infection) has to be $>0.73$ ]

PEP following insertive exposures is reported to be marginally cost-effective at best (the cost-utility ratio is > US $\$ 100,000$ per QALY saved regardless of the probability of HIV infection)

The cost-utility ratio for ZDV/3TC PEP following receptive anal intercourse among men who have sex with men is US\$6354 per QALY saved 


\section{Study characteristics}

Sensitivity analysis

The sensitivity analyses indicated that the results for the receptive anal case were not sensitive to changes in the parameter values and PEP was always cost-effective across a range of values

Both the insertive anal and insertive vaginal cases were not sensitive and were not costeffective across a (plausible) range of values. The receptive vaginal case was sensitive to the probability of the sexual partner of the patient being HIV infected. In this case, if the probability of infection is $>0.73$ then PEP may be cost-effective

PEP is cost saving for receptive anal intercourse if the probability that the partner is infected is $>0.25$

Triple PEP therapy was unlikely to be cost-effective relative to dual combination PEP (the additional drug costs will not be offset by treatment savings)

The results did not appear to be sensitive to repeated exposure and PEP

\section{Conclusions}

PEP following suspected sexual exposure to HIV is only cost-effective for receptive anal intercourse or receptive vaginal intercourse with a partner who is likely to be infected

If the probability that the partner is infected is very small then PEP may not be costeffective following receptive anal intercourse

PEP after insertive vaginal intercourse or insertive anal intercourse is probably not costeffective, regardless of the partner's risk status

The authors report that from a purely economic standpoint PEP should be restricted to partners of infected persons (e.g. serodiscordant couples), to patients reporting unprotected receptive anal intercourse (including condom breakage) and possibly to cases in which there is a substantial likelihood that the partner is infected. Providing PEP to all who request it does not appear to be an economically efficient use of limited HIV prevention and treatment resources

\section{Caveats}

Uncertainty in the effectiveness of PEP has implications for its cost-effectiveness

Authors have assumed that PEP is completely ineffective when the antiretroviral regimen is discontinued prematurely

Analysis assumes that all individuals receiving PEP are uninfected and that PEP therefore can prevent an infection. Therefore, the above results may disproportionately overstate the cost-effectiveness of PEP in high prevalence communities

PEP for receptive anal intercourse may not be cost-effective (authors state US\$100,000 per QALY) if the probability that the partner is infected is quite small

There are limitations with the per-contact probabilities: they are not known with certainty and the probable ranges may overlap. Stage of disease, viral load, genetics and facilitation by sexually transmitted diseases are believed to also affect the risk of transmission; even greater uncertainty surrounds the probability of transmission for oral sex 


\begin{tabular}{|c|c|}
\hline \multicolumn{2}{|l|}{ Study characteristics } \\
\hline Study & Pinkerton et al. $2004^{23}$ \\
\hline Country of origin & US \\
\hline Base year prices & 2000 US\$ \\
\hline Intervention & $\begin{array}{l}\text { An initial 7-day supply of antiretroviral medication; additional } 21 \text { days supplied at follow-up visit } \\
7 \text { days later } \\
\text { The protocol for this study included discussion of potential benefits and negative consequences } \\
\text { of PEP, medical evaluation, HIV risk assessment, risk reduction counselling and medication } \\
\text { adherence counselling, and information on previous antiretroviral use and response to } \\
\text { medication of HIV-infected sources was obtained if possible to tailor the regimen offered as PEP } \\
\text { to one to which the infection would most likely be susceptible. Base-case values were assigned } \\
\text { to these parameters }\end{array}$ \\
\hline Study type & Cost-utility study \\
\hline Study group & $\begin{array}{l}40 \text { I participants with possible non-occupational exposure to HIV [sexual, needle sharing, non- } \\
\text { occupational needlestick injury, other (bite or assault)]. Distribution of patients was by exposure } \\
\text { type, percentage of patients who completed PEP in each exposure group and proportion of } \\
\text { completers with a known HIV-infected source. Patients who reported multiple exposures were } \\
\text { classified according to the highest risk exposure. In total, } 312 \text { patients }(78 \%) \text { were known to } \\
\text { have completed the PEP regimen; } 46 \% \text { reported that they knew that their source was infected } \\
\text { with HIV }\end{array}$ \\
\hline Perspective & Societal: included all identifiable costs, regardless of who bore these \\
\hline Industry role & $\begin{array}{l}\text { None stated (one of the authors has received honorariums from GlaxoSmithKline, Bristol-Myers } \\
\text { Squibb and Agouron Pharmaceuticals) }\end{array}$ \\
\hline Effectiveness parameter & Probability PEP effective 0.8 I from occupational study ${ }^{27}$ \\
\hline Costs assessment & $\begin{array}{l}\text { Five drug costs (for the five different drugs): US } \$ 312 \text {, US } \$ 267 \text {, US } \$ 222 \text {, US } \$ 280 \text { and US } \$ 679 \\
\text { from published literature (reference given) } \\
\text { Itemised laboratory and clinic costs from published literature (reference given) } \\
\text { Wages and travel costs from financial records kept by study investigators }\end{array}$ \\
\hline Utilities assessment & $\begin{array}{l}\text { Quality-adjusted life-years (QALYs) lost per HIV infection: 9.3I. Obtained from published } \\
\text { literature (reference given) }\end{array}$ \\
\hline Ranges for sensitivity & Effectiveness: $0.48-1.0$ \\
\hline analyses & Costs: least expensive regimen US\$502 and most expensive regimen US\$I 258 \\
\hline & QALYS saved: $4.28-18.23$ \\
\hline $\begin{array}{l}\text { Study base case 'headline' } \\
\text { predictions/findings }\end{array}$ & $\begin{array}{l}\text { For this study population, HIV PEP was cost-effective by conventional standards and cost saving } \\
\text { for persons seeking PEP after male-male receptive intercourse }\end{array}$ \\
\hline
\end{tabular}




\section{Study characteristics}

\section{Results}

Base case

Sensitivity analysis
Use of PEP reduced the expected number of infections to 0.77 and therefore prevented an estimated I.59 infections (expected infections in the absence of PEP in the exposures reported by the $40 \mathrm{I}$ patients would be 2.36). The authors have adjusted for continuing risk behaviours over the subsequent 10 years and report that PEP in this case would have averted I.26 infections and saved US\$28I,323 medical care costs and II.74 associated QALYs

PEP effectiveness was set at $81 \%$

The overall cost-utility ratio was US\$14,449 per QALY saved

The authors used thresholds of US\$40,000-\$60,000 per QALY for cost-effectiveness and US $\$ 200,000$ for non-cost-effectiveness

In total, $96 \%$ of averted infections were among men who reported exposure through receptive anal intercourse (RAI) with other men. When restricted to this subgroup the PEP programme was cost saving

Exposure through injection drugs: US\$86,462 per QALY saved; male-female RAI: US\$165,289 per QALY saved

Overall cost-utility ratio for men reporting exposure through male-male sex (receptive or insertive anal sex, receptive oral sex or 'other') was US\$8607 per QALY saved. Cost-utility ratio for all other exposures combined was US\$258,667 per QALY saved

The PEP programme was cost saving for patients who reported that their partner was HIV positive. The cost-utility ratio was US $\$ 58,025$ when the HIV status of the partner was unknown. The authors state that these results are mainly driven by the men with exposures through RAI as these were cost-saving; the cost-utility ratio for the 93 patients who were exposed through other routes was US\$278,67I

Authors assumed that patients remained at risk of infection for 10 years after participating in the PEP programme, with an annual risk equal to the incidence of infection in the associated exposure group

The programme remained cost-effective when the PEP effectiveness parameter was set to $48 \%$

The programme would not be cost saving even if the antiretroviral regimen was $100 \%$ effective

The programme was cost-effective for PEP completion rates $>29 \%$

The programme remained cost-effective regardless of the percentage of partners known to be infected with HIV or the prevalence of infection among partners whose HIV status was unknown

The results were not sensitive to the HIV-related treatment cost and QALYs saved parameters

The programme was cost-effective provided that at least 2.24 QALYs were saved per averted infection and was cost-effective regardless of the cost of treating HIV and AIDS 


\section{Study characteristics}

Sensitivity analysis The programme was still cost-effective if a $5 \%$ discount rate was used. When a $0 \%$ discount rate was used the cost-utility ratio decreased to US\$2385 per QALY saved

The cost-utility ratio was most sensitive to RAI transmission probability. The threshold analysis indicated that the PEP programme would be cost saving overall if this probability exceeded 0.033 and would be cost-effective (cost-utility ratio of US\$60,000 per QALY saved) for probabilities as small as 0.009 (base case was 0.02 )

The programme would not be cost-effective (cost-utility ratio > US $\$ 200,000$ per QALY saved) if the per-exposure transmission probability for RAl was less than 0.003

Using alternative published HIV incidence and prevalence rates for San Francisco: US\$I I,08I per QALY saved, lower than the base-case value

Cost-utility ratio increased to US\$7I,38I when the transmission probabilities were set to their smallest values and decreased to less than zero (cost saving) when they were set to their largest values

\section{Conclusions}

HIV PEP was cost-effective by conventional standards (here defined as between US $\$ 40,000$ and US $\$ 60,000$ ) and cost saving for men seeking PEP after male-male RAI. It is possibly costeffective for injection drug exposures and women reporting RAI but probably not cost-effective for other exposures. Although fewer than half of the patients reported male-male RAI, the PEP programme was cost-effective overall and authors suggest an economically sound use of societal health promotion resources

\section{Caveats}

The effectiveness of PEP after sexual exposures is unknown: authors assumed that dual and triple drug PEP was as effective as zidovudine PEP in a case-control study of occupational exposures

Differences in the transmission dynamics of sexual (mucosal) and occupational (percutaneous) exposures may also impact on PEP effectiveness 


\section{Study characteristics}

\begin{tabular}{|c|c|}
\hline Study & Pinkerton et al. $2004^{24}$ \\
\hline Country of origin & US \\
\hline Base year prices & 2000 US\$ \\
\hline Intervention & $\begin{array}{l}\text { Hypothetical PEP programme in } 96 \text { US metropolitan statistical areas (MSAs), based on San } \\
\text { Francisco PEP programme (no further detail provided in this paper) }\end{array}$ \\
\hline Study type & Cost-effectiveness analysis \\
\hline Study group & $\begin{array}{l}\text { Information on PEP clients was taken from the San Francisco PEP programme. Potential } \\
\text { PEP clients were divided into four risk groups based on exposure type: men who have sex } \\
\text { with men (MSM), intravenous drug users (IDUs), male/female heterosexuals and other non- } \\
\text { occupational exposures (bites, assaults involving mucosal exposure). It was assumed that } \\
\text { the same proportion of each group would access PEP in each MSA as they had in the San } \\
\text { Francisco PEP study. This was then used to estimate the number of potential PEP clients in } \\
\text { each group in each MSA. Previously published estimates of HIV prevalence in the } 96 \text { MSAs for } \\
\text { each risk group were used. It was assumed that the distribution of PEP-prompting exposures } \\
\text { (e.g. receptive anal intercourse, injection-related exposure, etc.) in each MSAs would mimic } \\
\text { the distribution observed in San Francisco. It was also assumed that risk group exposure could } \\
\text { be inferred from exposure type (e.g. man reporting vaginal intercourse is in heterosexual } \\
\text { group and source partner belongs to same group; one exception: non-occupational } \\
\text { needlestick injuries usually come from discarded needles and so the HIV prevalence in IDUs } \\
\text { was used to estimate the prevalence of infection among needlestick exposure sources) }\end{array}$ \\
\hline Perspective & Societal \\
\hline Industry role & Not stated \\
\hline Effectiveness parameter & Probability PEP effective $0.8 \mathrm{I}$ from occupational study ${ }^{27}$ \\
\hline Costs assessment & $\begin{array}{l}\text { Total cost of PEP programme in a particular MSA was calculated using a formula (given) } \\
\text { including: drug costs for completers US\$597 (non-completers US\$454); laboratory work } \\
\text { completers US\$26 (non-completers US\$I4); other clinical services completers US\$523 (non- } \\
\text { completers US\$240). Obtained from published literature (references given) and data from San } \\
\text { Francisco PEP programme data }\end{array}$ \\
\hline
\end{tabular}

Utilities assessment

Quality-adjusted life-years (QALYs) saved per infection prevented: 9.31. Obtained from published literature (references given)

Ranges for sensitivity analyses

Effectiveness: $0.48-0.94$

Costs: not used

QALYs lost: 10.29-8.37

Study base case 'headline' predictions/findings
Proportion of clients completing therapy was set at $77.8 \%$ (based on San Francisco PEP study). The effectiveness of PEP in preventing HIV infection was assumed to be $81 \%$, based on the findings of a case-control study in health-care workers (HCWs) exposed occupationally. Across the 96 MSAs the hypothetical PEP programmes would serve 19,154 clients at a total cost of US\$21.7m, averting 63.9 HIV infections (primarily MSM - $96.1 \%$ of the averted infections, constituting $75.9 \%$ of PEP clients)

\section{Results}

Base case
The combined cost-utility ratio (CUR) for the 96 MSA was US\$12,567 per QALY saved. This ranged from US\$4I37 (San Francisco) to US\$39, I0I (Stockton-Lodi MSA) per QALY saved. Only two MSAs had CUR greater than US\$30,000. The mean and median CUR were US\$15,728 and US\$15,367 respectively

PEP was cost saving (CUR < US\$0) for male-male and male-female receptive anal intercourse exposures

The CUR for needle-sharing exposures and needlestick exposures was US\$97,867 and US\$159,686 respectively

CUR exceeded $\$ 380,000$ per QALY saved for all other types of exposure 


\section{Study characteristics}

Sensitivity analysis

Key parameters were varied one at a time in univariate sensitivity analyses. Only one of the parameter manipulations (reducing the per-exposure transmission probability for receptive anal intercourse from 0.02 to 0.008 ) resulted in a CUR > US $\$ 60,000$ per QALY saved.

Individually varying the other transmission probabilities within plausible ranges produced $<4 \%$ deviation from the base CUR

Several prevalence-related measures were moderately to strongly correlated with the inverse of the CUR values for individual MSAs (although overall the CUR across the 96 MSAs was not especially sensitive to the prevalence of infection)

The authors report that the results were moderately sensitive to the effectiveness of PEP and somewhat sensitive to the proportions of persons who completed the PEP regimen, the proportion of PEP clients with known infected source partners and the lifetime costs of medical care and lost QALYs associated with a case of HIV infection

In particular, the proportion of the 'high-risk' MSM, IDUs, heterosexual subpopulation classified as HIV-infected MSM was strongly correlated with the inverse CUR

\section{Conclusions}

PEP for HIV could be a cost-effective adjunct to existing HIV prevention efforts

Overall across the 96 MSAs, PEP was cost saving for receptive anal intercourse and possibly cost-effective for needle sharing and non-occupational needlestick injuries, but of questionable economic value for all other types of exposure

PEP was highly cost-effective for MSM, less so for IDUs and high-risk women, and probably not cost-effective for general population exposures or heterosexual men

\section{Caveats}

The effectiveness of PEP in preventing infection and the per-exposure transmission probability are not established. HIV prevalence and population size estimates were based on a study published in 1996 (therefore reflecting HIV epidemiology in the early 1990s). Analysis did not take into account the ages of clients (which would affect the number of QALYs lost to infection) or whether or not a particular client completed the PEP regimen or was known to have been exposed to HIV by an HIV-positive partner. The analysis assumed that the distribution of client exposure groups in each MSA would mimic that observed in the San Francisco study. Implementation of PEP services in a given locale is likely to differ from the San Francisco experience 


\section{Study characteristics}

$\begin{array}{ll}\text { Study } & \text { Herida et al. } 2006^{25} \\ \text { Country of origin } & \text { France } \\ \text { Base year prices } & 2002 \text { Euros } \\ \text { Intervention } & \text { Comparison of PEP programme with 'no PEP' alternative. For patients in PEP programme } \\ & \text { clinicians prescribe drugs of their choice (usually tri-therapy containing protease inhibitor). HIV/ } \\ & \text { hepatitis B/hepatitis C serology tests, a pregnancy test and 'other' laboratory tests carried out } \\ & \text { at the baseline visit. Three follow-up visits scheduled at days I5, } 30 \text { and } 90 \text { after exposure. } \\ & \text { Laboratory tests scheduled at day I5. HIV and hepatitis serology is repeated at day } 30 \text { (end of } \\ & \text { treatment), I } 20 \text { and I80. PEP physician provides patient with 4-week supply of antiretroviral } \\ & \text { drugs and counselling at each visit. Information on patients' characteristics, risk of exposure, } \\ & \text { treatments prescribed, serology and potential adverse effects were recorded by clinicians during } \\ & \text { follow-up visits and entered in an anonymous database. A total of I5 drugs were used in various } \\ & \text { two-drug }(9 \%), \text { three-drug }(90 \%) \text { and four-drug (I\%) combinations }\end{array}$

Study type

Cost-effectiveness analysis based on decision tree. As parameters vary according to exposure risks, a separate decision tree was built for each type of exposure event

Study group

Perspective

Industry role

Effectiveness parameter

Costs assessment

Utilities assessment

Ranges for sensitivity analyses

Study base case 'headline' predictions/findings

\section{Results}

Base case
I2,55 I individuals sought PEP between July 1999 and December 2003. Of these, 8958 (7I\%) were prescribed PEP and included in a national hospital-based voluntary surveillance of PEP programme for both occupational and non-occupational exposure (set up in 1999); 68I2 (76\%) of those prescribed PEP had a sexual exposure event, 2092 (23.4\%) had an occupational exposure event $(68.9 \%$ of these were HCWs) and $54(0.6 \%)$ were exposed through sharing drug injection equipment. In the sexual exposure group, 2546 (28.4\%) were men who have sex with men (MSM) and $4266(47.6 \%)$ were heterosexual. The source was known to be HIV infected for 2413 individuals $(27.1 \%)$

Societal

Not stated

Probability PEP effective 0.80 from occupational study ${ }^{27}$ (in fact, 0.81 from reference)

Total cost: $€ 988$; cost of PEP therapy per patient: $€ 745$; physician visits: $€ 80$; laboratory costs: $€ 163$. Obtained from PEP treatment prescribed between 1999 and 2003 using published prices (reference given)

Quality-adjusted life-years (QALYs) saved per infection prevented: 8.34. Obtained from published literature (references given)

Effectiveness: $0.48-0.94$

Costs: not used

QALYs saved: II.58-4.3।

Number of infections averted and number of QALYs saved during 1999-2003. On the basis of the model it was estimated that among 8958 treated individuals, 12 cases of HIV infection would have occurred if none had received PEP and 4.3 cases would have occurred if all had received PEP

Five individuals became infected during follow-up - two were considered PEP failures (receptive anal intercourse in a gay man and a women); the three remaining patients (all MSM) were considered by physicians to have seroconversions resulting from high-risk sexual behaviour after the PEP treatment

Cost of the PEP programme (providing PEP to 8958 individuals) was estimated at $€ 7,670,002$ and the cost-effectiveness ratio (CER) at €996, 104 per infection averted

The total cost of the programme (including the cost of caring for the estimated 4.3 cases of HIV infection that occurred among the 8958 treated individuals) was $€ 3,035,075$

The cost of caring for the estimated I 2 cases of HIV infection that would have occurred without the PEP programme was $€ 8,752,150$

The estimated marginal cost was $€ 5,717,075$ and the CER was $€ 88,692$ per QALY saved 


\section{Study characteristics}

Sensitivity analysis

There were major differences in the CER according to the type of exposure. PEP after receptive anal intercourse with an HIV-infected individual was cost saving in men and women (negative ratio of $€ 22,|4|$ and $€ 22,03$ I per QALY saved respectively). PEP after an intravenous drug user (IDU) sharing needle with an HIV-infected person was cost saving (€I I I I per QALY saved). PEP is cost-effective $(<€ 50,000$ per QALY saved) for HCW after percutaneous exposure to material from an HIV-infected patient, and for MSM having receptive anal intercourse with a partner of unknown status. These five exposures accounted for $15.7 \%$ of prescriptions. In other exposures PEP was not considered cost-effective: $72 \%$ of exposures had CER $>€ 200,000$ per QALY saved and $52 \%$ of cases had CER $>€ 2 m$ per QALY saved

One-way sensitivity analyses were performed on compliance according to the low estimation of the compliance, and on life expectancy of HIV-infected individuals according to the higher lifetime HIV cost resulting from longer survival (other parameters were kept fixed at base-case values)

Patients with missing follow-up information were considered as compliant as those known to have attended the I-month follow-up (this compliance was used in the base case); patients with missing follow-up information were considered as lost to follow-up with a compliance $=0$ (this estimated compliance was used in the sensitivity analysis). In this case the programme would prevent 3.8 infections and save 31.7 QALYs at a marginal cost of $€ 5,087,998$, resulting in a CER of $€ 160,382$ per QALY saved. As before, PEP after receptive anal intercourse with an HIVinfected individual remains cost saving $(-€ I 7,778$ and $-€ I 8,860$ per QALY saved for MSM and heterosexual women respectively). PEP to an IDU after needle sharing with an HIV-infected person remains cost-effective but is no longer cost saving (€I8,445 per QALY saved)

One-way sensitivity analyses were performed on the life expectancy of HIV-infected individuals according to the higher value of life expectancy and higher lifetime HIV cost resulting from longer survival ( 16.82 QALYs compared to base case of 12.79 , and $€ 331,869$ lifetime HIV/AIDS care costs compared to base case of $€ 252,768$; both costs and QALYs are discounted at $3 \%$ ). According to this scenario the programme is less cost-effective than the base case (33.3 QALYs prevented at marginal cost of $€ 5,105,998$; CER $=€ I 53,24 I$ per QALY saved). The three exposure risks with negative ratios in the base-case analysis remain cost saving but with higher cost ratios

Threshold analyses were performed for exposures with CER under $€ 200,000$ per QALY saved, using minimum values of prevalence, per-contact HIV transmission or compliance required to achieve the cost-saving threshold ( $€ 0$ per QALY saved) or the cost-effective threshold $(€ 50,000$ per QALY saved). PEP for MSM after receptive anal intercourse with a partner of unknown HIV status would be cost saving for a per-contact transmission risk of at least equal to $0.04 \mathrm{II}$ or an HIV prevalence of at least 0.208 . After needle sharing with an individual of unknown serostatus, to achieve cost-effectiveness ( $€ 50,000$ per QALY saved) the compliance should be $\geq 0.92$ with both the highest values of prevalence $(0.2 \mathrm{I})$ and of the per-contact transmission risk $(0.0092)$. For receptive vaginal intercourse with an HIV-infected partner, a per-contact transmission risk equal to 0.0208 would allow the CER to be reached

\section{Conclusions}

According to international standards that use US\$50,000 per QALY saved as a threshold, the French PEP programme appears not to be a cost-effective intervention; only I5.7\% of PEP courses in the French programme can be considered cost-effective

The PEP programme is less cost-effective than other French prevention or screening programmes 


\section{Study characteristics}

\section{Caveats}

The authors list several limitations. They had to make several initial assumptions (and used sensitivity analyses to overcome this). Compliance could only be estimated for $47 \%$ of PEP prescriptions and so overall compliance was estimated at 0.75 . Any overestimation of compliance would improve the CER (demonstrated in the sensitivity analysis by using low estimate of compliance)

There are no available data for lifetime HIV/AIDS costs in France and so the authors estimated these

The model did not take into account the possibility that some patients seeking PEP may continue at-risk behaviour

The study did not consider PEP adverse events. The authors state that taking these into account would further reduce the CER of the overall PEP programme: $65 \%$ of 2138 treated patients in the French PEP programme had clinical adverse events and $8 \%$ presented with biological abnormalities

The number of HIV infections predicted by the model was higher than that seen; however, HIV serology 6 months after PEP initiation was only available for $18 \%$ of patients and so the true number of PEP failures may be higher 


\section{Health Technology Assessment reports published to date}

\section{Volume I, I 997}

No. 1

Home parenteral nutrition: a systematic review.

By Richards DM, Deeks JJ, Sheldon TA, Shaffer JL.

No. 2

Diagnosis, management and screening of early localised prostate cancer.

A review by Selley S, Donovan J, Faulkner A, Coast J, Gillatt D.

No. 3

The diagnosis, management, treatment and costs of prostate cancer in England and Wales.

A review by Chamberlain J, Melia J, Moss S, Brown J.

No. 4

Screening for fragile $\mathrm{X}$ syndrome.

A review by Murray J, Cuckle $\mathrm{H}$, Taylor G, Hewison J.

No. 5

A review of near patient testing in primary care

By Hobbs FDR, Delaney BC, Fitzmaurice DA, Wilson S, Hyde CJ, Thorpe GH, et al.

No. 6

Systematic review of outpatient services for chronic pain control.

By McQuay HJ, Moore RA, Eccleston

C, Morley S, de C Williams AC.

No. 7

Neonatal screening for inborn errors of metabolism: cost, yield and outcome.

A review by Pollitt RJ, Green A,

McCabe CJ, Booth A, Cooper NJ,

Leonard JV, et al.

No. 8

Preschool vision screening.

A review by Snowdon SK,

Stewart-Brown SL.

No. 9

Implications of socio-cultural contexts for the ethics of clinical trials.

A review by Ashcroft RE, Chadwick DW, Clark SRL, Edwards RHT, Frith L, Hutton JL.

No. 10

A critical review of the role of neonatal hearing screening in the detection of congenital hearing impairment.

By Davis A, Bamford J, Wilson I,

Ramkalawan T, Forshaw M, Wright S.
No. 11

Newborn screening for inborn errors of metabolism: a systematic review.

By Seymour CA, Thomason MJ, Chalmers RA, Addison GM, Bain MD, Cockburn F, et al.

No. 12

Routine preoperative testing: a systematic review of the evidence. By Munro J, Booth A, Nicholl J.

No. 13

Systematic review of the effectiveness of laxatives in the elderly.

By Petticrew M, Watt I, Sheldon T.

No. 14

When and how to assess fast-changing technologies: a comparative study of medical applications of four generic technologies.

A review by Mowatt G, Bower DJ, Brebner JA, Cairns JA, Grant AM, McKee L.

\section{Volume 2, 1998}

No. 1

Antenatal screening for Down's syndrome.

A review by Wald NJ, Kennard A, Hackshaw A, McGuire A

No. 2

Screening for ovarian cancer: a systematic review.

By Bell R, Petticrew M, Luengo S, Sheldon TA.

No. 3

Consensus development methods, and their use in clinical guideline development.

A review by Murphy MK, Black NA, Lamping DL, McKee CM, Sanderson CFB, Askham J, et al.

No. 4

A cost-utility analysis of interferon beta for multiple sclerosis.

By Parkin D, McNamee P, Jacoby A, Miller P, Thomas S, Bates D.

No. 5

Effectiveness and efficiency of methods of dialysis therapy for end-stage renal disease: systematic reviews

By MacLeod A, Grant A, Donaldson

C, Khan I, Campbell M, Daly C, et al.
No. 6

Effectiveness of hip prostheses in primary total hip replacement: a critical review of evidence and an economic model.

By Faulkner A, Kennedy LG, Baxter K, Donovan J, Wilkinson M, Bevan G.

No. 7

Antimicrobial prophylaxis in colorectal surgery: a systematic review of randomised controlled trials.

By Song F, Glenny AM.

No. 8

Bone marrow and peripheral blood stem cell transplantation for malignancy.

A review by Johnson PWM,

Simnett SJ, Sweetenham JW, Morgan GJ, Stewart LA.

No. 9

Screening for speech and language delay: a systematic review of the literature.

By Law J, Boyle J, Harris F, Harkness A, Nye C.

No. 10

Resource allocation for chronic stable angina: a systematic review of effectiveness, costs and cost-effectiveness of alternative interventions.

By Sculpher MJ, Petticrew M, Kelland JL, Elliott RA, Holdright DR, Buxton MJ.

No. 11

Detection, adherence and control of hypertension for the prevention of stroke: a systematic review. By Ebrahim S

No. 12

Postoperative analgesia and vomiting, with special reference to day-case surgery: a systematic review.

By McQuay HJ, Moore RA.

No. 13

Choosing between randomised and nonrandomised studies: a systematic review.

By Britton A, McKee M, Black N, McPherson K, Sanderson C, Bain C.

No. 14

Evaluating patient-based outcome measures for use in clinical trials.

A review by Fitzpatrick R, Davey C, Buxton MJ, Jones DR. 


\section{No. 15}

Ethical issues in the design and conduct of randomised controlled trials.

A review by Edwards SJL, Lilford RJ, Braunholtz DA, Jackson JC, Hewison J, Thornton J.

\section{No. 16}

Qualitative research methods in health technology assessment: a review of the literature.

By Murphy E, Dingwall R,

Greatbatch D, Parker S, Watson P.

\section{No. 17}

The costs and benefits of paramedic skills in pre-hospital trauma care.

By Nicholl J, Hughes S, Dixon S, Turner J, Yates D.

\section{No. 18}

Systematic review of endoscopic ultrasound in gastro-oesophageal cancer.

By Harris KM, Kelly S, Berry E, Hutton J, Roderick P, Cullingworth J, et al.

\section{No. 19}

Systematic reviews of trials and other studies.

By Sutton AJ, Abrams KR, Jones DR, Sheldon TA, Song F.

\section{No. 20}

Primary total hip replacement surgery: a systematic review of outcomes and modelling of cost-effectiveness associated with different prostheses.

A review by Fitzpatrick R, Shortall E, Sculpher M, Murray D, Morris R, Lodge M, et al.

\section{Volume 3, 1999}

No. 1

Informed decision making: an annotated bibliography and systematic review.

By Bekker H, Thornton JG, Airey CM, Connelly JB, Hewison J, Robinson $\mathrm{MB}$, et al.

No. 2

Handling uncertainty when performing economic evaluation of healthcare interventions.

A review by Briggs AH, Gray AM.

No. 3

The role of expectancies in the placebo effect and their use in the delivery of health care: a systematic review.

By Crow R, Gage H, Hampson S,
No. 4

A randomised controlled trial of different approaches to universal antenatal HIV testing: uptake and acceptability. Annex: Antenatal HIV testing - assessment of a routine voluntary approach.

By Simpson WM, Johnstone FD, Boyd FM, Goldberg DJ, Hart GJ, Gormley SM, et al.

\section{No. 5}

Methods for evaluating area-wide and organisation-based interventions in health and health care: a systematic review.

By Ukoumunne OC, Gulliford MC, Chinn S, Sterne JAC, Burney PGJ.

\section{No. 6}

Assessing the costs of healthcare technologies in clinical trials.

A review by Johnston K, Buxton MJ, Jones DR, Fitzpatrick R.

\section{No. 7}

Cooperatives and their primary care emergency centres: organisation and impact.

By Hallam L, Henthorne K.

No. 8

Screening for cystic fibrosis. A review by Murray J, Cuckle H, Taylor G, Littlewood J, Hewison J.

\section{No. 9}

A review of the use of health status measures in economic evaluation.

By Brazier J, Deverill M, Green C, Harper R, Booth A.

No. 10

Methods for the analysis of qualityof-life and survival data in health technology assessment.

A review by Billingham LJ,

Abrams KR, Jones DR.

\section{No. 11}

Antenatal and neonatal

haemoglobinopathy screening in the

UK: review and economic analysis. By Zeuner D, Ades AE, Karnon J, Brown J, Dezateux C, Anionwu EN.

\section{No. 12}

Assessing the quality of reports of randomised trials: implications for the conduct of meta-analyses.

A review by Moher D, Cook DJ, Jadad AR, Tugwell P, Moher M, Jones A, et al.

\section{No. 13}

'Early warning systems' for identifying new healthcare technologies.

By Robert G, Stevens A, Gabbay J.

No. 14

A systematic review of the role of human papillomavirus testing within a cervical screening programme.

By Cuzick J, Sasieni P, Davies P, Adams J, Normand C, Frater A, et al.
No. 15

Near patient testing in diabetes clinics: appraising the costs and outcomes.

By Grieve R, Beech R, Vincent J, Mazurkiewicz J.

\section{No. 16}

Positron emission tomography: establishing priorities for health technology assessment.

A review by Robert G, Milne $\mathrm{R}$.

\section{No. 17 (Pt 1)}

The debridement of chronic wounds: a systematic review.

By Bradley M, Cullum N, Sheldon T.

\section{No. 17 (Pt 2)}

Systematic reviews of wound care management: (2) Dressings and topical agents used in the healing of chronic wounds.

By Bradley M, Cullum N, Nelson EA, Petticrew M, Sheldon T, Torgerson D.

No. 18

A systematic literature review of spiral and electron beam computed tomography: with particular reference to clinical applications in hepatic lesions, pulmonary embolus and coronary artery disease.

By Berry E, Kelly S, Hutton J, Harris KM, Roderick P, Boyce JC, et al.

No. 19

What role for statins? A review and economic model.

By Ebrahim S, Davey Smith G, McCabe C, Payne N, Pickin M, Sheldon TA, et al.

No. 20

Factors that limit the quality, number and progress of randomised controlled trials.

A review by Prescott RJ, Counsell CE, Gillespie WJ, Grant AM, Russell IT, Kiauka S, et al.

No. 21

Antimicrobial prophylaxis in total hip replacement: a systematic review. By Glenny AM, Song F.

No. 22

Health promoting schools and health promotion in schools: two systematic reviews.

By Lister-Sharp D, Chapman S, Stewart-Brown S, Sowden A.

No. 23

Economic evaluation of a primary care-based education programme for patients with osteoarthritis of the knee.

A review by Lord J, Victor C,

Littlejohns P, Ross FM, Axford JS 


\section{Volume 4, 2000}

No. 1

The estimation of marginal time preference in a UK-wide sample (TEMPUS) project.

A review by Cairns JA, van der Pol MM.

\section{No. 2}

Geriatric rehabilitation following fractures in older people: a systematic review.

By Cameron I, Crotty M, Currie C, Finnegan T, Gillespie L, Gillespie W, et al.

No. 3

Screening for sickle cell disease and thalassaemia: a systematic review with supplementary research.

By Davies SC, Cronin E, Gill M, Greengross P, Hickman M, Normand C.

No. 4

Community provision of hearing aids and related audiology services.

A review by Reeves DJ, Alborz A, Hickson FS, Bamford JM.

No. 5

False-negative results in screening programmes: systematic review of impact and implications.

By Petticrew MP, Sowden AJ, Lister-Sharp D, Wright K.

No. 6

Costs and benefits of community postnatal support workers: a randomised controlled trial.

By Morrell CJ, Spiby H, Stewart P, Walters S, Morgan A

\section{No. 7}

Implantable contraceptives (subdermal implants and hormonally impregnated intrauterine systems) versus other forms of reversible contraceptives: two systematic reviews to assess relative effectiveness, acceptability, tolerability and cost-effectiveness.

By French RS, Cowan FM,

Mansour DJA, Morris S, Procter T, Hughes D, et al.

No. 8

An introduction to statistical methods for health technology assessment.

A review by White SJ, Ashby D, Brown PJ.

No. 9

Disease-modifying drugs for multiple sclerosis: a rapid and systematic review. By Clegg A, Bryant J, Milne R.

No. 10

Publication and related biases.

A review by Song F, Eastwood AJ, Gilbody S, Duley L, Sutton AJ.

\section{No. 11}

Cost and outcome implications of the organisation of vascular services.

By Michaels J, Brazier J,

Palfreyman S, Shackley P, Slack R.

\section{No. 12}

Monitoring blood glucose control in diabetes mellitus: a systematic review.

By Coster S, Gulliford MC, Seed PT, Powrie JK, Swaminathan R.

\section{No. 13}

The effectiveness of domiciliary health visiting: a systematic review of international studies and a selective review of the British literature.

By Elkan R, Kendrick D, Hewitt M, Robinson JJA, Tolley K, Blair M, et al.

\section{No. 14}

The determinants of screening uptake and interventions for increasing uptake: a systematic review.

By Jepson R, Clegg A, Forbes C, Lewis R, Sowden A, Kleijnen J.

\section{No. 15}

The effectiveness and cost-effectiveness of prophylactic removal of wisdom teeth.

A rapid review by Song F, O'Meara $S$, Wilson P, Golder S, Kleijnen J.

\section{No. 16}

Ultrasound screening in pregnancy: a systematic review of the clinical effectiveness, cost-effectiveness and women's views.

By Bricker L, Garcia J, Henderson J, Mugford M, Neilson J, Roberts T, et al.

\section{No. 17}

A rapid and systematic review of the effectiveness and cost-effectiveness of the taxanes used in the treatment of advanced breast and ovarian cancer.

By Lister-Sharp D, McDonagh MS, Khan KS, Kleijnen J.

\section{No. 18}

Liquid-based cytology in cervical screening: a rapid and systematic review.

By Payne N, Chilcott J, McGoogan E.

No. 19

Randomised controlled trial of nondirective counselling, cognitivebehaviour therapy and usual general practitioner care in the management of depression as well as mixed anxiety and depression in primary care.

By King M, Sibbald B, Ward E, Bower P, Lloyd M, Gabbay M, et al.

\section{No. 20}

Routine referral for radiography of patients presenting with low back pain: is patients' outcome influenced by GPs' referral for plain radiography?

By Kerry S, Hilton S, Patel S, Dundas D, Rink E, Lord J.
No. 21

Systematic reviews of wound care management: (3) antimicrobial agents for chronic wounds; (4) diabetic foot ulceration.

By O'Meara S, Cullum N, Majid M, Sheldon T.

No. 22

Using routine data to complement and enhance the results of randomised controlled trials.

By Lewsey JD, Leyland AH, Murray GD, Boddy FA.

\section{No. 23}

Coronary artery stents in the treatment of ischaemic heart disease: a rapid and systematic review.

By Meads C, Cummins C, Jolly K, Stevens A, Burls A, Hyde C.

\section{No. 24}

Outcome measures for adult critical care: a systematic review.

By Hayes JA, Black NA, Jenkinson C, Young JD, Rowan KM, Daly K, et al.

No. 25

A systematic review to evaluate the effectiveness of interventions to promote the initiation of breastfeeding. By Fairbank L, O'Meara S,

Renfrew MJ, Woolridge M, Sowden AJ, Lister-Sharp D.

No. 26

Implantable cardioverter defibrillators: arrhythmias. A rapid and systematic review.

By Parkes J, Bryant J, Milne R.

\section{No. 27}

Treatments for fatigue in multiple sclerosis: a rapid and systematic review.

By Brañas P, Jordan R, Fry-Smith A, Burls A, Hyde C.

No. 28

Early asthma prophylaxis, natural history, skeletal development and economy (EASE): a pilot randomised controlled trial.

By Baxter-Jones ADG, Helms PJ, Russell G, Grant A, Ross S, Cairns JA, et al.

\section{No. 29}

Screening for hypercholesterolaemia versus case finding for familial hypercholesterolaemia: a systematic review and cost-effectiveness analysis.

By Marks D, Wonderling

D, Thorogood M, Lambert H, Humphries SE, Neil HAW.

\section{No. 30}

A rapid and systematic review of the clinical effectiveness and costeffectiveness of glycoprotein IIb/IIIa antagonists in the medical management of unstable angina.

By McDonagh MS, Bachmann LM, Golder S, Kleijnen J, ter Riet G. 
No. 31

A randomised controlled trial of prehospital intravenous fluid replacement therapy in serious trauma.

By Turner J, Nicholl J, Webber L, Cox H, Dixon S, Yates D.

\section{No. 32}

Intrathecal pumps for giving opioids in chronic pain: a systematic review. By Williams JE, Louw G,

Towlerton G.

\section{No. 33}

Combination therapy (interferon alfa and ribavirin) in the treatment of chronic hepatitis $\mathrm{C}$ : a rapid and systematic review.

By Shepherd J, Waugh N,

Hewitson P.

\section{No. 34}

A systematic review of comparisons of effect sizes derived from randomised and non-randomised studies.

By MacLehose RR, Reeves BC, Harvey IM, Sheldon TA, Russell IT, Black AMS.

\section{No. 35}

Intravascular ultrasound-guided interventions in coronary artery disease: a systematic literature review, with decision-analytic modelling, of outcomes and cost-effectiveness.

By Berry E, Kelly S, Hutton J, Lindsay HSJ, Blaxill JM, Evans JA, et al.

\section{No. 36}

A randomised controlled trial to evaluate the effectiveness and costeffectiveness of counselling patients with chronic depression.

By Simpson S, Corney R, Fitzgerald P, Beecham J.

\section{No. 37}

Systematic review of treatments for atopic eczema.

By Hoare C, Li Wan Po A, Williams $\mathrm{H}$.

\section{No. 38}

Bayesian methods in health technology assessment: a review.

By Spiegelhalter DJ, Myles JP, Jones DR, Abrams KR.

\section{No. 39}

The management of dyspepsia: a systematic review.

By Delaney B, Moayyedi P, Deeks J, Innes $\mathrm{M}$, Soo $\mathrm{S}$, Barton $\mathrm{P}$, et al.

\section{No. 40}

A systematic review of treatments for severe psoriasis.

By Griffiths CEM, Clark CM,

\section{Volume 5, 200 I}

No. 1

Clinical and cost-effectiveness

of donepezil, rivastigmine and

galantamine for Alzheimer's disease: a rapid and systematic review.

By Clegg A, Bryant J, Nicholson T, McIntyre L, De Broe S, Gerard K, et al.

No. 2

The clinical effectiveness and costeffectiveness of riluzole for motor neurone disease: a rapid and systematic review.

By Stewart A, Sandercock J, Bryan S, Hyde C, Barton PM, Fry-Smith A, et al.

No. 3

Equity and the economic evaluation of healthcare.

By Sassi F, Archard L, Le Grand J.

No. 4

Quality-of-life measures in chronic diseases of childhood.

By Eiser C, Morse R.

No. 5

Eliciting public preferences for healthcare: a systematic review of techniques.

By Ryan M, Scott DA, Reeves C, Bate A, van Teijlingen ER, Russell EM, et al.

No. 6

General health status measures for people with cognitive impairment: learning disability and acquired brain injury.

By Riemsma RP, Forbes CA, Glanville JM, Eastwood AJ, Kleijnen J.

\section{No. 7}

An assessment of screening strategies for fragile $\mathrm{X}$ syndrome in the UK.

By Pembrey ME, Barnicoat AJ, Carmichael B, Bobrow M, Turner G.

No. 8

Issues in methodological research: perspectives from researchers and commissioners.

By Lilford RJ, Richardson A, Stevens A, Fitzpatrick R, Edwards S, Rock F, et al.

\section{No. 9}

Systematic reviews of wound care management: (5) beds; (6) compression; (7) laser therapy, therapeutic ultrasound, electrotherapy and electromagnetic therapy.

By Cullum N, Nelson EA, Flemming K, Sheldon T.

\section{No. 10}

Effects of educational and psychosocial interventions for adolescents with diabetes mellitus: a systematic review.

By Hampson SE, Skinner TC, Hart J, Storey L, Gage H, Foxcroft D, et al.
No. 11

Effectiveness of autologous chondrocyte transplantation for hyaline cartilage defects in knees: a rapid and systematic review.

By Jobanputra P, Parry D, Fry-Smith A, Burls A.

\section{No. 12}

Statistical assessment of the learning curves of health technologies.

By Ramsay CR, Grant AM, Wallace SA, Garthwaite PH, Monk AF, Russell IT.

No. 13

The effectiveness and cost-effectiveness of temozolomide for the treatment of recurrent malignant glioma: a rapid and systematic review.

By Dinnes J, Cave C, Huang S, Major K, Milne R.

No. 14

A rapid and systematic review of the clinical effectiveness and costeffectiveness of debriding agents in treating surgical wounds healing by secondary intention.

By Lewis R, Whiting P, ter Riet G, O'Meara S, Glanville J.

\section{No. 15}

Home treatment for mental health problems: a systematic review.

By Burns T, Knapp M, Catty J, Healey A, Henderson J, Watt $\mathrm{H}$, et al.

No. 16

How to develop cost-conscious guidelines.

By Eccles M, Mason J.

No. 17

The role of specialist nurses in multiple sclerosis: a rapid and systematic review.

By De Broe S, Christopher F, Waugh N.

\section{No. 18}

A rapid and systematic review of the clinical effectiveness and cost-effectiveness of orlistat in the management of obesity.

By O'Meara S, Riemsma R, Shirran L, Mather L, ter Riet G.

No. 19

The clinical effectiveness and costeffectiveness of pioglitazone for type 2 diabetes mellitus: a rapid and systematic review.

By Chilcott J, Wight J, Lloyd Jones M, Tappenden P.

\section{No. 20}

Extended scope of nursing practice: a multicentre randomised controlled trial of appropriately trained nurses and preregistration house officers in preoperative assessment in elective general surgery.

By Kinley H, Czoski-Murray C, George S, McCabe C, Primrose J, Reilly C, et al. 


\section{No. 21}

Systematic reviews of the effectiveness of day care for people with severe mental disorders: (1) Acute day hospital versus admission; (2) Vocational rehabilitation; (3) Day hospital versus outpatient care.

By Marshall M, Crowther R, Almaraz- Serrano A, Creed F, Sledge W, Kluiter $\mathrm{H}$, et al.

\section{No. 22}

The measurement and monitoring of surgical adverse events.

By Bruce J, Russell EM, Mollison J, Krukowski ZH.

\section{No. 23}

Action research: a systematic review and guidance for assessment.

By Waterman H, Tillen D, Dickson R, de Koning $\mathrm{K}$.

\section{No. 24}

A rapid and systematic review of the clinical effectiveness and costeffectiveness of gemcitabine for the treatment of pancreatic cancer.

By Ward S, Morris E, Bansback N, Calvert N, Crellin A, Forman D, et al.

\section{No. 25}

A rapid and systematic review of the evidence for the clinical effectiveness and cost-effectiveness of irinotecan, oxaliplatin and raltitrexed for the treatment of advanced colorectal cancer.

By Lloyd Jones M, Hummel S, Bansback N, Orr B, Seymour M.

\section{No. 26}

Comparison of the effectiveness of inhaler devices in asthma and chronic obstructive airways disease: a systematic review of the literature.

By Brocklebank D, Ram F, Wright J, Barry P, Cates C, Davies L, et al.

\section{No. 27}

The cost-effectiveness of magnetic resonance imaging for investigation of the knee joint.

By Bryan S, Weatherburn G, Bungay H, Hatrick C, Salas C, Parry D, et al.

\section{No. 28}

A rapid and systematic review of the clinical effectiveness and costeffectiveness of topotecan for ovarian cancer.

By Forbes C, Shirran L, Bagnall A-M, Duffy S, ter Riet G.

\section{No. 29}

Superseded by a report published in a later volume.

\section{No. 30}

The role of radiography in primary care patients with low back pain of at least 6 weeks duration: a randomised (unblinded) controlled trial.

By Kendrick D, Fielding K, Bentley E, Miller P, Kerslake R, Pringle M.

\section{No. 31}

Design and use of questionnaires: a review of best practice applicable to surveys of health service staff and patients.

By McColl E, Jacoby A, Thomas L, Soutter J, Bamford C, Steen N, et al.

\section{No. 32}

A rapid and systematic review of the clinical effectiveness and costeffectiveness of paclitaxel, docetaxel, gemcitabine and vinorelbine in nonsmall-cell lung cancer.

By Clegg A, Scott DA, Sidhu M, Hewitson P, Waugh N.

\section{No. 33}

Subgroup analyses in randomised controlled trials: quantifying the risks of false-positives and false-negatives.

By Brookes ST, Whitley E, Peters TJ, Mulheran PA, Egger M, Davey Smith G.

\section{No. 34}

Depot antipsychotic medication in the treatment of patients with schizophrenia: (1) Meta-review; (2) Patient and nurse attitudes.

By David AS, Adams C.

No. 35

A systematic review of controlled trials of the effectiveness and costeffectiveness of brief psychological treatments for depression.

By Churchill R, Hunot V, Corney R, Knapp M, McGuire H, Tylee A, et al.

\section{No. 36}

Cost analysis of child health surveillance.

By Sanderson D, Wright D, Acton C, Duree D.

\section{Volume 6, 2002}

No. 1

A study of the methods used to select review criteria for clinical audit.

By Hearnshaw H, Harker R, Cheater F, Baker R, Grimshaw G.

\section{No. 2}

Fludarabine as second-line therapy for B cell chronic lymphocytic leukaemia: a technology assessment.

By Hyde C, Wake B, Bryan S, Barton P, Fry-Smith A, Davenport C, et al.

No. 3

Rituximab as third-line treatment for refractory or recurrent Stage III or IV follicular non-Hodgkin's lymphoma: a systematic review and economic evaluation.

By Wake B, Hyde C, Bryan S, Barton P, Song F, Fry-Smith A, et al.

No. 4

A systematic review of discharge arrangements for older people.

By Parker SG, Peet SM, McPherson

A, Cannaby AM, Baker R, Wilson A, et al.
No. 5

The clinical effectiveness and costeffectiveness of inhaler devices used in the routine management of chronic asthma in older children: a systematic review and economic evaluation.

By Peters J, Stevenson M, Beverley C, Lim J, Smith S.

No. 6

The clinical effectiveness and costeffectiveness of sibutramine in the management of obesity: a technology assessment

By O’Meara S, Riemsma R, Shirran L, Mather L, ter Riet G.

No. 7

The cost-effectiveness of magnetic resonance angiography for carotid artery stenosis and peripheral vascular disease: a systematic review.

By Berry E, Kelly S, Westwood ME, Davies LM, Gough MJ, Bamford JM, et al.

No. 8

Promoting physical activity in South Asian Muslim women through 'exercise on prescription'.

By Carroll B, Ali N, Azam N.

No. 9

Zanamivir for the treatment of influenza in adults: a systematic review and economic evaluation.

By Burls A, Clark W, Stewart T, Preston C, Bryan S, Jefferson T, et al.

\section{No. 10}

A review of the natural history and epidemiology of multiple sclerosis: implications for resource allocation and health economic models.

By Richards RG, Sampson FC, Beard SM, Tappenden P.

No. 11

Screening for gestational diabetes: a systematic review and economic evaluation.

By Scott DA, Loveman E, McIntyre L, Waugh N.

\section{No. 12}

The clinical effectiveness and costeffectiveness of surgery for people with morbid obesity: a systematic review and economic evaluation.

By Clegg AJ, Colquitt J, Sidhu MK, Royle P, Loveman E, Walker A.

\section{No. 13}

The clinical effectiveness of trastuzumab for breast cancer: a systematic review.

By Lewis R, Bagnall A-M, Forbes C, Shirran E, Duffy S, Kleijnen J, et al.

No. 14

The clinical effectiveness and costeffectiveness of vinorelbine for breast cancer: a systematic review and economic evaluation.

By Lewis R, Bagnall A-M, King S, Woolacott N, Forbes C, Shirran L, et al. 


\section{No. 15}

A systematic review of the effectiveness and cost-effectiveness of metal-onmetal hip resurfacing arthroplasty for treatment of hip disease.

By Vale L, Wyness L, McCormack K, McKenzie L, Brazzelli M, Stearns SC.

\section{No. 16}

The clinical effectiveness and costeffectiveness of bupropion and nicotine replacement therapy for smoking cessation: a systematic review and economic evaluation.

By Woolacott NF, Jones L, Forbes CA, Mather LC, Sowden AJ, Song FJ, et al.

\section{No. 17}

A systematic review of effectiveness and economic evaluation of new drug treatments for juvenile idiopathic arthritis: etanercept.

By Cummins C, Connock M,

Fry-Smith A, Burls A.

\section{No. 18}

Clinical effectiveness and costeffectiveness of growth hormone in children: a systematic review and economic evaluation.

By Bryant J, Cave C, Mihaylova B, Chase D, McIntyre L, Gerard K, et al.

\section{No. 19}

Clinical effectiveness and costeffectiveness of growth hormone in adults in relation to impact on quality of life: a systematic review and economic evaluation.

By Bryant J, Loveman E, Chase D, Mihaylova B, Cave C, Gerard K, et al.

\section{No. 20}

Clinical medication review by a pharmacist of patients on repeat prescriptions in general practice: a randomised controlled trial.

By Zermansky AG, Petty DR, Raynor DK, Lowe CJ, Freementle N, Vail A.

\section{No. 21}

The effectiveness of infliximab and etanercept for the treatment of rheumatoid arthritis: a systematic review and economic evaluation.

By Jobanputra P, Barton P, Bryan S, Burls A.

\section{No. 22}

A systematic review and economic evaluation of computerised cognitive behaviour therapy for depression and anxiety.

By Kaltenthaler E, Shackley P, Stevens K, Beverley C, Parry G, Chilcott $\mathrm{J}$.

\section{No. 23}

A systematic review and economic evaluation of pegylated liposomal doxorubicin hydrochloride for ovarian cancer.

By Forbes C, Wilby J, Richardson G,
No. 24

A systematic review of the effectiveness of interventions based on a stages-ofchange approach to promote individual behaviour change.

By Riemsma RP, Pattenden J, Bridle C, Sowden AJ, Mather L, Watt IS, et al.

No. 25

A systematic review update of the clinical effectiveness and costeffectiveness of glycoprotein IIb/IIIa antagonists.

By Robinson M, Ginnelly L, Sculpher M, Jones L, Riemsma R, Palmer S, et al.

\section{No. 26}

A systematic review of the effectiveness, cost-effectiveness and barriers to implementation of thrombolytic and neuroprotective therapy for acute ischaemic stroke in the NHS.

By Sandercock P, Berge E, Dennis M, Forbes J, Hand P, Kwan J, et al.

No. 27

A randomised controlled crossover trial of nurse practitioner versus doctor-

led outpatient care in a bronchiectasis clinic.

By Caine N, Sharples LD,

Hollingworth W, French J, Keogan M, Exley A, et al.

\section{No. 28}

Clinical effectiveness and cost consequences of selective serotonin reuptake inhibitors in the treatment of sex offenders.

By Adi Y, Ashcroft D, Browne K, Beech A, Fry-Smith A, Hyde C.

\section{No. 29}

Treatment of established osteoporosis: a systematic review and cost-utility analysis.

By Kanis JA, Brazier JE, Stevenson M, Calvert NW, Lloyd Jones M.

No. 30

Which anaesthetic agents are costeffective in day surgery? Literature review, national survey of practice and randomised controlled trial.

By Elliott RA Payne K, Moore JK, Davies LM, Harper NJN, St Leger AS, et al.

\section{No. 31}

Screening for hepatitis C among injecting drug users and in genitourinary medicine clinics: systematic reviews of effectiveness, modelling study and national survey of current practice.

By Stein K, Dalziel K, Walker A McIntyre L, Jenkins B, Horne J, et al.

\section{No. 32}

The measurement of satisfaction with healthcare: implications for practice from a systematic review of the literature.

By Crow R, Gage H, Hampson S, Hart J, Kimber A, Storey L, et al.
No. 33

The effectiveness and cost-effectiveness of imatinib in chronic myeloid leukaemia: a systematic review. By Garside R, Round A, Dalziel K, Stein K, Royle R.

No. 34

A comparative study of hypertonic saline, daily and alternate-day rhDNase in children with cystic fibrosis.

By Suri R, Wallis C, Bush A,

Thompson S, Normand C, Flather M, et al.

No. 35

A systematic review of the costs and effectiveness of different models of paediatric home care.

By Parker G, Bhakta P, Lovett CA Paisley S, Olsen R, Turner D, et al.

\section{Volume 7, 2003}

No. 1

How important are comprehensive literature searches and the assessment of trial quality in systematic reviews? Empirical study.

By Egger M, Jüni P, Bartlett C, Holenstein F, Sterne J.

No. 2

Systematic review of the effectiveness and cost-effectiveness, and economic evaluation, of home versus hospital or satellite unit haemodialysis for people with end-stage renal failure.

By Mowatt G, Vale L, Perez J, Wyness L, Fraser C, MacLeod A, et al.

No. 3

Systematic review and economic evaluation of the effectiveness of infliximab for the treatment of Crohn's disease.

By Clark W, Raftery J, Barton P, Song F, Fry-Smith A, Burls A.

No. 4

A review of the clinical effectiveness and cost-effectiveness of routine anti-D prophylaxis for pregnant women who are rhesus negative.

By Chilcott J, Lloyd Jones M, Wight J, Forman K, Wray J, Beverley C, et al.

No. 5

Systematic review and evaluation of the use of tumour markers in paediatric oncology: Ewing's sarcoma and neuroblastoma.

By Riley RD, Burchill SA, Abrams KR, Heney D, Lambert PC, Jones DR, et al.

No. 6

The cost-effectiveness of screening for Helicobacter pylori to reduce mortality and morbidity from gastric cancer and peptic ulcer disease: a discrete-event simulation model.

By Roderick P, Davies R, Raftery J, Crabbe D, Pearce R, Bhandari P, et al. 
No. 7

The clinical effectiveness and costeffectiveness of routine dental checks: a systematic review and economic evaluation.

By Davenport C, Elley K, Salas C, Taylor-Weetman CL, Fry-Smith A, Bryan $\mathrm{S}$, et al.

\section{No. 8}

A multicentre randomised controlled trial assessing the costs and benefits of using structured information and analysis of women's preferences in the management of menorrhagia.

By Kennedy ADM, Sculpher MJ, Coulter A, Dwyer N, Rees M, Horsley S, et al.

\section{No. 9}

Clinical effectiveness and cost-utility of photodynamic therapy for wet age-related macular degeneration: a systematic review and economic evaluation.

By Meads C, Salas C, Roberts T, Moore D, Fry-Smith A, Hyde C.

\section{No. 10}

Evaluation of molecular tests for prenatal diagnosis of chromosome abnormalities.

By Grimshaw GM, Szczepura A, Hultén M, MacDonald F, Nevin NC, Sutton F, et al.

\section{No. 11}

First and second trimester antenatal screening for Down's syndrome: the results of the Serum, Urine and Ultrasound Screening Study (SURUSS).

By Wald NJ, Rodeck C, Hackshaw AK, Walters J, Chitty L, Mackinson AM.

No. 12

The effectiveness and cost-effectiveness of ultrasound locating devices for central venous access: a systematic review and economic evaluation.

By Calvert N, Hind D, McWilliams RG, Thomas SM, Beverley C, Davidson A.

No. 13

A systematic review of atypical antipsychotics in schizophrenia.

By Bagnall A-M, Jones L, Lewis R, Ginnelly L, Glanville J, Torgerson D, et al.

No. 14

Prostate Testing for Cancer and Treatment (ProtecT) feasibility study. By Donovan J, Hamdy F, Neal D, Peters T, Oliver S, Brindle L, et al.

\section{No. 15}

Early thrombolysis for the treatment of acute myocardial infarction: a systematic review and economic evaluation.

By Boland A, Dundar Y, Bagust A, Haycox A, Hill R, Mujica Mota R, et al.

\section{No. 16}

Screening for fragile X syndrome: a literature review and modelling.

By Song FJ, Barton P, Sleightholme V, Yao GL, Fry-Smith A

\section{No. 17}

Systematic review of endoscopic sinus surgery for nasal polyps.

By Dalziel K, Stein K, Round A, Garside R, Royle P.

\section{No. 18}

Towards efficient guidelines: how to monitor guideline use in primary care. By Hutchinson A, McIntosh A, Cox S, Gilbert C.

\section{No. 19}

Effectiveness and cost-effectiveness of acute hospital-based spinal cord injuries services: systematic review.

By Bagnall A-M, Jones L, Richardson G, Duffy S, Riemsma R.

No. 20

Prioritisation of health technology assessment. The PATHS model: methods and case studies.

By Townsend J, Buxton M, Harper G.

\section{No. 21}

Systematic review of the clinical effectiveness and cost-effectiveness of tension-free vaginal tape for treatment of urinary stress incontinence.

By Cody J, Wyness L, Wallace S, Glazener C, Kilonzo M, Stearns S, et al.

No. 22

The clinical and cost-effectiveness of patient education models for diabetes: a systematic review and economic evaluation.

By Loveman E, Cave C, Green C, Royle P, Dunn N, Waugh N.

No. 23

The role of modelling in prioritising and planning clinical trials.

By Chilcott J, Brennan A, Booth A, Karnon J, Tappenden P.

\section{No. 24}

Cost-benefit evaluation of routine influenza immunisation in people 65-74 years of age.

By Allsup S, Gosney M, Haycox A, Regan M.

\section{No. 25}

The clinical and cost-effectiveness of pulsatile machine perfusion versus cold storage of kidneys for transplantation retrieved from heart-beating and nonheart-beating donors.

By Wight J, Chilcott J, Holmes M, Brewer N

\section{No. 26}

Can randomised trials rely on existing electronic data? A feasibility study to explore the value of routine data in health technology assessment.

By Williams JG, Cheung WY,

Cohen DR, Hutchings HA, Longo MF, Russell IT.

\section{No. 27}

Evaluating non-randomised intervention studies.

By Deeks JJ, Dinnes J, D’Amico R, Sowden AJ, Sakarovitch C, Song F, et al.

No. 28

A randomised controlled trial to assess the impact of a package comprising a patient-orientated, evidence-based selfhelp guidebook and patient-centred consultations on disease management and satisfaction in inflammatory bowel disease.

By Kennedy A, Nelson E, Reeves D, Richardson G, Roberts C, Robinson A, et al.

\section{No. 29}

The effectiveness of diagnostic tests for the assessment of shoulder pain due to soft tissue disorders: a systematic review.

By Dinnes J, Loveman E, McIntyre L, Waugh N.

No. 30

The value of digital imaging in diabetic retinopathy.

By Sharp PF, Olson J, Strachan F, Hipwell J, Ludbrook A, O’Donnell M, et al.

No. 31

Lowering blood pressure to prevent myocardial infarction and stroke: a new preventive strategy.

By Law M, Wald N, Morris J.

No. 32

Clinical and cost-effectiveness of capecitabine and tegafur with uracil for the treatment of metastatic colorectal cancer: systematic review and economic evaluation.

By Ward S, Kaltenthaler E, Cowan J, Brewer N

No. 33

Clinical and cost-effectiveness of new and emerging technologies for early localised prostate cancer: a systematic review.

By Hummel S, Paisley S, Morgan A, Currie E, Brewer N.

\section{No. 34}

Literature searching for clinical and cost-effectiveness studies used in health technology assessment reports carried out for the National Institute for Clinical Excellence appraisal system. By Royle P, Waugh N. 
No. 35

Systematic review and economic decision modelling for the prevention and treatment of influenza A and B.

By Turner D, Wailoo A, Nicholson K, Cooper N, Sutton A, Abrams K.

\section{No. 36}

A randomised controlled trial to evaluate the clinical and costeffectiveness of Hickman line insertions in adult cancer patients by nurses.

By Boland A, Haycox A, Bagust A, Fitzsimmons L.

\section{No. 37}

Redesigning postnatal care: a randomised controlled trial of protocolbased midwifery-led care focused on individual women's physical and psychological health needs.

By MacArthur C, Winter HR, Bick DE, Lilford RJ, Lancashire RJ, Knowles $\mathrm{H}$, et al.

\section{No. 38}

Estimating implied rates of discount in healthcare decision-making.

By West RR, McNabb R, Thompson AGH, Sheldon TA, Grimley Evans J.

\section{No. 39}

Systematic review of isolation policies in the hospital management of methicillin-resistant Staphylococcus aureus: a review of the literature with epidemiological and economic modelling.

By Cooper BS, Stone SP, Kibbler CC, Cookson BD, Roberts JA, Medley GF, et al.

\section{No. 40}

Treatments for spasticity and pain in multiple sclerosis: a systematic review. By Beard S, Hunn A, Wight J.

\section{No. 41}

The inclusion of reports of randomised trials published in languages other than English in systematic reviews.

By Moher D, Pham B, Lawson ML, Klassen TP.

\section{No. 42}

The impact of screening on future health-promoting behaviours and health beliefs: a systematic review.

By Bankhead CR, Brett J, Bukach C, Webster P, Stewart-Brown S, Munafo M, et al.

\section{Volume 8, 2004}

\section{No. 1}

What is the best imaging strategy for acute stroke?

By Wardlaw JM, Keir SL, Seymour J,
No. 2

Systematic review and modelling of the investigation of acute and chronic chest pain presenting in primary care.

By Mant J, McManus RJ, Oakes RAL, Delaney BC, Barton PM, Deeks JJ, et al.

\section{No. 3}

The effectiveness and cost-effectiveness of microwave and thermal balloon endometrial ablation for heavy menstrual bleeding: a systematic review and economic modelling.

By Garside R, Stein K, Wyatt K, Round A, Price A.

No. 4

A systematic review of the role of bisphosphonates in metastatic disease. By Ross JR, Saunders Y,

Edmonds PM, Patel S, Wonderling D, Normand C, et al.

No. 5

Systematic review of the clinical effectiveness and cost-effectiveness of capecitabine (Xeloda ${ }^{\star}$ ) for locally advanced and/or metastatic breast cancer.

By Jones L, Hawkins N, Westwood M, Wright K, Richardson G, Riemsma R.

No. 6

Effectiveness and efficiency of guideline dissemination and implementation strategies.

By Grimshaw JM, Thomas RE, MacLennan G, Fraser C, Ramsay CR, Vale L, et al.

No. 7

Clinical effectiveness and costs of the Sugarbaker procedure for the treatment of pseudomyxoma peritonei.

By Bryant J, Clegg AJ, Sidhu MK, Brodin H, Royle P, Davidson P.

No. 8

Psychological treatment for insomnia in the regulation of long-term hypnotic drug use.

By Morgan K, Dixon S, Mathers N, Thompson J, Tomeny M.

\section{No. 9}

Improving the evaluation of therapeutic interventions in multiple sclerosis: development of a patientbased measure of outcome.

By Hobart JC, Riazi A, Lamping DL, Fitzpatrick R, Thompson AJ.

\section{No. 10}

A systematic review and economic evaluation of magnetic resonance cholangiopancreatography compared with diagnostic endoscopic retrograde cholangiopancreatography.

By Kaltenthaler E, Bravo Vergel Y, Chilcott J, Thomas S, Blakeborough T, Walters SJ, et al.

\section{No. 11}

The use of modelling to evaluate new drugs for patients with a chronic condition: the case of antibodies against tumour necrosis factor in rheumatoid arthritis.

By Barton P, Jobanputra P, Wilson J, Bryan S, Burls A.

No. 12

Clinical effectiveness and costeffectiveness of neonatal screening for inborn errors of metabolism using tandem mass spectrometry: a systematic review.

By Pandor A, Eastham J, Beverley C, Chilcott J, Paisley S.

No. 13

Clinical effectiveness and costeffectiveness of pioglitazone and rosiglitazone in the treatment of type 2 diabetes: a systematic review and economic evaluation.

By Czoski-Murray C, Warren E, Chilcott J, Beverley C, Psyllaki MA, Cowan J.

\section{No. 14}

Routine examination of the newborn: the EMREN study. Evaluation of an extension of the midwife role including a randomised controlled trial of appropriately trained midwives and paediatric senior house officers.

By Townsend J, Wolke D, Hayes J, Davé S, Rogers C, Bloomfield L, et al.

No. 15

Involving consumers in research and development agenda setting for the NHS: developing an evidence-based approach.

By Oliver S, Clarke-Jones L, Rees R, Milne R, Buchanan P, Gabbay J, et al.

No. 16

A multi-centre randomised controlled trial of minimally invasive direct coronary bypass grafting versus percutaneous transluminal coronary angioplasty with stenting for proximal stenosis of the left anterior descending coronary artery.

By Reeves BC, Angelini GD, Bryan AJ, Taylor FC, Cripps T, Spyt TJ, et al.

\section{No. 17}

Does early magnetic resonance imaging influence management or improve outcome in patients referred to secondary care with low back pain? A pragmatic randomised controlled trial.

By Gilbert FJ, Grant AM, Gillan MGC, Vale L, Scott NW, Campbell MK, et al.

\section{No. 18}

The clinical and cost-effectiveness of anakinra for the treatment of rheumatoid arthritis in adults: a systematic review and economic analysis.

By Clark W, Jobanputra P, Barton P, Burls A. 


\section{No. 19}

A rapid and systematic review and economic evaluation of the clinical and cost-effectiveness of newer drugs for treatment of mania associated with bipolar affective disorder.

By Bridle C, Palmer S, Bagnall A-M, Darba J, Duffy S, Sculpher M, et al.

\section{No. 20}

Liquid-based cytology in cervical screening: an updated rapid and systematic review and economic analysis.

By Karnon J, Peters J, Platt J, Chilcott J, McGoogan E, Brewer N.

\section{No. 21}

Systematic review of the long-term effects and economic consequences of treatments for obesity and implications for health improvement.

By Avenell A, Broom J, Brown TJ, Poobalan A, Aucott L, Stearns SC, et al.

\section{No. 22}

Autoantibody testing in children with newly diagnosed type 1 diabetes mellitus.

By Dretzke J, Cummins C, Sandercock J, Fry-Smith A, Barrett T, Burls A.

No. 23

Clinical effectiveness and costeffectiveness of prehospital intravenous fluids in trauma patients.

By Dretzke J, Sandercock J, Bayliss S, Burls A.

\section{No. 24}

Newer hypnotic drugs for the shortterm management of insomnia: a systematic review and economic evaluation.

By Dündar Y, Boland A, Strobl J, Dodd S, Haycox A, Bagust A, et al.

\section{No. 25}

Development and validation of methods for assessing the quality of diagnostic accuracy studies.

By Whiting P, Rutjes AWS, Dinnes J, Reitsma JB, Bossuyt PMM, Kleijnen J.

\section{No. 26}

EVALUATE hysterectomy trial: a multicentre randomised trial comparing abdominal, vaginal and laparoscopic methods of hysterectomy. By Garry R, Fountain J, Brown J,

Manca A, Mason S, Sculpher M, et al.

\section{No. 27}

Methods for expected value of information analysis in complex health economic models: developments on the health economics of interferon- $\beta$ and glatiramer acetate for multiple sclerosis.

By Tappenden P, Chilcott JB, Eggington S, Oakley J, McCabe C.

\section{No. 28}

Effectiveness and cost-effectiveness of imatinib for first-line treatment of chronic myeloid leukaemia in chronic phase: a systematic review and economic analysis.

By Dalziel K, Round A, Stein K, Garside R, Price A.

\section{No. 29}

VenUS I: a randomised controlled trial of two types of bandage for treating venous leg ulcers.

By Iglesias C, Nelson EA, Cullum NA, Torgerson DJ, on behalf of the VenUS Team.

\section{No. 30}

Systematic review of the effectiveness and cost-effectiveness, and economic evaluation, of myocardial perfusion scintigraphy for the diagnosis and management of angina and myocardial infarction.

By Mowatt G, Vale L, Brazzelli M, Hernandez R, Murray A, Scott N, et al.

\section{No. 31}

A pilot study on the use of decision theory and value of information analysis as part of the NHS Health Technology Assessment programme.

By Claxton K, Ginnelly L, Sculpher M, Philips Z, Palmer S.

\section{No. 32}

The Social Support and Family Health Study: a randomised controlled trial and economic evaluation of two alternative forms of postnatal support for mothers living in disadvantaged inner-city areas.

By Wiggins M, Oakley A, Roberts I, Turner H, Rajan L, Austerberry H, et al.

\section{No. 33}

Psychosocial aspects of genetic screening of pregnant women and newborns: a systematic review.

By Green JM, Hewison J, Bekker HL, Bryant, Cuckle HS.

\section{No. 34}

Evaluation of abnormal uterine bleeding: comparison of three outpatient procedures within cohorts defined by age and menopausal status.

By Critchley HOD, Warner P, Lee AJ, Brechin S, Guise J, Graham B.

\section{No. 35}

Coronary artery stents: a rapid systematic review and economic evaluation.

By Hill R, Bagust A, Bakhai A, Dickson R, Dündar Y, Haycox A, et al.

\section{No. 36}

Review of guidelines for good practice in decision-analytic modelling in health technology assessment.

By Philips Z, Ginnelly L, Sculpher M, Claxton K, Golder S, Riemsma R, et al.

\section{No. 37}

Rituximab (MabThera ${ }^{\circledR}$ for aggressive non-Hodgkin's lymphoma: systematic review and economic evaluation.

By Knight C, Hind D, Brewer N, Abbott V.

\section{No. 38}

Clinical effectiveness and costeffectiveness of clopidogrel and modified-release dipyridamole in the secondary prevention of occlusive vascular events: a systematic review and economic evaluation.

By Jones L, Griffin S, Palmer S, Main C, Orton V, Sculpher M, et al.

\section{No. 39}

Pegylated interferon $\alpha-2 a$ and $-2 b$ in combination with ribavirin in the treatment of chronic hepatitis C: a systematic review and economic evaluation.

By Shepherd J, Brodin H, Cave C, Waugh N, Price A, Gabbay J.

\section{No. 40}

Clopidogrel used in combination with aspirin compared with aspirin alone in the treatment of non-ST-segmentelevation acute coronary syndromes: a systematic review and economic evaluation.

By Main C, Palmer S, Griffin S, Jones L, Orton V, Sculpher M, et al.

\section{No. 41}

Provision, uptake and cost of cardiac rehabilitation programmes: improving services to under-represented groups.

By Beswick AD, Rees K, Griebsch I, Taylor FC, Burke M, West RR, et al.

No. 42

Involving South Asian patients in clinical trials.

By Hussain-Gambles M, Leese B, Atkin K, Brown J, Mason S, Tovey P.

No. 43

Clinical and cost-effectiveness of continuous subcutaneous insulin infusion for diabetes.

By Colquitt JL, Green C, Sidhu MK, Hartwell D, Waugh N.

\section{No. 44}

Identification and assessment of ongoing trials in health technology assessment reviews.

By Song FJ, Fry-Smith A, Davenport C, Bayliss S, Adi Y, Wilson JS, et al.

\section{No. 45}

Systematic review and economic evaluation of a long-acting insulin analogue, insulin glargine

By Warren E, Weatherley-Jones E, Chilcott J, Beverley C. 


\section{No. 46}

Supplementation of a home-based exercise programme with a classbased programme for people with osteoarthritis of the knees: a randomised controlled trial and health economic analysis.

By McCarthy CJ, Mills PM, Pullen R, Richardson G, Hawkins N, Roberts CR, et al.

\section{No. 47}

Clinical and cost-effectiveness of oncedaily versus more frequent use of same potency topical corticosteroids for atopic eczema: a systematic review and economic evaluation.

By Green C, Colquitt JL, Kirby J, Davidson P, Payne E.

\section{No. 48}

Acupuncture of chronic headache disorders in primary care: randomised controlled trial and economic analysis.

By Vickers AJ, Rees RW, Zollman CE, McCarney R, Smith CM, Ellis N, et al.

\section{No. 49}

Generalisability in economic evaluation studies in healthcare: a review and case studies.

By Sculpher MJ, Pang FS, Manca A, Drummond MF, Golder S, Urdahl H, et al.

\section{No. 50}

Virtual outreach: a randomised controlled trial and economic evaluation of joint teleconferenced medical consultations.

By Wallace P, Barber J, Clayton W, Currell R, Fleming K, Garner P, et al.

\section{Volume 9, 2005}

No. 1

Randomised controlled multiple treatment comparison to provide a costeffectiveness rationale for the selection of antimicrobial therapy in acne.

By Ozolins M, Eady EA, Avery A, Cunliffe WJ, O'Neill C, Simpson NB, et al.

\section{No. 2}

Do the findings of case series studies vary significantly according to methodological characteristics?

By Dalziel K, Round A, Stein K, Garside R, Castelnuovo E, Payne L.

\section{No. 3}

Improving the referral process for familial breast cancer genetic counselling: findings of three randomised controlled trials of two interventions.

By Wilson BJ, Torrance N, Mollison J, Wordsworth S, Gray JR,
No. 4

Randomised evaluation of alternative electrosurgical modalities to treat bladder outflow obstruction in men with benign prostatic hyperplasia.

By Fowler C, McAllister W, Plail R, Karim O, Yang Q.

No. 5

A pragmatic randomised controlled trial of the cost-effectiveness of palliative therapies for patients with inoperable oesophageal cancer.

By Shenfine J, McNamee P, Steen N, Bond J, Griffin SM.

\section{No. 6}

Impact of computer-aided detection prompts on the sensitivity and specificity of screening mammography. By Taylor P, Champness J, GivenWilson R, Johnston K, Potts H.

\section{No. 7}

Issues in data monitoring and interim analysis of trials.

By Grant AM, Altman DG, Babiker $\mathrm{AB}$, Campbell MK, Clemens FJ, Darbyshire JH, et al.

\section{No. 8}

Lay public's understanding of equipoise and randomisation in randomised controlled trials.

By Robinson EJ, Kerr CEP, Stevens AJ, Lilford RJ, Braunholtz DA, Edwards SJ, et al.

\section{No. 9}

Clinical and cost-effectiveness of electroconvulsive therapy for depressive illness, schizophrenia, catatonia and mania: systematic reviews and economic modelling studies.

By Greenhalgh J, Knight C, Hind D, Beverley C, Walters S.

\section{No. 10}

Measurement of health-related quality of life for people with dementia: development of a new instrument (DEMQOL) and an evaluation of current methodology.

By Smith SC, Lamping DL, Banerjee S, Harwood R, Foley B, Smith P, et al.

\section{No. 11}

Clinical effectiveness and costeffectiveness of drotrecogin alfa (activated) (Xigris ${ }^{\star}$ ) for the treatment of severe sepsis in adults: a systematic review and economic evaluation.

By Green C, Dinnes J, Takeda A, Shepherd J, Hartwell D, Cave C, et al.

\section{No. 12}

A methodological review of how heterogeneity has been examined in systematic reviews of diagnostic test accuracy.

By Dinnes J, Deeks J, Kirby J, Roderick P.
No. 13

Cervical screening programmes: can automation help? Evidence from systematic reviews, an economic analysis and a simulation modelling exercise applied to the UK.

By Willis BH, Barton P, Pearmain P, Bryan S, Hyde C.

\section{No. 14}

Laparoscopic surgery for inguinal hernia repair: systematic review of effectiveness and economic evaluation. By McCormack K, Wake B, Perez J, Fraser C, Cook J, McIntosh E, et al.

No. 15

Clinical effectiveness, tolerability and cost-effectiveness of newer drugs for epilepsy in adults: a systematic review and economic evaluation.

By Wilby J, Kainth A, Hawkins N, Epstein D, McIntosh H, McDaid C, et al.

No. 16

A randomised controlled trial to compare the cost-effectiveness of tricyclic antidepressants, selective serotonin reuptake inhibitors and lofepramine.

By Peveler R, Kendrick T, Buxton M, Longworth L, Baldwin D, Moore M, et al.

\section{No. 17}

Clinical effectiveness and costeffectiveness of immediate angioplasty for acute myocardial infarction: systematic review and economic evaluation.

By Hartwell D, Colquitt J, Loveman E, Clegg AJ, Brodin H, Waugh N, et al.

\section{No. 18}

A randomised controlled comparison of alternative strategies in stroke care.

By Kalra L, Evans A, Perez I,

Knapp M, Swift C, Donaldson N.

No. 19

The investigation and analysis of critical incidents and adverse events in healthcare.

By Woloshynowych M, Rogers S, Taylor-Adams S, Vincent C.

\section{No. 20}

Potential use of routine databases in health technology assessment.

By Raftery J, Roderick P, Stevens A.

\section{No. 21}

Clinical and cost-effectiveness of newer immunosuppressive regimens in renal transplantation: a systematic review and modelling study.

By Woodroffe R, Yao GL, Meads C, Bayliss S, Ready A, Raftery J, et al.

\section{No. 22}

A systematic review and economic evaluation of alendronate, etidronate, risedronate, raloxifene and teriparatide for the prevention and treatment of postmenopausal osteoporosis.

By Stevenson M, Lloyd Jones M, De Nigris E, Brewer N, Davis S, Oakley J. 


\section{No. 23}

A systematic review to examine the impact of psycho-educational interventions on health outcomes and costs in adults and children with difficult asthma.

By Smith JR, Mugford M, Holland R, Candy B, Noble MJ, Harrison BDW, et al.

\section{No. 24}

An evaluation of the costs, effectiveness and quality of renal replacement therapy provision in renal satellite units in England and Wales.

By Roderick P, Nicholson T, Armitage A, Mehta R, Mullee M, Gerard K, et al.

\section{No. 25}

Imatinib for the treatment of patients with unresectable and/or metastatic gastrointestinal stromal tumours: systematic review and economic evaluation.

By Wilson J, Connock M, Song F, Yao G, Fry-Smith A, Raftery J, et al.

\section{No. 26}

Indirect comparisons of competing interventions.

By Glenny AM, Altman DG, Song F, Sakarovitch C, Deeks JJ, D’Amico R, et al.

\section{No. 27}

Cost-effectiveness of alternative strategies for the initial medical management of non-ST elevation acute coronary syndrome: systematic review and decision-analytical modelling.

By Robinson M, Palmer S, Sculpher M, Philips Z, Ginnelly L, Bowens A, et al.

\section{No. 28}

Outcomes of electrically stimulated gracilis neosphincter surgery.

By Tillin T, Chambers M, Feldman R.

\section{No. 29}

The effectiveness and cost-effectiveness of pimecrolimus and tacrolimus for atopic eczema: a systematic review and economic evaluation.

By Garside R, Stein K, Castelnuovo E, Pitt M, Ashcroft D, Dimmock P, et al.

\section{No. 30}

Systematic review on urine albumin testing for early detection of diabetic complications.

By Newman DJ, Mattock MB, Dawnay ABS, Kerry S, McGuire A, Yaqoob M, et al.

No. 31

Randomised controlled trial of the costeffectiveness of water-based therapy for lower limb osteoarthritis.

By Cochrane T, Davey RC, Matthes Edwards SM.

\section{No. 32}

Longer term clinical and economic benefits of offering acupuncture care to patients with chronic low back pain.

By Thomas KJ, MacPherson H, Ratcliffe J, Thorpe L, Brazier J, Campbell $\mathrm{M}$, et al.

\section{No. 33}

Cost-effectiveness and safety of epidural steroids in the management of sciatica.

By Price C, Arden N, Coglan L, Rogers P.

\section{No. 34}

The British Rheumatoid Outcome Study Group (BROSG) randomised controlled trial to compare the effectiveness and cost-effectiveness of aggressive versus symptomatic therapy in established rheumatoid arthritis.

By Symmons D, Tricker K, Roberts C, Davies L, Dawes P, Scott DL.

\section{No. 35}

Conceptual framework and systematic review of the effects of participants' and professionals' preferences in randomised controlled trials.

By King M, Nazareth I, Lampe F, Bower P, Chandler M, Morou M, et al.

\section{No. 36}

The clinical and cost-effectiveness of implantable cardioverter defibrillators: a systematic review.

By Bryant J, Brodin H, Loveman E, Payne E, Clegg A.

\section{No. 37}

A trial of problem-solving by community mental health nurses for anxiety, depression and life difficulties among general practice patients. The CPN-GP study.

By Kendrick T, Simons L, Mynors-Wallis L, Gray A, Lathlean J, Pickering $\mathrm{R}$, et al.

\section{No. 38}

The causes and effects of sociodemographic exclusions from clinical trials.

By Bartlett C, Doyal L, Ebrahim S, Davey P, Bachmann M, Egger M, et al.

\section{No. 39}

Is hydrotherapy cost-effective? A randomised controlled trial of combined hydrotherapy programmes compared with physiotherapy land techniques in children with juvenile idiopathic arthritis.

By Epps H, Ginnelly L, Utley M, Southwood T, Gallivan S, Sculpher M, et al.

\section{No. 40}

A randomised controlled trial and cost-effectiveness study of systematic screening (targeted and total population screening) versus routine practice for the detection of atrial fibrillation in people aged 65 and over. The SAFE study.

By Hobbs FDR, Fitzmaurice DA, Mant J, Murray E, Jowett S, Bryan S, et al.

\section{No. 41}

Displaced intracapsular hip fractures in fit, older people: a randomised comparison of reduction and fixation, bipolar hemiarthroplasty and total hip arthroplasty.

By Keating JF, Grant A, Masson M, Scott NW, Forbes JF.

\section{No. 42}

Long-term outcome of cognitive behaviour therapy clinical trials in central Scotland.

By Durham RC, Chambers JA, Power KG, Sharp DM, Macdonald RR, Major KA, et al.

\section{No. 43}

The effectiveness and cost-effectiveness of dual-chamber pacemakers compared with single-chamber pacemakers for bradycardia due to atrioventricular block or sick sinus syndrome: systematic review and economic evaluation.

By Castelnuovo E, Stein K, Pitt M, Garside R, Payne E.

\section{No. 44}

Newborn screening for congenital heart defects: a systematic review and costeffectiveness analysis.

By Knowles R, Griebsch I, Dezateux C, Brown J, Bull C, Wren C.

\section{No. 45}

The clinical and cost-effectiveness of left ventricular assist devices for endstage heart failure: a systematic review and economic evaluation.

By Clegg AJ, Scott DA, Loveman E, Colquitt J, Hutchinson J, Royle P, et al.

\section{No. 46}

The effectiveness of the Heidelberg Retina Tomograph and laser diagnostic glaucoma scanning system (GDx) in detecting and monitoring glaucoma. By Kwartz AJ, Henson DB, Harper RA, Spencer AF, McLeod D.

\section{No. 47}

Clinical and cost-effectiveness of autologous chondrocyte implantation for cartilage defects in knee joints: systematic review and economic evaluation.

By Clar C, Cummins E, McIntyre L, Thomas S, Lamb J, Bain L, et al. 


\section{No. 48}

Systematic review of effectiveness of different treatments for childhood retinoblastoma.

By McDaid C, Hartley S, Bagnall A-M, Ritchie G, Light K, Riemsma R.

\section{No. 49}

Towards evidence-based guidelines for the prevention of venous thromboembolism: systematic reviews of mechanical methods, oral anticoagulation, dextran and regional anaesthesia as thromboprophylaxis.

By Roderick P, Ferris G, Wilson K, Halls H, Jackson D, Collins R, et al.

\section{No. 50}

The effectiveness and cost-effectiveness of parent training/education programmes for the treatment of conduct disorder, including oppositional defiant disorder, in children.

By Dretzke J, Frew E, Davenport C, Barlow J, Stewart-Brown S, Sandercock J, et al.

\section{Volume 10, 2006}

No. 1

The clinical and cost-effectiveness of donepezil, rivastigmine, galantamine and memantine for Alzheimer's disease.

By Loveman E, Green C, Kirby J, Takeda A, Picot J, Payne E, et al.

\section{No. 2}

FOOD: a multicentre randomised trial evaluating feeding policies in patients admitted to hospital with a recent stroke.

By Dennis M, Lewis S, Cranswick G, Forbes J.

No. 3

The clinical effectiveness and costeffectiveness of computed tomography screening for lung cancer: systematic reviews.

By Black C, Bagust A, Boland A, Walker S, McLeod C, De Verteuil R, et al.

No. 4

A systematic review of the effectiveness and cost-effectiveness of neuroimaging assessments used to visualise the seizure focus in people with refractory epilepsy being considered for surgery.

By Whiting P, Gupta R, Burch J, Mujica Mota RE, Wright K, Marson A, et al.

No. 5

Comparison of conference abstracts and presentations with full-text articles in the health technology assessments of rapidly evolving technologies.

By Dundar Y, Dodd S, Dickson R,

\section{No. 6}

Systematic review and evaluation of methods of assessing urinary incontinence.

By Martin JL, Williams KS, Abrams KR, Turner DA, Sutton AJ, Chapple C, et al.

No. 7

The clinical effectiveness and costeffectiveness of newer drugs for children with epilepsy. A systematic review.

By Connock M, Frew E, Evans B-W, Bryan S, Cummins C, Fry-Smith A, et al.

\section{No. 8}

Surveillance of Barrett's oesophagus: exploring the uncertainty through systematic review, expert workshop and economic modelling.

By Garside R, Pitt M, Somerville M, Stein K, Price A, Gilbert N.

\section{No. 9}

Topotecan, pegylated liposomal doxorubicin hydrochloride and paclitaxel for second-line or subsequent treatment of advanced ovarian cancer: a systematic review and economic evaluation.

By Main C, Bojke L, Griffin S, Norman G, Barbieri M, Mather L, et al.

\section{No. 10}

Evaluation of molecular techniques in prediction and diagnosis of cytomegalovirus disease in immunocompromised patients.

By Szczepura A, Westmoreland D, Vinogradova Y, Fox J, Clark M.

\section{No. 11}

Screening for thrombophilia in highrisk situations: systematic review and cost-effectiveness analysis. The Thrombosis: Risk and Economic Assessment of Thrombophilia Screening (TREATS) study. By Wu O, Robertson L, Twaddle S, Lowe GDO, Clark P, Greaves M, et al.

No. 12

A series of systematic reviews to inform a decision analysis for sampling and treating infected diabetic foot ulcers By Nelson EA, O'Meara S, Craig D, Iglesias C, Golder S, Dalton J, et al.

\section{No. 13}

Randomised clinical trial, observational study and assessment of costeffectiveness of the treatment of varicose veins (REACTIV trial)

By Michaels JA, Campbell WB, Brazier JE, MacIntyre JB, Palfreyman SJ, Ratcliffe J, et al.

\section{No. 14}

The cost-effectiveness of screening for oral cancer in primary care.

By Speight PM, Palmer S, Moles DR, Downer MC, Smith DH, Henriksson M, et al.

\section{No. 15}

Measurement of the clinical and costeffectiveness of non-invasive diagnostic testing strategies for deep vein thrombosis.

By Goodacre S, Sampson F, Stevenson M, Wailoo A, Sutton A, Thomas $\mathrm{S}$, et al.

No. 16

Systematic review of the effectiveness and cost-effectiveness of HealOzone for the treatment of occlusal pit/fissure caries and root caries.

By Brazzelli M, McKenzie L, Fielding $\mathrm{S}$, Fraser C, Clarkson J, Kilonzo M, et al.

No. 17

Randomised controlled trials of conventional antipsychotic versus new atypical drugs, and new atypical drugs versus clozapine, in people with schizophrenia responding poorly to, or intolerant of, current drug treatment.

By Lewis SW, Davies L, Jones PB, Barnes TRE, Murray RM, Kerwin R, et al.

\section{No. 18}

Diagnostic tests and algorithms used in the investigation of haematuria: systematic reviews and economic evaluation

By Rodgers M, Nixon J, Hempel S, Aho T, Kelly J, Neal D, et al.

No. 19

Cognitive behavioural therapy in addition to antispasmodic therapy for irritable bowel syndrome in primary care: randomised controlled trial.

By Kennedy TM, Chalder T, McCrone P, Darnley S, Knapp M, Jones RH, et al.

No. 20

A systematic review of the clinical effectiveness and costeffectiveness of enzyme replacement therapies for Fabry's disease and mucopolysaccharidosis type 1 .

By Connock M, Juarez-Garcia A, Frew E, Mans A, Dretzke J, Fry-Smith A, et al.

\section{No. 21}

Health benefits of antiviral therapy for mild chronic hepatitis $\mathrm{C}$ : randomised controlled trial and economic evaluation.

By Wright M, Grieve R, Roberts J Main J, Thomas HC, on behalf of the UK Mild Hepatitis C Trial Investigators.

\section{No. 22}

Pressure relieving support surfaces: a randomised evaluation.

By Nixon J, Nelson EA, Cranny G, Iglesias CP, Hawkins K, Cullum NA, et al. 


\section{No. 23}

A systematic review and economic model of the effectiveness and costeffectiveness of methylphenidate, dexamfetamine and atomoxetine for the treatment of attention deficit hyperactivity disorder in children and adolescents.

By King S, Griffin S, Hodges Z, Weatherly H, Asseburg C, Richardson G, et al.

\section{No. 24}

The clinical effectiveness and costeffectiveness of enzyme replacement therapy for Gaucher's disease: a systematic review.

By Connock M, Burls A, Frew E, Fry-Smith A, Juarez-Garcia A, McCabe C, et al.

\section{No. 25}

Effectiveness and cost-effectiveness of salicylic acid and cryotherapy for cutaneous warts. An economic decision model.

By Thomas KS, Keogh-Brown MR, Chalmers JR, Fordham RJ, Holland RC, Armstrong SJ, et al.

\section{No. 26}

A systematic literature review of the effectiveness of non-pharmacological interventions to prevent wandering in dementia and evaluation of the ethical implications and acceptability of their use.

By Robinson L, Hutchings D, Corner L, Beyer F, Dickinson H, Vanoli A, et al.

\section{No. 27}

A review of the evidence on the effects and costs of implantable cardioverter defibrillator therapy in different patient groups, and modelling of costeffectiveness and cost-utility for these groups in a UK context.

By Buxton M, Caine N, Chase D, Connelly D, Grace A, Jackson C, et al.

\section{No. 28}

Adefovir dipivoxil and pegylated interferon alfa-2a for the treatment of chronic hepatitis B: a systematic review and economic evaluation.

By Shepherd J, Jones J, Takeda A, Davidson P, Price A.

\section{No. 29}

An evaluation of the clinical and costeffectiveness of pulmonary artery catheters in patient management in intensive care: a systematic review and a randomised controlled trial.

By Harvey S, Stevens K, Harrison D, Young D, Brampton W, McCabe C, et al.

No. 30

Accurate, practical and cost-effective assessment of carotid stenosis in the UK.

By Wardlaw JM, Chappell FM, Stevenson M, De Nigris E, Thomas S, Gillard J, et al.

\section{No. 31}

Etanercept and infliximab for the treatment of psoriatic arthritis: a systematic review and economic evaluation.

By Woolacott N, Bravo Vergel Y, Hawkins N, Kainth A, Khadjesari Z, Misso K, et al.

No. 32

The cost-effectiveness of testing for hepatitis $\mathrm{C}$ in former injecting drug users.

By Castelnuovo E, Thompson-Coon J, Pitt M, Cramp M, Siebert U, Price A, et al.

\section{No. 33}

Computerised cognitive behaviour therapy for depression and anxiety update: a systematic review and economic evaluation.

By Kaltenthaler E, Brazier J, De Nigris E, Tumur I, Ferriter M, Beverley C, et al.

No. 34

Cost-effectiveness of using prognostic information to select women with breas cancer for adjuvant systemic therapy.

By Williams C, Brunskill S, Altman D, Briggs A, Campbell H, Clarke M, et al.

\section{No. 35}

Psychological therapies including dialectical behaviour therapy for borderline personality disorder: a systematic review and preliminary economic evaluation.

By Brazier J, Tumur I, Holmes M, Ferriter M, Parry G, Dent-Brown K, et al.

\section{No. 36}

Clinical effectiveness and costeffectiveness of tests for the diagnosis and investigation of urinary tract infection in children: a systematic review and economic model.

By Whiting P, Westwood M, Bojke L, Palmer S, Richardson G, Cooper J, et al.

\section{No. 37}

Cognitive behavioural therapy in chronic fatigue syndrome: a randomised controlled trial of an outpatient group programme. By O'Dowd H, Gladwell P, Rogers CA, Hollinghurst S, Gregory A.

\section{No. 38}

A comparison of the cost-effectiveness of five strategies for the prevention of nonsteroidal anti-inflammatory drug-induced gastrointestinal toxicity: a systematic review with economic modelling.

By Brown TJ, Hooper L, Elliott RA, Payne K, Webb R, Roberts C, et al

\section{No. 39}

The effectiveness and cost-effectiveness of computed tomography screening for coronary artery disease: systematic review.

By Waugh N, Black C, Walker S, McIntyre L, Cummins E, Hillis G.
No. 40

What are the clinical outcome and costeffectiveness of endoscopy undertaken by nurses when compared with doctors? A Multi-Institution Nurse Endoscopy Trial (MINuET).

By Williams J, Russell I, Durai D, Cheung W-Y, Farrin A, Bloor K, et al.

\section{No. 41}

The clinical and cost-effectiveness of oxaliplatin and capecitabine for the adjuvant treatment of colon cancer: systematic review and economic evaluation.

By Pandor A, Eggington S, Paisley S, Tappenden P, Sutcliffe P.

No. 42

A systematic review of the effectiveness of adalimumab, etanercept and infliximab for the treatment of rheumatoid arthritis in adults and an economic evaluation of their costeffectiveness.

By Chen Y-F, Jobanputra P, Barton P, Jowett S, Bryan S, Clark W, et al.

No. 43

Telemedicine in dermatology: a randomised controlled trial.

By Bowns IR, Collins K, Walters SJ, McDonagh AJG.

\section{No. 44}

Cost-effectiveness of cell salvage and alternative methods of minimising perioperative allogeneic blood transfusion: a systematic review and economic model.

By Davies L, Brown TJ, Haynes S, Payne K, Elliott RA, McCollum C.

\section{No. 45}

Clinical effectiveness and costeffectiveness of laparoscopic surgery for colorectal cancer: systematic reviews and economic evaluation.

By Murray A, Lourenco T, de Verteuil R, Hernandez R, Fraser C, McKinley A, et al.

\section{No. 46}

Etanercept and efalizumab for the treatment of psoriasis: a systematic review.

By Woolacott N, Hawkins N, Mason A, Kainth A, Khadjesari Z, Bravo Vergel Y, et al.

\section{No. 47}

Systematic reviews of clinical decision tools for acute abdominal pain.

By Liu JLY, Wyatt JC, Deeks JJ, Clamp S, Keen J, Verde P, et al.

\section{No. 48}

Evaluation of the ventricular assist device programme in the UK.

By Sharples L, Buxton M, Caine N, Cafferty F, Demiris N, Dyer M, et al. 


\section{No. 49}

A systematic review and economic model of the clinical and costeffectiveness of immunosuppressive therapy for renal transplantation in children.

By Yao G, Albon E, Adi Y, Milford D, Bayliss S, Ready A, et al.

\section{No. 50}

Amniocentesis results: investigation of anxiety. The ARIA trial.

By Hewison J, Nixon J, Fountain J, Cocks K, Jones C, Mason G, et al.

\section{Volume I I, 2007}

\section{No. 1}

Pemetrexed disodium for the treatment of malignant pleural mesothelioma: a systematic review and economic evaluation.

By Dundar Y, Bagust A, Dickson R, Dodd S, Green J, Haycox A, et al.

\section{No. 2}

A systematic review and economic model of the clinical effectiveness and cost-effectiveness of docetaxel in combination with prednisone or prednisolone for the treatment of hormone-refractory metastatic prostate cancer.

By Collins R, Fenwick E, Trowman R, Perard R, Norman G, Light K, et al.

No. 3

A systematic review of rapid diagnostic tests for the detection of tuberculosis infection.

By Dinnes J, Deeks J, Kunst H, Gibson A, Cummins E, Waugh N, et al.

\section{No. 4}

The clinical effectiveness and costeffectiveness of strontium ranelate for the prevention of osteoporotic fragility fractures in postmenopausal women.

By Stevenson M, Davis S, Lloyd-Jones M, Beverley C.

\section{No. 5}

A systematic review of quantitative and qualitative research on the role and effectiveness of written information available to patients about individual medicines.

By Raynor DK, Blenkinsopp A, Knapp P, Grime J, Nicolson DJ, Pollock K, et al.

No. 6

Oral naltrexone as a treatment for relapse prevention in formerly opioiddependent drug users: a systematic review and economic evaluation.

By Adi Y, Juarez-Garcia A, Wang D,
No. 7

Glucocorticoid-induced osteoporosis: a systematic review and cost-utility analysis.

By Kanis JA, Stevenson M, McCloskey EV, Davis S, Lloyd-Jones M.

No. 8

Epidemiological, social, diagnostic and economic evaluation of population screening for genital chlamydial infection.

By Low N, McCarthy A, Macleod J, Salisbury C, Campbell R, Roberts TE, et al.

\section{No. 9}

Methadone and buprenorphine for the management of opioid dependence: a systematic review and economic evaluation.

By Connock M, Juarez-Garcia A, Jowett S, Frew E, Liu Z, Taylor RJ, et al.

No. 10

Exercise Evaluation Randomised Trial (EXERT): a randomised trial comparing GP referral for leisure centre-based exercise, community-based walking and advice only.

By Isaacs AJ, Critchley JA, See Tai

S, Buckingham K, Westley D, Harridge SDR, et al.

\section{No. 11}

Interferon alfa (pegylated and nonpegylated) and ribavirin for the treatment of mild chronic hepatitis C: a systematic review and economic evaluation.

By Shepherd J, Jones J, Hartwell D, Davidson P, Price A, Waugh N.

\section{No. 12}

Systematic review and economic evaluation of bevacizumab and cetuximab for the treatment of metastatic colorectal cancer.

By Tappenden P, Jones R, Paisley S, Carroll C.

No. 13

A systematic review and economic evaluation of epoetin alfa, epoetin beta and darbepoetin alfa in anaemia associated with cancer, especially that attributable to cancer treatment.

By Wilson J, Yao GL, Raftery J, Bohlius J, Brunskill S, Sandercock J, et al.

\section{No. 14}

A systematic review and economic evaluation of statins for the prevention of coronary events.

By Ward S, Lloyd Jones M, Pandor A, Holmes M, Ara R, Ryan A, et al.

\section{No. 15}

A systematic review of the effectiveness and cost-effectiveness of different models of community-based respite care for frail older people and their carers.

By Mason A, Weatherly H, Spilsbury $\mathrm{K}$, Arksey H, Golder S, Adamson J, et al.
No. 16

Additional therapy for young children with spastic cerebral palsy: a randomised controlled trial.

By Weindling AM, Cunningham CC, Glenn SM, Edwards RT, Reeves DJ.

No. 17

Screening for type 2 diabetes: literature review and economic modelling.

By Waugh N, Scotland G, McNamee P, Gillett M, Brennan A, Goyder E, et al.

No. 18

The effectiveness and cost-effectiveness of cinacalcet for secondary

hyperparathyroidism in end-stage renal disease patients on dialysis: a systematic review and economic evaluation.

By Garside R, Pitt M, Anderson R, Mealing S, Roome C, Snaith A, et al.

No. 19

The clinical effectiveness and costeffectiveness of gemcitabine for metastatic breast cancer: a systematic review and economic evaluation.

By Takeda AL, Jones J, Loveman E, Tan SC, Clegg AJ.

\section{No. 20}

A systematic review of duplex ultrasound, magnetic resonance angiography and computed tomography angiography for the diagnosis and assessment of symptomatic, lower limb peripheral arterial disease.

By Collins R, Cranny G, Burch J, Aguiar-Ibáñez R, Craig D, Wright K, et al.

No. 21

The clinical effectiveness and costeffectiveness of treatments for children with idiopathic steroid-resistant nephrotic syndrome: a systematic review.

By Colquitt JL, Kirby J, Green C, Cooper K, Trompeter RS.

No. 22

A systematic review of the routine monitoring of growth in children of primary school age to identify growthrelated conditions.

By Fayter D, Nixon J, Hartley S, Rithalia A, Butler G, Rudolf M, et al.

No. 23

Systematic review of the effectiveness of preventing and treating Staphylococcus aureus carriage in reducing peritoneal catheter-related infections.

By McCormack K, Rabindranath K, Kilonzo M, Vale L, Fraser C, McIntyre L, et al. 


\section{No. 24}

The clinical effectiveness and cost of repetitive transcranial magnetic stimulation versus electroconvulsive therapy in severe depression: a multicentre pragmatic randomised controlled trial and economic analysis.

By McLoughlin DM, Mogg A, Eranti S, Pluck G, Purvis R, Edwards D, et al.

\section{No. 25}

A randomised controlled trial and economic evaluation of direct versus indirect and individual versus group modes of speech and language therapy for children with primary language impairment.

By Boyle J, McCartney E, Forbes J, O'Hare A.

\section{No. 26}

Hormonal therapies for early breast cancer: systematic review and economic evaluation.

By Hind D, Ward S, De Nigris E, Simpson E, Carroll C, Wyld L.

\section{No. 27}

Cardioprotection against the toxic effects of anthracyclines given to children with cancer: a systematic review.

By Bryant J, Picot J, Levitt G, Sullivan I, Baxter L, Clegg A.

\section{No. 28}

Adalimumab, etanercept and infliximab for the treatment of ankylosing spondylitis: a systematic review and economic evaluation.

By McLeod C, Bagust A, Boland A, Dagenais P, Dickson R, Dundar Y, et al.

\section{No. 29}

Prenatal screening and treatment strategies to prevent group B streptococcal and other bacterial infections in early infancy: costeffectiveness and expected value of information analyses.

By Colbourn T, Asseburg C, Bojke L, Philips Z, Claxton K, Ades AE, et al.

\section{No. 30}

Clinical effectiveness and costeffectiveness of bone morphogenetic proteins in the non-healing of fractures and spinal fusion: a systematic review.

By Garrison KR, Donell S, Ryder J, Shemilt I, Mugford M, Harvey I, et al.

\section{No. 31}

A randomised controlled trial of postoperative radiotherapy following breast-conserving surgery in a minimum-risk older population. The PRIME trial.

By Prescott RJ, Kunkler IH, Williams LJ, King CC, Jack W, van der Pol M, et al.

\section{No. 32}

Current practice, accuracy, effectiveness and cost-effectiveness of the school entry hearing screen.

By Bamford J, Fortnum H, Bristow K, Smith J, Vamvakas G, Davies L, et al.

\section{No. 33}

The clinical effectiveness and costeffectiveness of inhaled insulin in diabetes mellitus: a systematic review and economic evaluation.

By Black C, Cummins E, Royle P, Philip S, Waugh N.

\section{No. 34}

Surveillance of cirrhosis for hepatocellular carcinoma: systematic review and economic analysis.

By Thompson Coon J, Rogers G, Hewson P, Wright D, Anderson R, Cramp M, et al.

\section{No. 35}

The Birmingham Rehabilitation Uptake Maximisation Study (BRUM). Homebased compared with hospitalbased cardiac rehabilitation in a multiethnic population: cost-effectiveness and patient adherence.

By Jolly K, Taylor R, Lip GYH, Greenfield S, Raftery J, Mant J, et al.

\section{No. 36}

A systematic review of the clinical, public health and cost-effectiveness of rapid diagnostic tests for the detection and identification of bacterial intestinal pathogens in faeces and food.

By Abubakar I, Irvine L, Aldus CF, Wyatt GM, Fordham R, Schelenz S, et al.

\section{No. 37}

A randomised controlled trial examining the longer-term outcomes of standard versus new antiepileptic drugs. The SANAD trial.

By Marson AG, Appleton R, Baker GA, Chadwick DW, Doughty J, Eaton B, et al.

\section{No. 38}

Clinical effectiveness and costeffectiveness of different models of managing long-term oral anticoagulation therapy: a systematic review and economic modelling.

By Connock M, Stevens C, Fry-Smith A, Jowett S, Fitzmaurice D, Moore D, et al.

\section{No. 39}

A systematic review and economic model of the clinical effectiveness and cost-effectiveness of interventions for preventing relapse in people with bipolar disorder.

By Soares-Weiser K, Bravo Vergel Y, Beynon S, Dunn G, Barbieri M, Duffy S, et al.

\section{No. 40}

Taxanes for the adjuvant treatment of early breast cancer: systematic review and economic evaluation.

By Ward S, Simpson E, Davis S, Hind D, Rees A, Wilkinson A.

No. 41

The clinical effectiveness and costeffectiveness of screening for open angle glaucoma: a systematic review and economic evaluation.

By Burr JM, Mowatt G, Hernández R, Siddiqui MAR, Cook J, Lourenco T, et al.

\section{No. 42}

Acceptability, benefit and costs of early screening for hearing disability: a study of potential screening tests and models.

By Davis A, Smith P, Ferguson M, Stephens D, Gianopoulos I.

No. 43

Contamination in trials of educational interventions

By Keogh-Brown MR, Bachmann MO, Shepstone L, Hewitt C, Howe A, Ramsay CR, et al.

\section{No. 44}

Overview of the clinical effectiveness of positron emission tomography imaging in selected cancers.

By Facey K, Bradbury I, Laking G, Payne E.

\section{No. 45}

The effectiveness and cost-effectiveness of carmustine implants and temozolomide for the treatment of newly diagnosed high-grade glioma: a systematic review and economic evaluation.

By Garside R, Pitt M, Anderson R, Rogers G, Dyer M, Mealing S, et al.

\section{No. 46}

Drug-eluting stents: a systematic review and economic evaluation.

By Hill RA, Boland A, Dickson R, Dündar Y, Haycox A, McLeod C, et al.

\section{No. 47}

The clinical effectiveness and cost-effectiveness of cardiac resynchronisation (biventricular pacing) for heart failure: systematic review and economic model.

By Fox M, Mealing S, Anderson R, Dean J, Stein K, Price A, et al.

\section{No. 48}

Recruitment to randomised trials: strategies for trial enrolment and participation study. The STEPS study.

By Campbell MK, Snowdon C, Francis D, Elbourne D, McDonald AM, Knight R, et al. 


\section{No. 49}

Cost-effectiveness of functional cardiac testing in the diagnosis and management of coronary artery disease: a randomised controlled trial. The CECaT trial.

By Sharples L, Hughes V, Crean A, Dyer M, Buxton M, Goldsmith K, et al.

\section{No. 50}

Evaluation of diagnostic tests when there is no gold standard. A review of methods.

By Rutjes AWS, Reitsma

JB, Coomarasamy A, Khan KS, Bossuyt PMM.

\section{No. 51}

Systematic reviews of the clinical effectiveness and cost-effectiveness of proton pump inhibitors in acute upper gastrointestinal bleeding.

By Leontiadis GI, Sreedharan A, Dorward S, Barton P, Delaney B, Howden CW, et al.

\section{No. 52}

A review and critique of modelling in prioritising and designing screening programmes.

By Karnon J, Goyder E, Tappenden P, McPhie S, Towers I, Brazier J, et al.

\section{No. 53}

An assessment of the impact of the NHS Health Technology Assessment Programme.

By Hanney S, Buxton M, Green C, Coulson D, Raftery J.

\section{Volume 12, 2008}

\section{No. 1}

A systematic review and economic model of switching from

nonglycopeptide to glycopeptide antibiotic prophylaxis for surgery.

By Cranny G, Elliott R, Weatherly H, Chambers D, Hawkins N, Myers L, et al.

\section{No. 2}

'Cut down to quit' with nicotine replacement therapies in smoking cessation: a systematic review of effectiveness and economic analysis.

By Wang D, Connock M, Barton P, Fry-Smith A, Aveyard P, Moore D.

\section{No. 3}

A systematic review of the effectiveness of strategies for reducing fracture risk in children with juvenile idiopathic arthritis with additional data on longterm risk of fracture and cost of disease management.

By Thornton J, Ashcroft D, O'Neill T,
No. 4

Does befriending by trained lay workers improve psychological well-being and quality of life for carers of people with dementia, and at what cost? A randomised controlled trial.

By Charlesworth G, Shepstone L, Wilson E, Thalanany M, Mugford M, Poland F.

\section{No. 5}

A multi-centre retrospective cohort study comparing the efficacy, safety and cost-effectiveness of hysterectomy and uterine artery embolisation for the treatment of symptomatic uterine fibroids. The HOPEFUL study.

By Hirst A, Dutton S, Wu O, Briggs A, Edwards C, Waldenmaier L, et al.

No. 6

Methods of prediction and prevention of pre-eclampsia: systematic reviews of accuracy and effectiveness literature with economic modelling.

By Meads CA, Cnossen JS, Meher S, Juarez-Garcia A, ter Riet G, Duley L, et al.

\section{No. 7}

The use of economic evaluations in NHS decision-making: a review and empirical investigation.

By Williams I, McIver S, Moore D, Bryan S.

\section{No. 8}

Stapled haemorrhoidectomy (haemorrhoidopexy) for the treatment of haemorrhoids: a systematic review and economic evaluation.

By Burch J, Epstein D, Baba-Akbari A, Weatherly H, Fox D, Golder S, et al.

No. 9

The clinical effectiveness of diabetes education models for Type 2 diabetes: a systematic review.

By Loveman E, Frampton GK, Clegg AJ.

\section{No. 10}

Payment to healthcare professionals for patient recruitment to trials: systematic review and qualitative study.

By Raftery J, Bryant J, Powell J, Kerr C, Hawker S.

\section{No. 11}

Cyclooxygenase-2 selective nonsteroidal anti-inflammatory drugs (etodolac, meloxicam, celecoxib, rofecoxib, etoricoxib, valdecoxib and lumiracoxib) for osteoarthritis and rheumatoid arthritis: a systematic review and economic evaluation.

By Chen Y-F, Jobanputra P, Barton P, Bryan S, Fry-Smith A, Harris G, et al.
No. 12

The clinical effectiveness and costeffectiveness of central venous catheters treated with anti-infective agents in preventing bloodstream infections: a systematic review and economic evaluation.

By Hockenhull JC, Dwan K, Boland A, Smith G, Bagust A, Dundar Y, et al.

No. 13

Stepped treatment of older adults on laxatives. The STOOL trial.

By Mihaylov S, Stark C, McColl E, Steen N, Vanoli A, Rubin G, et al.

No. 14

A randomised controlled trial of cognitive behaviour therapy in adolescents with major depression treated by selective serotonin reuptake inhibitors. The ADAPT trial.

By Goodyer IM, Dubicka B, Wilkinson P, Kelvin R, Roberts C, Byford S, et al.

\section{No. 15}

The use of irinotecan, oxaliplatin and raltitrexed for the treatment of advanced colorectal cancer: systematic review and economic evaluation.

By Hind D, Tappenden P, Tumur I, Eggington E, Sutcliffe P, Ryan A.

No. 16

Ranibizumab and pegaptanib for the treatment of age-related macular degeneration: a systematic review and economic evaluation.

By Colquitt JL, Jones J, Tan SC, Takeda A, Clegg AJ, Price A.

No. 17

Systematic review of the clinical effectiveness and cost-effectiveness of 64-slice or higher computed tomography angiography as an alternative to invasive coronary angiography in the investigation of coronary artery disease.

By Mowatt G, Cummins E, Waugh N, Walker S, Cook J, Jia X, et al.

No. 18

Structural neuroimaging in psychosis: a systematic review and economic evaluation.

By Albon E, Tsourapas A, Frew E, Davenport C, Oyebode F, Bayliss S, et al.

No. 19

Systematic review and economic analysis of the comparative effectiveness of different inhaled corticosteroids and their usage with long-acting beta ${ }_{2}$ agonists for the treatment of chronic asthma in adults and children aged 12 years and over.

By Shepherd J, Rogers G, Anderson R, Main C, Thompson-Coon J, Hartwell D, et al. 


\section{No. 20}

Systematic review and economic analysis of the comparative effectiveness of different inhaled corticosteroids and their usage with long-acting beta ${ }_{2}$ agonists for the treatment of chronic asthma in children under the age of 12 years.

By Main C, Shepherd J, Anderson R, Rogers G, Thompson-Coon J, Liu Z, et al.

\section{No. 21}

Ezetimibe for the treatment of hypercholesterolaemia: a systematic review and economic evaluation.

By Ara R, Tumur I, Pandor A, Duenas A, Williams R, Wilkinson A, et al.

No. 22

Topical or oral ibuprofen for chronic knee pain in older people. The TOIB study.

By Underwood M, Ashby D, Carnes D, Castelnuovo E, Cross P, Harding G, et al.

\section{No. 23}

A prospective randomised comparison of minor surgery in primary and secondary care. The MiSTIC trial.

By George S, Pockney P, Primrose J, Smith H, Little P, Kinley H, et al.

No. 24

A review and critical appraisal of measures of therapist-patient interactions in mental health settings.

By Cahill J, Barkham M, Hardy G, Gilbody S, Richards D, Bower P, et al.

\section{No. 25}

The clinical effectiveness and costeffectiveness of screening programmes for amblyopia and strabismus in children up to the age of $4-5$ years: a systematic review and economic evaluation.

By Carlton J, Karnon J, CzoskiMurray C, Smith KJ, Marr J.

\section{No. 26}

A systematic review of the clinical effectiveness and cost-effectiveness and economic modelling of minimal incision total hip replacement approaches in the management of arthritic disease of the hip.

By de Verteuil R, Imamura M, Zhu S, Glazener C, Fraser C, Munro N, et al.

\section{No. 27}

A preliminary model-based assessment of the cost-utility of a screening programme for early age-related macular degeneration.

By Karnon J, Czoski-Murray C, Smith K, Brand C, Chakravarthy U, Davis S, et al.

\section{No. 28}

Intravenous magnesium sulphate and sotalol for prevention of atrial fibrillation after coronary artery bypass surgery: a systematic review and economic evaluation.

By Shepherd J, Jones J, Frampton GK, Tanajewski L, Turner D, Price A.

\section{No. 29}

Absorbent products for urinary/faecal incontinence: a comparative evaluation of key product categories.

By Fader M, Cottenden A, Getliffe K, Gage H, Clarke-O'Neill S, Jamieson K, et al.

No. 30

A systematic review of repetitive functional task practice with modelling of resource use, costs and effectiveness.

By French B, Leathley M, Sutton C, McAdam J, Thomas L, Forster A, et al.

No. 31

The effectiveness and cost-effectivness of minimal access surgery amongst people with gastro-oesophageal reflux disease - a UK collaborative study. The REFLUX trial.

By Grant A, Wileman S, Ramsay C, Bojke L, Epstein D, Sculpher M, et al.

\section{No. 32}

Time to full publication of studies of anti-cancer medicines for breast cancer and the potential for publication bias: a short systematic review.

By Takeda A, Loveman E, Harris P, Hartwell D, Welch K.

\section{No. 33}

Performance of screening tests for child physical abuse in accident and emergency departments.

By Woodman J, Pitt M, Wentz R, Taylor B, Hodes D, Gilbert RF.

\section{No. 34}

Curative catheter ablation in atrial fibrillation and typical atrial flutter: systematic review and economic evaluation.

By Rodgers M, McKenna C, Palmer S, Chambers D, Van Hout S, Golder S, et al.

\section{No. 35}

Systematic review and economic modelling of effectiveness and cost utility of surgical treatments for men with benign prostatic enlargement.

By Lourenco T, Armstrong N, N'Dow J, Nabi G, Deverill M, Pickard R, et al.

\section{No. 36}

Immunoprophylaxis against respiratory syncytial virus (RSV) with palivizumab in children: a systematic review and economic evaluation.

By Wang D, Cummins C, Bayliss S, Sandercock J, Burls A.

\section{Volume 13, 2009}

No. 1

Deferasirox for the treatment of iron

overload associated with regular

blood transfusions (transfusional haemosiderosis) in patients suffering with chronic anaemia: a systematic review and economic evaluation.

By McLeod C, Fleeman N, Kirkham J, Bagust A, Boland A, Chu P, et al.

No. 2

Thrombophilia testing in people with venous thromboembolism: systematic review and cost-effectiveness analysis. By Simpson EL, Stevenson MD, Rawdin A, Papaioannou D.

No. 3

Surgical procedures and non-surgical devices for the management of nonapnoeic snoring: a systematic review of clinical effects and associated treatment costs.

By Main C, Liu Z, Welch K, Weiner G, Quentin Jones S, Stein K.

No. 4

Continuous positive airway pressure devices for the treatment of obstructive sleep apnoea-hypopnoea syndrome: a systematic review and economic analysis.

By McDaid C, Griffin S, Weatherly H, Durée K, van der Burgt M, van Hout $S$, Akers J, et al.

No. 5

Use of classical and novel biomarkers as prognostic risk factors for localised prostate cancer: a systematic review.

By Sutcliffe P, Hummel S, Simpson E, Young T, Rees A, Wilkinson A, et al.

No. 6

The harmful health effects of recreational ecstasy: a systematic review of observational evidence.

By Rogers G, Elston J, Garside R, Roome C, Taylor R, Younger P, et al.

No. 7

Systematic review of the clinical effectiveness and cost-effectiveness of oesophageal Doppler monitoring in critically ill and high-risk surgical patients.

By Mowatt G, Houston G, Hernández R, de Verteuil R, Fraser C, Cuthbertson $\mathrm{B}$, et al.

No. 8

The use of surrogate outcomes in model-based cost-effectiveness analyses: a survey of UK Health Technology Assessment reports.

By Taylor RS, Elston J.

No. 9

Controlling Hypertension and Hypotension Immediately Post Stroke (CHHIPS) - a randomised controlled trial.

By Potter J, Mistri A, Brodie F, Chernova J, Wilson E, Jagger C, et al. 


\section{No. 10}

Routine antenatal anti-D prophylaxis for RhD-negative women: a systematic review and economic evaluation.

By Pilgrim H, Lloyd-Jones M, Rees A.

\section{No. 11}

Amantadine, oseltamivir and zanamivir for the prophylaxis of influenza (including a review of existing guidance no. 67): a systematic review and economic evaluation.

By Tappenden P, Jackson R, Cooper K, Rees A, Simpson E, Read R, et al

\section{No. 12}

Improving the evaluation of

therapeutic interventions in multiple sclerosis: the role of new psychometric methods.

By Hobart J, Cano S.
No. 13

Treatment of severe ankle sprain: a pragmatic randomised controlled trial comparing the clinical effectiveness and cost-effectiveness of three types of mechanical ankle support with tubular bandage. The CAST trial.

By Cooke MW, Marsh JL, Clark M, Nakash R, Jarvis RM, Hutton JL, et al., on behalf of the CAST trial group. 


\section{Health Technology Assessment Programme}

\author{
Director, \\ Professor Tom Walley, \\ Director, NIHR HTA \\ Programme, Professor of \\ Clinical Pharmacology, \\ University of Liverpoo
}

\author{
Deputy Director, \\ Professor Jon Nicholl, \\ Director, Medical Care Research \\ Unit, University of Sheffield
}

Members

\section{Chair,}

Professor Tom Walley,

Director, NIHR HTA

Programme, Professor of

Clinical Pharmacology,

University of Liverpool

\section{Deputy Chair,}

Professor Jon Nicholl,

Director, Medical Care Research

Unit, University of Sheffield

Dr Bob Coates,

Consultant Advisor, NCCHTA

\section{Prioritisation Strategy Group}

\author{
Dr Andrew Cook, \\ Consultant Advisor, NCCHTA \\ Dr Peter Davidson, \\ Director of Science Support, \\ NCCHTA \\ Professor Robin E Ferner, \\ Consultant Physician and \\ Director, West Midlands Centre \\ for Adverse Drug Reactions, \\ City Hospital NHS Trust, \\ Birmingham
}

\author{
Professor Paul Glasziou, \\ Professor of Evidence-Based \\ Medicine, University of Oxford \\ Dr Nick Hicks, \\ Director of NHS Support, \\ NCCHTA \\ Dr Edmund Jessop, \\ Medical Adviser, National \\ Specialist, National \\ Commissioning Group (NCG), \\ Department of Health, London
}

Ms Lynn Kerridge,

Chief Executive Officer, NETSCC and NCCHTA

Dr Ruairidh Milne,

Director of Strategy and Development, NETSCC

Ms Kay Pattison,

Section Head, NHS R\&D

Programme, Department of Health

Ms Pamela Young,

Specialist Programme Manager, NCCHTA

\section{HTA Commissioning Board}

\section{Members}

Programme Director,

Professor Tom Walley,

Director, NIHR HTA

Programme, Professor of

Clinical Pharmacology,

University of Liverpool

Chair,

Professor Jon Nicholl, Director, Medical Care Research

Unit, University of Sheffield

\section{Deputy Chair,}

Dr Andrew Farmer,

Senior Lecturer in General

Practice, Department of

Primary Health Care,

University of Oxford

Professor Ann Ashburn,

Professor of Rehabilitation

and Head of Research,

Southampton General Hospital
Professor Deborah Ashby, Professor of Medical Statistics, Queen Mary, University of London

Professor John Cairns, Professor of Health Economics, London School of Hygiene and Tropical Medicine

Professor Peter Croft, Director of Primary Care Sciences Research Centre, Keele University

Professor Nicky Cullum, Director of Centre for EvidenceBased Nursing, University of York

Professor Jenny Donovan, Professor of Social Medicine, University of Bristol

Professor Steve Halligan, Professor of Gastrointestinal Radiology, University College Hospital, London
Professor Freddie Hamdy, Professor of Urology,

University of Sheffield

Professor Allan House, Professor of Liaison Psychiatry, University of Leeds

Dr Martin J Landray, Reader in Epidemiology, Honorary Consultant Physician, Clinical Trial Service Unit, University of Oxford

Professor Stuart Logan, Director of Health \& Social Care Research, The Peninsula Medical School, Universities of Exeter and Plymouth

Dr Rafael Perera,

Lecturer in Medical Statisitics, Department of Primary Health Care, Univeristy of Oxford
Professor Ian Roberts, Professor of Epidemiology \& Public Health, London School of Hygiene and Tropical Medicine

Professor Mark Sculpher, Professor of Health Economics, University of York

Professor Helen Smith, Professor of Primary Care, University of Brighton

Professor Kate Thomas, Professor of Complementary \& Alternative Medicine Research, University of Leeds

Professor David John Torgerson,

Director of York Trials Unit, University of York

Professor Hywel Williams, Professor of DermatoEpidemiology, University of Nottingham

Observers

Ms Kay Pattison,

Section Head, NHS R\&D

Programmes, Research and

Development Directorate,

Department of Health
Dr Morven Roberts,

Clinical Trials Manager,

Medical Research Council 


\section{Diagnostic Technologies \& Screening Panel}

Members

\section{Chair,}

Professor Paul Glasziou,

Professor of Evidence-Based

Medicine, University of Oxford

\section{Deputy Chair,}

\section{Dr David Elliman,}

Consultant Paediatrician and

Honorary Senior Lecturer

Great Ormond Street Hospital,

London

Professor Judith E Adams,

Consultant Radiologist,

Manchester Royal Infirmary,

Central Manchester \&

Manchester Children's

University Hospitals NHS

Trust, and Professor of

Diagnostic Radiology, Imaging

Science and Biomedical

Engineering, Cancer \&

Imaging Sciences, University of

Manchester

Ms Jane Bates,

Consultant Ultrasound

Practitioner, Ultrasound

Department, Leeds Teaching

Hospital NHS Trust
Dr Stephanie Dancer,

Consultant Microbiologist,

Hairmyres Hospital, East

Kilbride

Professor Glyn Elwyn,

Primary Medical Care Research

Group, Swansea Clinical School,

University of Wales

Dr Ron Gray,

Consultant Clinical

Epidemiologist, Department

of Public Health, University of

Oxford

Professor Paul D Griffiths,

Professor of Radiology,

University of Sheffield

Dr Jennifer J Kurinczuk,

Consultant Clinical

Epidemiologist, National

Perinatal Epidemiology Unit,

Oxford

Dr Susanne M Ludgate,

Medical Director, Medicines \&

Healthcare Products Regulatory

Agency, London
Dr Anne Mackie,

Director of Programmes, UK

National Screening Committee

Dr Michael Millar,

Consultant Senior Lecturer in

Microbiology, Barts and The

London NHS Trust, Royal

London Hospital

Mr Stephen Pilling,

Director, Centre for Outcomes,

Research \& Effectiveness,

Joint Director, National

Collaborating Centre for

Mental Health, University

College London

Mrs Una Rennard,

Service User Representative

Dr Phil Shackley,

Senior Lecturer in Health

Economics, School of

Population and Health

Sciences, University of

Newcastle upon Tyne
Dr W Stuart A Smellie,

Consultant in Chemical

Pathology, Bishop Auckland General Hospital

Dr Nicholas Summerton, Consultant Clinical and Public Health Advisor, NICE

Ms Dawn Talbot, Service User Representative

Dr Graham Taylor, Scientific Advisor, Regional DNA Laboratory, St James' University Hospital, Leeds

Professor Lindsay Wilson Turnbull,

Scientific Director of the Centre for Magnetic Resonance Investigations and YCR Professor of Radiology, Hul Royal Infirmary

\section{Observers}

Dr Tim Elliott,

Team Leader, Cancer

Screening, Department of Health
Dr Catherine Moody, Programme Manager Neuroscience and Mental

Health Board
Dr Ursula Wells, Principal Research Officer Department of Health

\section{Pharmaceuticals Panel}

Members

\section{Chair,}

Professor Robin Ferner,

Consultant Physician and Director, West Midlands Centre for Adverse Drug Reactions, City Hospital NHS Trust, Birmingham

\section{Deputy Chair}

Professor Imti Choonara,

Professor in Child Health,

University of Nottingham

Mrs Nicola Carey,

Senior Research Fellow,

School of Health and Social

Care, The University of

Reading

Mr John Chapman,

Service User Representative

\section{Dr Peter Elton,}

Director of Public Health,

Bury Primary Care Trust

Dr Ben Goldacre,

Research Fellow, Division of

Psychological Medicine and

Psychiatry, King's College

London

Mrs Barbara Greggains, Service User Representative

Dr Bill Gutteridge,

Medical Adviser, London

Strategic Health Authority

Dr Dyfrig Hughes,

Reader in Pharmacoeconomics and Deputy Director, Centre for Economics and Policy in

Health, IMSCaR, Bangor

University
Professor Jonathan Ledermann, Professor of Medical Oncology and Director of the Cancer Research UK and University College London Cancer Trials Centre

Dr Yoon K Loke,

Senior Lecturer in Clinical Pharmacology, University of East Anglia

Professor Femi Oyebode, Consultant Psychiatrist and Head of Department, University of Birmingham

Dr Andrew Prentice,

Senior Lecturer and Consultant Obstetrician and Gynaecologist, The Rosie Hospital, University of Cambridge
Dr Martin Shelly, General Practitioner, Leeds, and Associate Director, NHS Clinical Governance Support Team, Leiceste

Dr Gillian Shepherd, Director, Health and Clinical Excellence, Merck Serono Ltd

Mrs Katrina Simister, Assistant Director New

Medicines, National Prescribing Centre, Liverpool

Mr David Symes, Service User Representative

Dr Lesley Wise,

Unit Manager,

Pharmacoepidemiology

Research Unit, VRMM,

Medicines \& Healthcare

Products Regulatory Agency

\section{Observers}

Mr Simon Reeve,

Head of Clinical and Cost-

Effectiveness, Medicines,

Pharmacy and Industry Group,

Department of Health
Dr Ursula Wells,

Dr Heike Weber,

Programme Manager,

Medical Research Council

Principal Research Officer,

Department of Health 


\section{Therapeutic Procedures Panel}

Members

\section{Chair, \\ Dr John C Pounsford,}

Consultant Physician, North

Bristol NHS Trust

\section{Deputy Chair,}

Professor Scott Weich,

Professor of Psychiatry, Division

of Health in the Community,

University of Warwick, Coventry

Professor Jane Barlow,

Professor of Public Health in

the Early Years, Health Sciences

Research Institute, Warwick

Medical School, Coventry

Ms Maree Barnett,

Acting Branch Head of Vascular

Programme, Department of

Health
Mrs Val Carlill,

Service User Representative

Mrs Anthea De Barton-Watson, Service User Representative

Mr Mark Emberton,

Senior Lecturer in Oncological

Urology, Institute of Urology,

University College Hospital,

London

Professor Steve Goodacre,

Professor of Emergency

Medicine, University of

Sheffield

Professor Christopher Griffiths, Professor of Primary Care, Barts and The London School of

Medicine and Dentistry
Mr Paul Hilton,

Consultant Gynaecologist and Urogynaecologist, Royal

Victoria Infirmary, Newcastle upon Tyne

Professor Nicholas James, Professor of Clinical Oncology, University of Birmingham, and Consultant in Clinical Oncology, Queen Elizabeth Hospital

Dr Peter Martin,

Consultant Neurologist,

Addenbrooke's Hospital,

Cambridge
Dr Kate Radford, Senior Lecturer (Research), Clinical Practice Research Unit, University of Central Lancashire, Preston

Mr Jim Reece Service User Representative

Dr Karen Roberts,

Nurse Consultant, Dunston Hill Hospital Cottages

\section{Observers}

Dr Phillip Leech,

Principal Medical Officer for Primary Care, Department of Health

Ms Kay Pattison,

Section Head, NHS R\&D

Programme, Department of

Health
Dr Morven Roberts,

Clinical Trials Manager,

Medical Research Council
Professor Tom Walley, Director, NIHR HTA Programme, Professor of

Clinical Pharmacology,

University of Liverpool
Dr Ursula Wells,

Principal Research Officer, Department of Health

Members

\section{Chair,}

Dr Edmund Jessop,

Medical Adviser, National

Specialist, National

Commissioning Group (NCG),

London

Deputy Chair,

Dr David Pencheon,

Director, NHS Sustainable

Development Unit, Cambridge

Dr Elizabeth Fellow-Smith,

Medical Director, West London

Mental Health Trust, Middlesex

\author{
Dr John Jackson, \\ General Practitioner, Parkway \\ Medical Centre, Newcastle \\ upon Tyne \\ Professor Mike Kelly, \\ Director, Centre for Public \\ Health Excellence, NICE, \\ London \\ Dr Chris McCall, \\ General Practitioner, The \\ Hadleigh Practice, Corfe \\ Mullen, Dorset \\ Ms Jeanett Martin, \\ Director of Nursing, BarnDoc \\ Limited, Lewisham Primary \\ Care Trust
}

Dr Julie Mytton,

Locum Consultant in Public

Health Medicine, Bristol

Primary Care Trust

Miss Nicky Mullany,

Service User Representative

Professor Ian Roberts,

Professor of Epidemiology and Public Health, London

School of Hygiene \& Tropical Medicine

Professor Ken Stein,

Senior Clinical Lecturer in

Public Health, University of

Exeter
Dr Kieran Sweeney,

Honorary Clinical Senior

Lecturer, Peninsula College of Medicine and Dentistry,

Universities of Exeter and

Plymouth

Professor Carol Tannahill, Glasgow Centre for Population Health

Professor Margaret Thorogood, Professor of Epidemiology, University of Warwick Medical School, Coventry

\section{Observers}

Ms Christine McGuire, Research \& Development, Department of Health
Dr Caroline Stone,

Programme Manager, Medical

Research Council 


\section{Expert Advisory Network}

Members

Professor Douglas Altman,

Professor of Statistics in

Medicine, Centre for Statistics

in Medicine, University of

Oxford

Professor John Bond,

Professor of Social Gerontology

\& Health Services Research,

University of Newcastle upon

Tyne

Professor Andrew Bradbury, Professor of Vascular Surgery, Solihull Hospital, Birmingham

Mr Shaun Brogan,

Chief Executive, Ridgeway

Primary Care Group, Aylesbury

Mrs Stella Burnside OBE, Chief Executive, Regulation and Improvement Authority, Belfast

Ms Tracy Bury,

Project Manager, World

Confederation for Physical

Therapy, London

Professor Iain T Cameron, Professor of Obstetrics and Gynaecology and Head of the School of Medicine, University of Southampton

Dr Christine Clark,

Medical Writer and Consultan Pharmacist, Rossendale

Professor Collette Clifford, Professor of Nursing and Head of Research, The Medical School, University of Birmingham

Professor Barry Cookson, Director, Laboratory of Hospital Infection, Public Health Laboratory Service, London

Dr Carl Counsell,

Clinical Senior Lecturer in Neurology, University of Aberdeen

Professor Howard Cuckle, Professor of Reproductive Epidemiology, Department of Paediatrics, Obstetrics \& Gynaecology, University of Leeds

Dr Katherine Darton, Information Unit, MIND - The Mental Health Charity, London

Professor Carol Dezateux, Professor of Paediatric

Epidemiology, Institute of Child Health, London

Mr John Dunning,

Consultant Cardiothoracic Surgeon, Papworth Hospital NHS Trust, Cambridge
Mr Jonothan Earnshaw,

Consultant Vascular Surgeon,

Gloucestershire Royal Hospital, Gloucester

Professor Martin Eccles,

Professor of Clinical

Effectiveness, Centre for Health

Services Research, University of

Newcastle upon Tyne

Professor Pam Enderby,

Dean of Faculty of Medicine,

Institute of General Practice

and Primary Care, University of Sheffield

Professor Gene Feder,

Professor of Primary Care

Research \& Development,

Centre for Health Sciences,

Barts and The London School

of Medicine and Dentistry

Mr Leonard R Fenwick,

Chief Executive, Freeman

Hospital, Newcastle upon Tyne

Mrs Gillian Fletcher,

Antenatal Teacher and Tutor

and President, National

Childbirth Trust, Henfield

Professor Jayne Franklyn,

Professor of Medicine,

University of Birmingham

Mr Tam Fry,

Honorary Chairman, Child

Growth Foundation, London

Professor Fiona Gilbert,

Consultant Radiologist and

NCRN Member, University of Aberdeen

Professor Paul Gregg,

Professor of Orthopaedic

Surgical Science, South Tees

Hospital NHS Trust

Bec Hanley,

Co-director, TwoCan Associates,

West Sussex

Dr Maryann L Hardy,

Senior Lecturer, University of

Bradford

Mrs Sharon Hart,

Healthcare Management

Consultant, Reading

Professor Robert E Hawkins,

CRC Professor and Director

of Medical Oncology, Christie

CRC Research Centre,

Christie Hospital NHS Trust,

Manchester

Professor Richard Hobbs,

Head of Department of Primary

Care \& General Practice,

University of Birmingham
Professor Alan Horwich, Dean and Section Chairman, The Institute of Cancer

Research, London

Professor Allen Hutchinson, Director of Public Health and Deputy Dean of ScHARR,

University of Sheffield

Professor Peter Jones,

Professor of Psychiatry,

University of Cambridge,

Cambridge

Professor Stan Kaye,

Cancer Research UK Professor

of Medical Oncology, Royal

Marsden Hospital and Institute

of Cancer Research, Surrey

Dr Duncan Keeley,

General Practitioner (Dr Burch

\& Ptnrs), The Health Centre,

Thame

Dr Donna Lamping,

Research Degrees Programme

Director and Reader in

Psychology, Health Services

Research Unit, London School

of Hygiene and Tropical

Medicine, London

Mr George Levvy,

Chief Executive, Motor

Neurone Disease Association,

Northampton

Professor James Lindesay,

Professor of Psychiatry for the

Elderly, University of Leicester

Professor Julian Little,

Professor of Human Genome

Epidemiology, University of

Ottawa

Professor Alistaire McGuire,

Professor of Health Economics,

London School of Economics

Professor Rajan Madhok,

Medical Director and Director

of Public Health, Directorate

of Clinical Strategy \& Public

Health, North \& East Yorkshire

\& Northern Lincolnshire

Health Authority, York

Professor Alexander Markham, Director, Molecular Medicine

Unit, St James's University

Hospital, Leeds

Dr Peter Moore,

Freelance Science Writer,

Ashtead

Dr Andrew Mortimore,

Public Health Director,

Southampton City Primary

Care Trust

Dr Sue Moss,

Associate Director, Cancer

Screening Evaluation Unit,

Institute of Cancer Research,

Sutton
Professor Miranda Mugford,

Professor of Health Economics and Group Co-ordinator, University of East Anglia

Professor Jim Neilson,

Head of School of Reproductive \& Developmental Medicine and Professor of Obstetrics and Gynaecology, University of Liverpool

Mrs Julietta Patnick,

National Co-ordinator, NHS

Cancer Screening Programmes, Sheffield

Professor Robert Peveler, Professor of Liaison Psychiatry, Royal South Hants Hospital, Southampton

Professor Chris Price,

Director of Clinical Research,

Bayer Diagnostics Europe,

Stoke Poges

Professor William Rosenberg, Professor of Hepatology and Consultant Physician,

University of Southampton

Professor Peter Sandercock, Professor of Medical Neurology, Department of Clinical

Neurosciences, University of Edinburgh

Dr Susan Schonfield,

Consultant in Public Health,

Hillingdon Primary Care Trust, Middlesex

Dr Eamonn Sheridan, Consultant in Clinical Genetics, St James's University Hospital, Leeds

Dr Margaret Somerville, Director of Public Health Learning, Peninsula Medical School, University of Plymouth

Professor Sarah Stewart-Brown, Professor of Public Health, Division of Health in the Community, University of Warwick, Coventry

Professor Ala Szczepura, Professor of Health Service Research, Centre for Health Services Studies, University of Warwick, Coventry

Mrs Joan Webster,

Consumer Member, Southern

Derbyshire Community Health Council

Professor Martin Whittle, Clinical Co-director, National Co-ordinating Centre for Women's and Children's Health, Lymington 



\section{Feedback}

The HTA Programme and the authors would like to know your views about this report.

The Correspondence Page on the HTA website

(www.hta.ac.uk) is a convenient way to publish your comments. If you prefer, you can send your comments

to the address below, telling us whether you would like us to transfer them to the website.

\section{We look forward to hearing from you.}

The NIHR Coordinating Centre for Health Technology Assessment

Alpha House, Enterprise Road

Southampton Science Park

Chilworth

Southampton SOI6 7NS, UK

Email: hta@hta.ac.uk

www.hta.ac.uk 